Portland State University

PDXScholar

\title{
Informal Trails and the Spread of Invasive Species in Urban Natural Areas: Spatial Analysis of Informal Trails and their Effects on Understory Plant Communities in Forest Park, Portland, Oregon
}

Jill Elise Van Winkle

Portland State University

Follow this and additional works at: https://pdxscholar.library.pdx.edu/open_access_etds

Part of the Forest Management Commons

Let us know how access to this document benefits you.

\section{Recommended Citation}

Van Winkle, Jill Elise, "Informal Trails and the Spread of Invasive Species in Urban Natural Areas: Spatial Analysis of Informal Trails and their Effects on Understory Plant Communities in Forest Park, Portland, Oregon" (2014). Dissertations and Theses. Paper 1841.

https://doi.org/10.15760/etd.1840

This Thesis is brought to you for free and open access. It has been accepted for inclusion in Dissertations and Theses by an authorized administrator of PDXScholar. Please contact us if we can make this document more accessible: pdxscholar@pdx.edu. 
Informal Trails and the Spread of Invasive Species in Urban Natural Areas: Spatial Analysis of Informal Trails and their Effects on Understory Plant Communities in

\author{
Forest Park, Portland, Oregon
}

by

Jill Elise Van Winkle

A thesis submitted in partial fulfillment of the requirements for the degree of

\author{
Master of Science \\ in \\ Environmental Science and Management \\ Thesis Committee: \\ Marion Dresner, Chair \\ Robert Scheller \\ Jeff Gerwing \\ Portland State University \\ 2014
}


(C) 2014 Jill Elise Van Winkle 


\begin{abstract}
The risk of spread and establishment of invasive species to interior habitat within urban parks is of great concern to park managers and ecologists. Informal trails as a vector for this transmission are not well understood. To characterize effects of informal trails on understory plant communities, I conducted a study of the informal trail network in Forest Park, Portland, Oregon. The system of 382 informal trails was mapped and evaluated qualitatively, and from this population a systematic sample was selected for analysis. To identify hotspots of informal trail activity, showing the relationship of informal trails to formal trails, other park features, and trail use level, I evaluated all mapped trails using line density spatial analysis tools. To characterize understory communities, thirty transects were placed along informal trails, with paired transects along nearby formal trails for comparison. I measured percent cover by species for non-graminoid understory plants, and percent total plant cover at different structural layers, for quadrats at regular intervals from the trail edge. I calculated richness and Shannon-Weaver diversity for nongraminoid understory plants. For community analysis, species were grouped by dispersal strategy, native status, and growth form.
\end{abstract}

Observations from system mapping suggest that "hidden" behaviors drive many informal trails: bathroom stops, party spots, waste dumping, and camps make up $28 \%$ of all informal trails. Trails to private property are few but represent over $29 \%$ of total trail length. Informal trail density is highest along Balch Creek. Hotspots of informal trail presence are associated with trailheads, trail intersections, and water access. Quadrats located within one meter of informal trails showed higher richness and diversity due to increased number of introduced and ruderal species. Formal trails exhibit these same 
patterns to a stronger degree and over a greater distance (two meters) from the trail edge. Distance from trail edge explained variation in plant communities when grouped by dispersal type, but not by growth form. This study shows that although informal trails are widely distributed throughout the park, they are concentrated in high-use areas. The presence of informal trails leads to significant changes in Forest Park plant communities that favor invasive and ruderal species, but these effects appear limited to two meters from the trail edge. 


\section{ACKNOWLEDGEMENTS}

I would like to thank my advisor, Marion Dresner, for her endless encouragement, advice, and confidence in my abilities throughout my graduate studies, in general, and with this thesis, in particular. To Rob Scheller, and Jeff Gerwing for their advice in my data analysis and in the drafting of this document. I also wish to thank Jeffrey Marion (USGS Patuxent Wildlife Research Center), Jeremy Wimpey (Applied Trails Research), Kendra Peterson-Morgan (Portland Parks and Recreation), and Sara Copp, Corinne Handelman, and Blair Edwards for their advice and assistance in the development and implementation of this study. The breadth of this study would not have been possible without the National Science Foundation, who funded my fellowship with the Cascades to Coast GK12 Project. For assistance with field work and for keeping me from going insane with quadrats, I am indebted to: Chris Bernhardt, Marion Dresner, Sara Copp, Corinne Handelmann, Blair Edwards, Monica Mogilewsky, and Bryce Kadin. Sara Copp kept me from many breakdowns along the way with emotional support, sound advice, and cheetah power. Finally, I express my gratitude to Chris Bernhardt for his love, patience, and support during my longer than expected graduate studies. 


\section{TABLE OF CONTENTS}

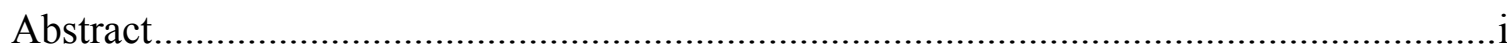

Acknowledgements .................................................................................................... ii

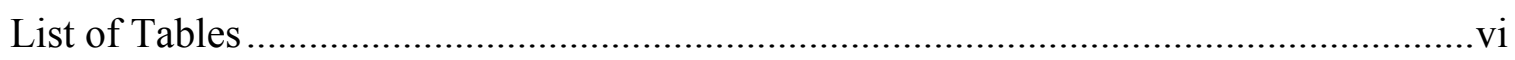

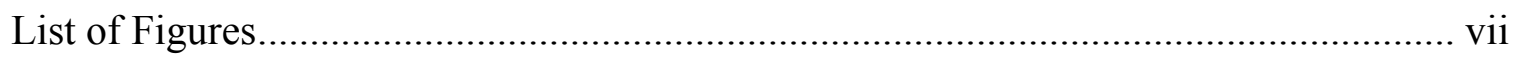

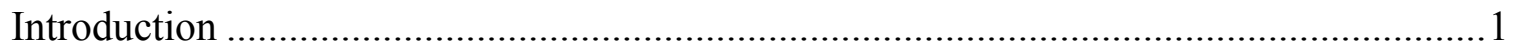

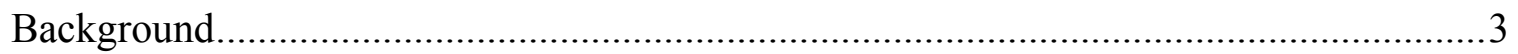

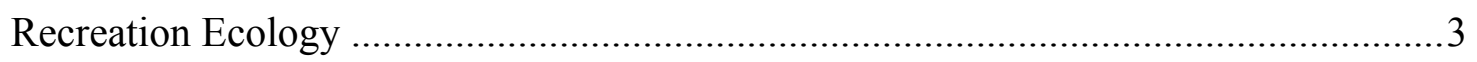

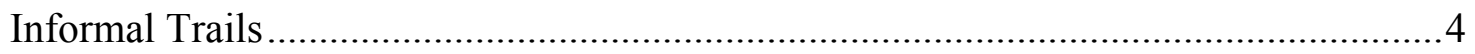

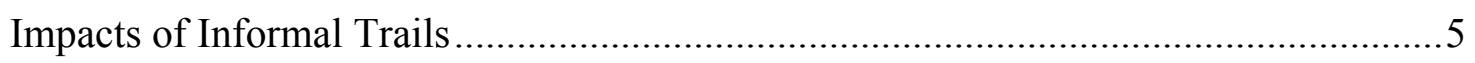

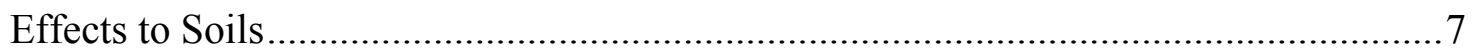

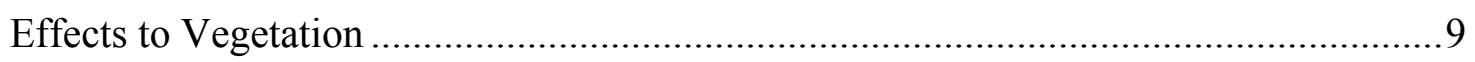

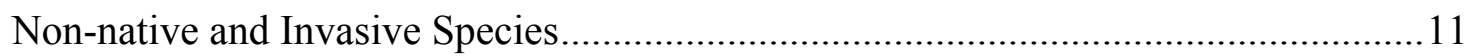

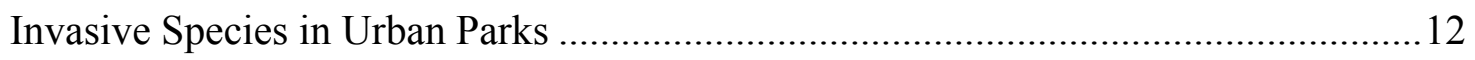

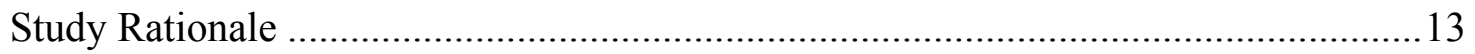

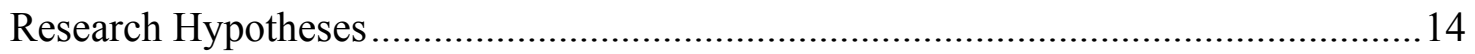

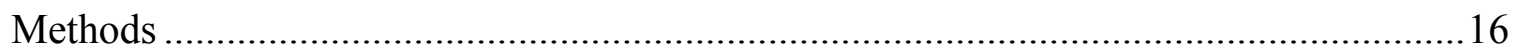

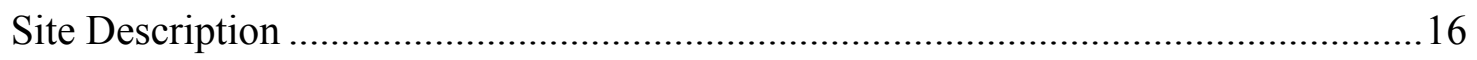

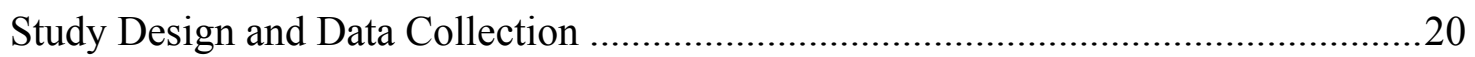

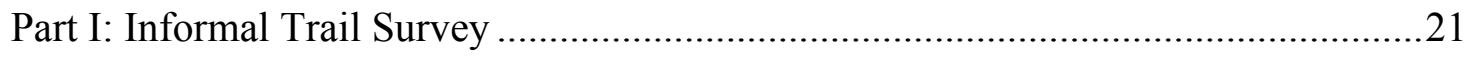

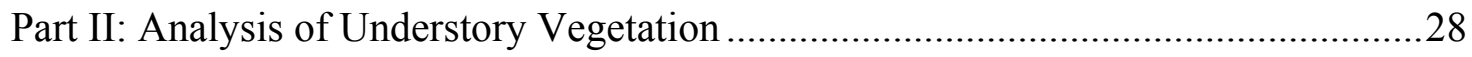

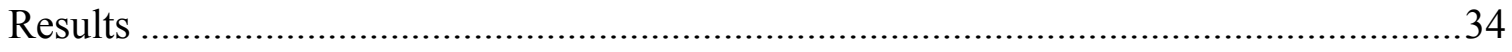

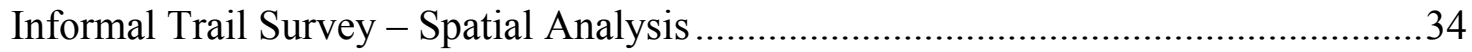

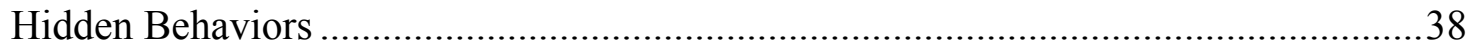

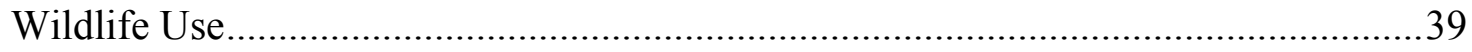

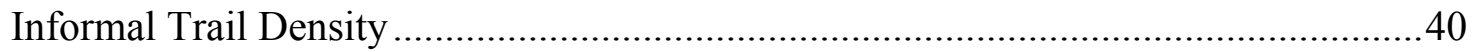

Understory Species Richness, Diversity, and Percent Cover ........................................46

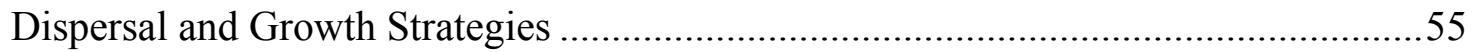

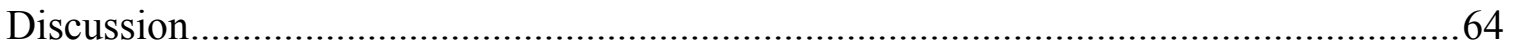

Hypothesis 1: Location and Density of Informal Trails ...........................................64

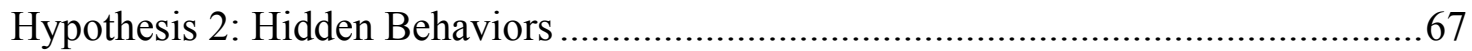

Hypothesis 3: Richness, Diversity, and Percent Cover .................................................69

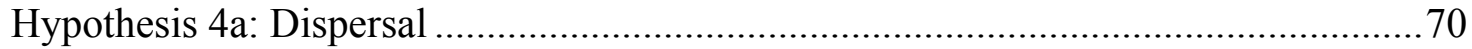


Hypothesis 4b: Growth Form and Ecology ............................................................ 71

Study Limitations and Considerations for Future Research ......................................72

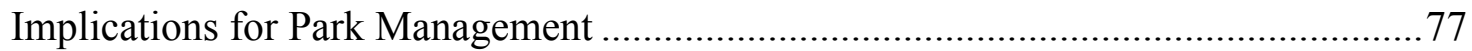

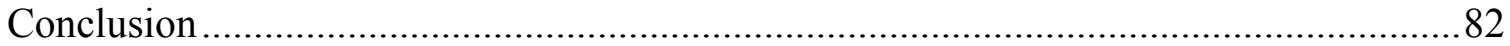

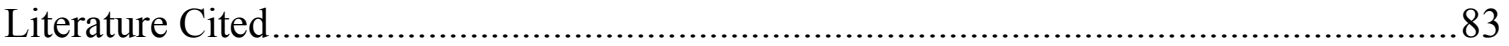

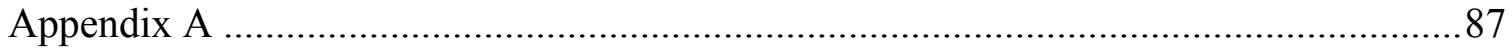

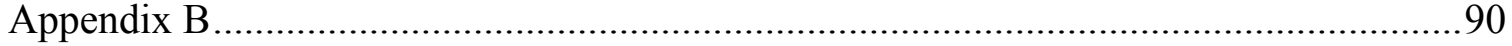




\section{LIST OF TABLES}

Table 1: Trail Condition Class Assessment (adapted from Wimpey \& Marion, 2011, with

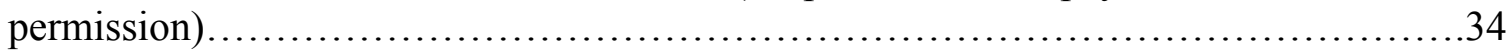

Table 2. Informal trails grouped by Condition Class showing frequency, total length, and

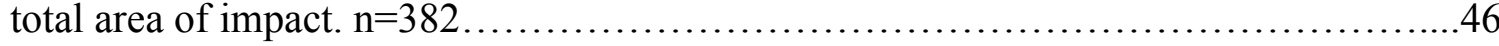

Table 3. Summary of percent cover in all quadrats for the six most common species....55

Table 4. Wilcoxon t-test for total, native, ruderal, and invasive species richness for distance from trail edge and control quadrats (at 10m). Significant values $(\alpha=0.05)$ shown

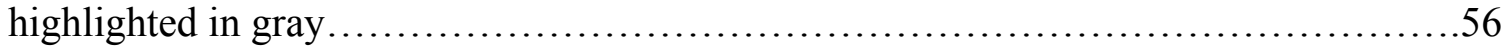

Table 5. T-test for Shannon-Weaver diversity for distance from trail edge to controls (at $10 \mathrm{~m})$; significant $\mathrm{p}$-values are highlighted in gray $(\alpha=0.05)$.

Table 6. Wilcoxon tests of percent total, native, and invasive herbaceous cover by distance from trail edge $(0,1,2 \mathrm{~m})$ and control $(10 \mathrm{~m})$ pairs. Significant $\mathrm{p}$-values are highlighted in gray $(\alpha=0.05)$. 


\section{LIST OF FIGURES}

Figure 1. Relationship between the amount of impact and the amount of use is asymptotic. Cole, 2004.

Figure 2. Model to explain some of the motivations in the formation of informal trails and how they affect understory plant communities.......................................

Figure 3. Forest Park, showing all park trails and roads.............................27

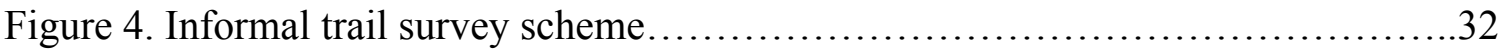

Figure 5. Transect and quadrat placement scheme.................................33

Figure 6. Transect and quadrat placement scheme.................................. 38

Figure 7. Shannon-Weaver diversity index $(H): s=$ total number of species (richness), p $i$ is the proportion of species $(s)$ made up of the $i$ th species............................40

Figure 8. shows park trails and roads and informal trails mapped as part of this study....44

Figures 9. Informal trails by Condition Class for the Balch Watershed area.............45

Figure 10. Informal trail origin relative to formal trail or road. Slopes of $<10 \%$ were

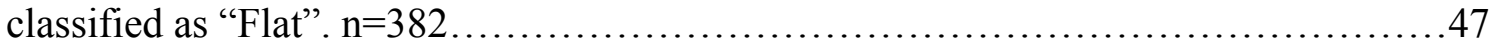

Figure 11. Informal trail frequency (blue bar) and area of impact (red diamond) by

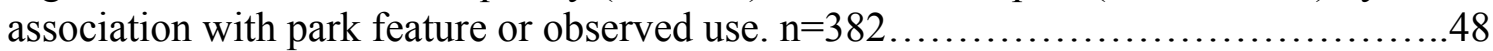

Figure 12. Trail density in meters per hectare. Trail length per hectare creates higher intensity where greater number of trails, but also where long trails form...............51

Figure 13. Trail density hotspots. Trail density by number of trails per unit area, based upon trail origin. Colored areas show relative intensity of informal trail formation.....52

Figure 14. Trail density hotspots by lineal extent and Condition Class. Values represent a combination of trail density $(100 \mathrm{~m} / \mathrm{ha})$ and trail Condition Class, so they can be interpreted as relative impact - with higher off-trail activity areas shown increasing

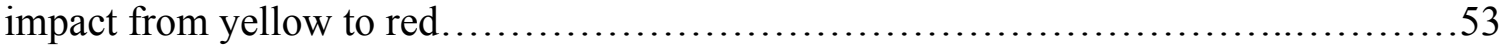

Figures $15 \mathrm{a} \& \mathrm{~b}$. Mean species richness by distance from trail edge for informal (left) and formal (right) trails. Each column represents mean total species richness, which is shown divided into native species (green), ruderal natives (blue), and introduced species (red). Error bars represent $95 \%$ confidence. 
Figure 16. Mean species richness by distance from trail edge for informal trails at distances greater than $100 \mathrm{~m}(\mathrm{n}=15)$. Each column represents mean total species richness (purple), which is shown divided into native species (green), ruderal natives (blue) and introduced species (red). Error bars represent 95\% CI

Figure 17. Shannon-Weaver diversity as a function of distance from informal (red) and formal (blue) trails $(n=30)$. Diversity for informal trails at $>100 \mathrm{~m}$ from origin are also shown (orange, $n=15$ ). Diversity is increased closer to the trail for both formal and informal trails. Error bars represent $95 \%$ CI......................................

Figure 18. Native, invasive, and ruderal Shannon-Weaver diversity by distance from trail edge for formal (upper left), informal (upper right), and informal trails $>100 \mathrm{~m}$ (lower). Error bars represent $95 \%$ CI for total diversity.

Figure 19 Mean total percent cover as a function of distance from trail edge for formal (left) and informal (right) trails. Bars represent 95\% CI............................61

Figures $20 \mathrm{a} \& \mathrm{~b}$. Figure a: NMDS informal trail and control quadrats with vectors for selected dispersal mechanisms and canopy cover. Figure b: NMDS informal trail and control quadrats by distance from trail edge for selected dispersal mechanisms (blue vectors) and canopy cover type variables (red vectors). Percent variance explained by each axis shown in parentheses next to axis label. Clusters for $0 \mathrm{~m}$ (black) and 10m (red) distances are highlighted with ovals. Log-transformed, $\mathrm{K}=2$, stress $=0.18$

Figure 21a\&b. Figure a: NMDS for formal trail and control quadrats with vectors for selected dispersal mechanisms and canopy cover. Figure b: NMDS for formal trail and control quadrats by distance from trail edge for selected dispersal mechanisms (blue vectors) and canopy cover type variables (red vectors). Percent variance explained by each axis shown in parentheses next to axis label. Clusters for 0m (black) and 10m (red) distances are highlighted with ovals. Log-transformed, $\mathrm{K}=2$, stress $=0.16 \ldots \ldots \ldots \ldots \ldots 6$

Figure 22. ANOSIM plot for formal trails by distance from trail edge for log-transformed

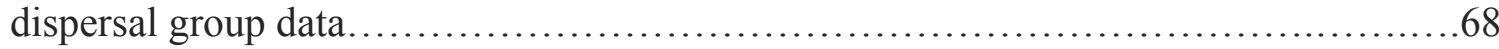

Figure 23. ANOSIM plot for informal trails by distance from trail edge for logtransformed dispersal group data....

Figures 24a and b. NMDS plots for informal trail quadrats by growth habit and ecological groups, log-transformed data. Upper plot shows NMDS with vectors for each grouping (blue vectors) and canopy cover type variables (red vectors). Percent variance explained by each axis shown in parentheses next to axis label. Lower plot shows quadrats by distance from trail edge. Log-transformed, $\mathrm{K}=3$, stress $=0.14$ 
Figures 25a and $\mathrm{b}$. NMDS plots for formal trail quadrats by growth habit and ecological groups, log-transformed data. Upper plot shows NMDS with vectors for each grouping(blue vectors) and canopy cover type variables (red vectors). Percent variance explained by each axis shown in parentheses next to axis label.. Lower plot shows quadrats by distance from trail edge. Log-transformed, $\mathrm{K}=3$, stress $=0.15$

Figure 26. Impacts from off-trail activity along Balch Creek. The Stone House has numerous informal trails surrounding and extending from it (upper left); signs and fences have been added in some locations along the creek to reduce off-trail activity (upper right); Erosion and loss of riparian vegetation along where the trail follows too closely to the stream (lower left)....

Figure 27. Trails to private property are longer than most informal trails and some show evidence of active maintenance............................................. 78

Figure 28. Fencing along Wildwood Trail within the Balch Watershed. Users shortcut trail at fence gap (left); sign added to fence to inform users about restoration efforts

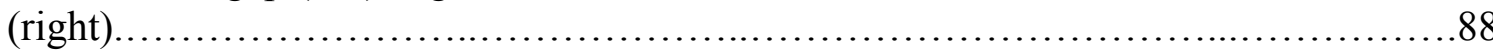




\section{INTRODUCTION}

Informal trails (also referred to as: visitor-created, demand, social, or illegal trails) represent a significant threat to natural areas (D. N. Cole, 1995; Liddle, 1975; Wimpey \& Marion, 2011). While formal trails alter the landscape, their intent is to allow for a managed use of an open space, usually with some design, construction, and maintenance criteria, whereby impacts can be contained and monitored within the defined use corridor (C. A. Walden-Schreiner, 2012; Wimpey \& Marion, 2011). Informal trails, created with no such guidelines, tend to follow less sustainable alignments and are generally unmonitored, resulting in greater erosion and soil compaction, and likely serve as vectors in the spread of non-native and invasive species (Chatterjea, 2007; Mount \& Pickering, 2009a; Potito \& Beatty, 2005). The spread of invasive species along formal trail corridors in natural areas has been well documented, and these corridors are commonly primary targets for Early Detection Rapid Response plans for emerging invasive species threats (City of Portland, 2008; Dennehy et al., 2011). The spread of invasive species from offtrail activity has not been well characterized, particularly in urban or otherwise high-use protected areas (C. M. Pickering, 2010; Potito \& Beatty, 2005; Rew, Maxwell, Dougher, \& Aspinall, 2006; Roovers, Bossuyt, Gulinck, \& Hermy, 2005). Indeed, informal trails, which may traverse areas intentionally protected from human activity, could facilitate the spread and establishment of invasive species before being detected, making them much

more difficult to eradicate (City of Portland, 2008; Dennehy et al., 2011; Underwood, Klinger, \& Moore, 2004). 
Urban forests play a complex role in biodiversity and conservation. They are set aside to serve diverse, and sometimes conflicting, purposes in urban areas. In addition to current uses, urban parks were often subject to disturbances prior to being set aside as park space. Urban natural areas provide critical refuge for the wildlife and native plants, and act as an important buffer and filter for storm-water runoff. They also serve an important role in providing access to nature, exercise, and education for residents and visitors. As reservoirs within an urban area, urban natural areas are particularly vulnerable to invasion because they are subject to many disturbances, including: urban edge, utility development, air pollution, and recreational use. Human traffic and recreation are major drivers of invasion, making high public use areas more susceptible to invasion than low-use areas (Holmes, 2010). 


\section{BACKGROUND}

\section{Recreation Ecology}

Environmental legislation and policy with respect to public lands changed dramatically during the 1960s and 70s (Y. Leung \& Marion, 2000; Monz, Cole, Leung, \& Marion, 2010; Westman, 1990). The passage of Wilderness Act and the National Environmental Policy Act mandated study of the effects to protected lands managed by the Federal government. In 1968, the National Park system adopted the recommendations of the Leopold Report, recommending science-based approaches to wildlife and habitat management with the ultimate goal of restoring ecosystems to pre-settlement conditions (Westman, 1990). Other federal and state agencies followed the National Park Service's lead adopting similar policies in park management.

Coincident with these changes in land use policy was the recognition of the importance of understanding human impacts to the land, from pristine and remote Wilderness areas to popular National Park settings. Recreation Ecology, a field of ecology formed through the study of protected areas, seeks to fill the void in our understanding of recreation impacts to the environment. Effects to natural areas from recreational use vary widely, from compaction and waste at campsites to rutting from Off-Highway-Vehicles to vandalism of cultural artifacts (Cole, 2004; Marion \& Reid, 2007). These effects have been characterized very well in some protected areas, particularly National Parks and designated Wilderness areas, while little is known of the character and extent of impacts in others.

While a basic understanding of soils, vegetation, and hydrology are applied in the design and construction of recreational trails, there is an alarming void when it comes to 
research regarding the impacts of these basic, primitive, and yet critical recreational facilities. This dearth of research leads recreation planners and resource specialists to "manage by anecdote" and create policies and management regimes based on untested information; this, in turn, leads to inconsistent and arbitrary policies, affecting recreational experiences and confounding ecological impacts.

Recreation Ecology, when applied to trails, involves studying how trails affect soils, vegetation, water, and wildlife. These effects come in a variety of forms: physical changes caused by the trail itself, such as the erosion of soil or trampling of vegetation; and impacts related to the use of trails, such as disturbance to wildlife or invasive species transmittance (D. N. Cole, 2004; Marion \& Leung, 2001; Wimpey \& Marion, 2011). While these may seem relatively minor, the natural areas that host trails serve as critical corridors for wildlife, reservoirs for water, refuge for plants, and filters for pollutants. Gaining a true understanding of the consequences of trail use is fundamental to protecting natural areas, and is most critical in urban areas where demand for access is greatest and threats to habitat the most acute (Bhuju \& Ohsawa, 1998; Cole, 1995; Kuss, 1986).

\section{Informal Trails}

Informal trails are user-created trails in protected areas, referred to in various settings as: social trails, illegal trails, desire lines, and shortcuts (Marion \& Leung, 2006; Wimpey \& Marion, 2011). They are unplanned and typically unmanaged. Informal trails are formed by off-trail activity, where trampling of vegetation and compaction of soil rapidly lead to the establishment of a discernable path. Once a corridor of disturbance is visible, it can create a "releaser cue" that induces other users to follow this same route (Wimpey \& Marion, 2011). These trails are most often formed unintentionally, through traveling off- 
trail, but may involve intentional activities as well, such as pruning of vegetation or excavation of soil or rock.

Informal trails form for a variety of reasons. Planned trail systems cannot accommodate or anticipate all of the needs and desires of park users. Some trails form for efficiency: a shortcut of a turn or from a parking area, or to access a natural feature more directly (Wimpey \& Marion, 2011). Others may form because the existing system provides no or limited access to a desirable feature, such as a known viewpoint, river, historic structure, private property, or a rock outcropping (Dickens, Gerhardt, \& Collinge, 2005; Walden-Schreiner \& Leung, 2013). Privacy is another compelling factor to go off trail: users do not want to be seen doing socially unacceptable or even illicit activities in public. These "hidden behaviors" range from going off-trail for a bathroom break to dumping trash to camping.

\section{Impacts of Informal Trails}

Effects from informal trails to natural areas tend to be localized, but they can also exacerbate other disturbances and contribute to changes at the landscape level (Kuss, 1986; Wimpey \& Marion, 2011). Informal trails can result in loss of native vegetation, habitat fragmentation, displacement of wildlife, soil compaction and erosion, altered hydrology, and spread of invasive species (Cole, 1995; Wimpey \& Marion, 2011). Early studies of off-trail activity in protected areas have focused on trampling, which is a good proxy for informal trails as all originate with trampling (Cole, 1995; Kuss, 1986; Liddle, 1975). Studies of trampling impacts from recreation were conducted as early as 1910, but most serious study began in the 1960 s, primarily in relation to dispersed use in designated Wilderness areas and National Parks (Y. Leung \& Marion, 2000; Monz et al., 2010). 
Observed effects to campsites and other recreation facilities from dispersed use, led to the creation of Limits of Acceptable Change monitoring regimes and Desired Future Condition plans in National Parks, and these plans were readily adopted by other land management agencies (Y. Leung \& Marion, 2000; Monz et al., 2010). While not described explicitly as such, these were effectively studies of and policy responses to offtrail activity and informal trails.

There have been few studies of informal trails outside of dispersed use areas. (Dispersed use is generally allowed only in areas with limited access, such as Wilderness and other remote backcountry areas, where formal trail and facility development are limited and use is presumed to be sufficiently low to allow for the landscape to recover.) While there have been a few studies of informal trails in high-use areas, these studies have focused on spatial characterization of informal trail development and motivations in their formation (Walden-Schreiner \& Leung, 2013; Wimpey \& Marion, 2011).

In a study of Great Falls Park, a popular park near Washington D.C., Wimpey and Marion mapped and characterized the system of informal trails and its relation to the formal trail system, topography, and other landscape characteristics (Wimpey \& Marion, 2011). They found that informal trails tend to form perpendicular to formal trails and have significantly higher trail grade and slope ratio compared to formal trails. They also found that informal trails are concentrated in areas with highest use and near viewpoints, the Potomac River, and rock outcroppings.

In another spatial analysis, visitor use was characterized with the presence of informal trails in the Yosemite Valley (Walden-Schreiner \& Leung, 2013). Open landscapes of the meadows make off-trail activity easier, and some informal trails are 
indistinguishable from formal trails, further reinforcing their presence. They found visitor use was clustered in meadows and distance off-trail was influenced by activity type, with stationary or "passive" users traveling twice as far off-trail as active users. Spatial analyses of informal trails and user motivations can help land managers in monitoring and developing strategies to minimize recreational impacts.

A recent study of informal trails in Aconcogua Provincial Park, Argentina, is representative of the effects vegetation and soils from informal trails (Barros, Gonnet, \& Pickering, 2013). While the setting of high elevation meadows is decidedly different than high-use areas in the United States, patterns of user behavior in the proliferation of informal trails are similar, as are biophysical impacts. Soil loss, increase in exposed soil, and changes in vegetation composition from trampling were all observed in this area of high conservation value. This is one of the few such studies to consider effects to neighboring vegetation from informal trails and associated spread of exotic species (Barros et al., 2013).

\section{Effects to Soils}

The formation of informal trails occurs in stages: trampling of vegetation, loss of organic soil material, and eventually compaction of soil. Depending upon the site slope, soil type, hydrology, and use intensity, soil displacement and erosion may also occur (Barros et al., 2013; J. L. Marion \& Leung, 2006). The creation of informal trails can lead to changes in soil structure (Cole, 2004; Marion \& Leung, 2001). Several interrelated physical properties of soil affect how informal trails might change soil structure: bulk density, compaction, infiltration rate, and texture (Millward, Paudel, \& Briggs, 2011). For instance, soils with a high clay or silt content are more susceptible to increases in bulk 
density and shear strength, and reduced infiltration resulting from compaction than sandy soils.

Compaction of soil can lead to reduced soil air, decreased macropore space, and increased penetration resistance (Liddle, 1975; Littlemore \& Barker, 2003). Trampling and compaction leads to decreased organic layer, which in turn can lead to decreased soil nutrient availability, greater soil moisture and temperature variability, limit fine root growth, and affect drainage properties and availability of moisture in the root zone (Kuss, 1986; Lei, 2004; Liddle, 1975).

Several studies of the recreational trails have demonstrated the relationship between level of use and changes to soil structure (Bhuju \& Ohsawa, 1998; Cole, 2004; Kuss, 1986; Littlemore \& Barker, 2003; Manning, Jacobi, \& Marion, 2006). While these effects are greatly influenced by soil, vegetation, precipitation, and landscape characteristics, generalizations about the effects on soils and vegetation from informal trails as use increases can be applied. The use-impact curve (Figure 1) shows an asymptotic relationship between the number of user passes and effects on vegetation and soils. A few user passes rapidly affects soil and vegetation in the form of increased bulk density and compaction, decreased soil moisture, and decreased vegetation. 


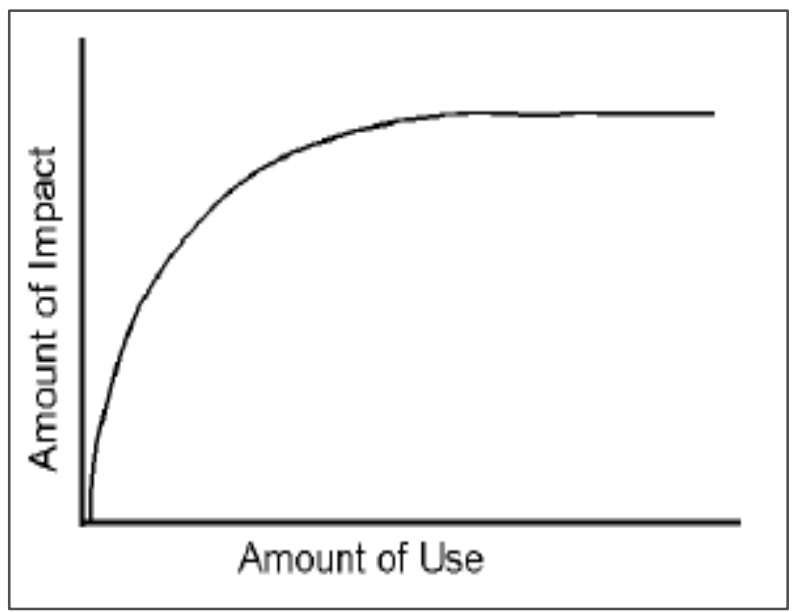

Figure 1. Relationship between the amount of impact and the amount of use is asymptotic. Cole, 2004.

\section{Effects to Vegetation}

Plants can be defined by their responses to trampling: sensitive, resistant, tolerant, and resilient (Cole, 1995; Kuss, 1986; Liddle, 1975). Sensitive plants are those that are highly susceptible to damage by trampling. Resistant plants are able to tolerate much greater amounts of disturbance than sensitive plants before sustaining irreparable damage, as defined by Cole (1995) in experimental trampling, this equates to survival two weeks after trampling. Kuss (1986), in his comprehensive review of the effects of trampling on plants, describes tolerant plants as having "morphological, phonological, or reproductive advantages that enable them to tolerate more use than susceptible plants but less than those classed as resistant". Under experimental trampling, this was assessed as those surviving one year after trampling (Cole, 1995). Resilience is the ability to recover following removal of disturbance. This is similar to tolerance, but assesses not just survival or ability to withstand disturbance, but is a measure of how much a plant recovers after relief from disturbance. For Cole's experimental study, this was evaluated 
by measure of change following two weeks of trampling over one year recovery period (Cole, 1995).

Several studies have assessed the ability of plants to recover following trampling, to assess tolerance and resilience (Cole, Foti, \& Brown, 2008; Littlemore \& Barker, 2003). In experimental trampling of vegetation, Cole (1995) found that plant morphological characteristics explained more of the variation in response to trampling than altitude, canopy cover, or total groundlayer cover (Cole, 1995). Similarly, Littlemore and Barker (2003) showed different types of plants were more tolerant and resilient under experimental trampling: ferns (Pteridium) being the highest and a low-growing forb (Hyacinthoides) with very low tolerance and resilience.

Hall and Kuss found that hemicryptophytes, plants with buds at or near the soil, such as rosettes or low growing species (e.g. grasses, moss, rosette species, ground spreaders), increased in dominance closer to trailside (Hall \& Kuss, 1989). They found that plants away from trails were more commonly woody species that have resistance to physiological stress but which are sensitive to mechanical stress (trampling). This is in contrast with trailside vegetation comprised primarily of ruderal species: low stress resistance and high trampling resistance. Additionally, plants with short generation times and producing large number of offspring or lots of seed are most suited to changing environmental conditions, as are present under recreational trampling stress (Cole, 1995; Kuss, 1986; Liddle, 1975). However, while growth or life form appeared to be the greatest predictor in tolerance to trampling, several other factors play key roles in plant responses to trampling stress. Plant succulence, height, and phenology, soil moisture, competition, and habitat preferences all influence plant vulnerability (Kuss, 1986). 
Experimental trampling has shown that very low levels of use (few user passes) are required to see noticeable and long-lasting effects to herb-layer vegetation and soils (Kuss \& Hall, 1991; Littlemore \& Barker, 2003; Thurston \& Reader, 2001). Littlemore and Barker, in a study conducted in British urban woodlands, found that fewer than 75 passes were needed to create an evident path in forests, and less than 25 in some vegetation types (2003). Cole conducted experimental trampling at various levels in five different mountainous regions of the US (WA, MT, CO, NC, and NH) and showed visible trails and measurable differences in vegetation from trampling following 25 to 75 passes.

\section{Non-native and Invasive Species}

Twenty-five thousand non-native species have been introduced to the United States and over 5000 have become established in natural areas; of those 1,500 are categorized as invasive plant species (Dickens et al., 2005; Vitosek, D’Antonio, Loope, \& Westbrooks, 1996). Non-native invasive species present a profound threat to natural areas. They displace native species, affect food and shelter resources for wildlife, and can affect hydrology and soils. For trails, they can affect the physical infrastructure as well as the aesthetic and educational experience for users. Trails and roads are well documented as a vector in the spread of non-native and ruderal species (Hansen \& Clevenger, 2005; Mount \& Pickering, 2009b; Potito \& Beatty, 2005). Disturbance to soil and native vegetation, daylighting of the corridor, and the direct transport of propagules by recreational users all facilitate the establishment of non-native and ruderal species along trail and road corridors. 
Dispersal by humans and pets along formal and informal trail corridors presents an opportunity for non-native and ruderal species to be transported widely within natural areas. In a global review of human-mediated transport of non-native seeds, Pickering and Mount (2010) found that of the 754 species transported via clothing, vehicles, pet fur, and pack animal dung, 650 were considered "weed" seeds somewhere in the world (C. Pickering \& Mount, 2010). The most common family accounting for seed dispersal was Poaceae (grasses), and seeds were predominantly from annual or perennial herbs and graminoids, rarely shrubs or trees. Many non-native invasive and ruderal species have seed that readily adhere to clothing facilitating transport along trail corridors (Mount \& Pickering, 2009a; Potito \& Beatty, 2005). Facilitation of the spread of invasive species into natural areas by informal trails is two-fold: seeds are transported by users and wildlife along the trail corridor, and the disturbance to native vegetation and soil creates an opening for these seed to establish.

\section{Invasive Species in Urban Parks}

High public use areas are more susceptible to invasion than low-use areas, with human traffic and recreation as major drivers (Holmes, Roy, Reed, \& Johnson, 2010). Urban forests play a complex role in biodiversity and conservation. They are set aside to serve diverse, and sometimes conflicting, purposes in urban areas. Urban natural areas provide critical refuge for the wildlife and native plants, and act as an important buffer and filter for storm-water runoff. They also serve an important role in providing access to nature, exercise, and education for residents and visitors. 
Urban natural areas are particularly vulnerable to invasion because they are subject to many disturbances: edge development, utilities, air pollution, fire suppression, and heavy recreational use (City of Portland, 2008; Hansen \& Clevenger, 2005). This is compounded by historical disturbances, as often parks were subject to disturbances prior to being set aside as park space (Broshot, 2007; Guntenspergen \& Levenson, 1997). The risk of spread and establishment of invasive species to interior habitat within urban parks is of great concern to park managers and ecologists (Broshot, 2007; City of Portland, 2008; McKinney, 2008).

\section{Study Rationale}

In order to better understand the relationship between informal trails and invasive species, I conducted a study of the informal trail network in Forest Park. How informal trails form in natural areas and the range of potential effects to understory vegetation are illustrated in Figure 2. Motivations for users go off-trail range widely - from shortcutting at turns and trailheads, to finding a place go to the bathroom, to accessing private property - and are greatly influenced by site-specific factors, such as topography, proximity to urban areas, and historic use (Cole, 1995; Kuss, 1986; Wimpey \& Marion, 2011). Likewise, plant communities can be affected by off-trail activity and the formation of informal trails in many ways, including soil compaction and erosion, trampling of native plants, and the dispersal and spread of invasive species (Barros et al., 2013; Kuss, 1986). This study involved mapping the system of informal trails, and assessing if informal trails were associated with the spread of invasive species. This study also 
included a look at the spatial relationship of informal trail location to formal trails, other park features (trailheads, intersections, landform/slope, viewpoints), and trail use level and type.

Forest Park is a 2,000 hectare forested park in Portland, Oregon, and one of the largest urban parks in the country. Increasing recreational trail use has led to proliferation of off-trail activity and creation of informal trails. The extent of informal trails and their effects to plant communities in Forest Park has not been characterized.

\section{Why users go off-trail: \\ - Lack of facilities: bathrooms! \\ - Desire lines: structures, views \\ - Water access \\ - Parking access \\ - Private property access \\ - Poor trail design \\ - Illicit/illegal activities: drugs, parties, camps}

Factors affecting trail location:

- Existing trails and park facilities

- Adjacent to private property

- Ability to be hidden

- Historic use corridors

- Openings, viewpoints, \& structures

- Utility corridors

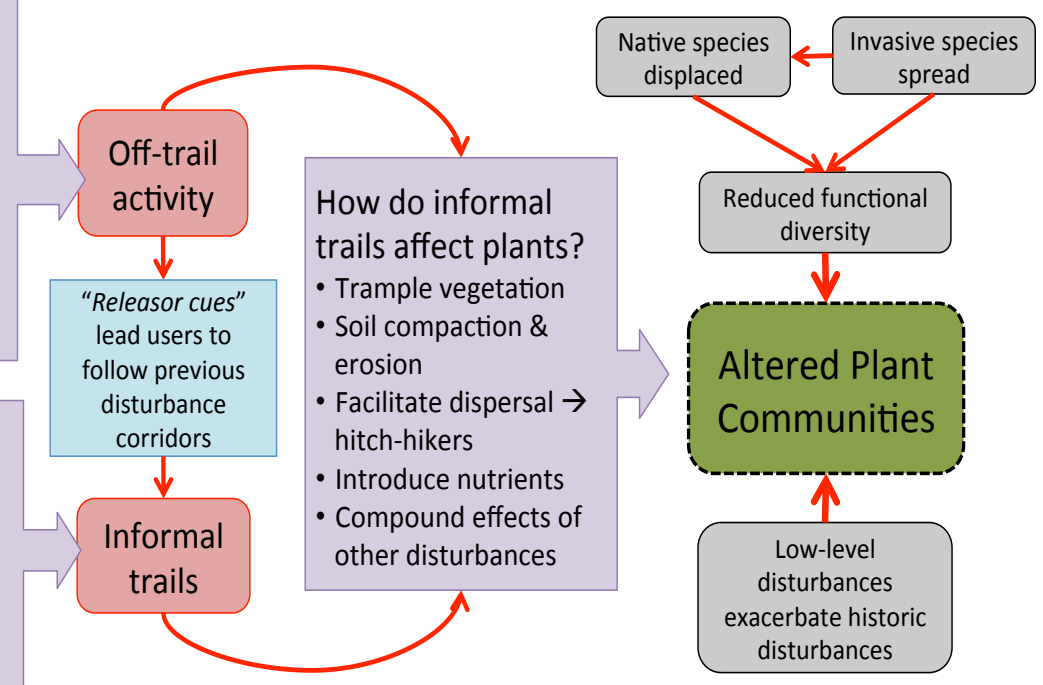

Figure 2. Model to explain some of the motivations in the formation of informal trails and how they affect understory plant communities.

\section{Research Hypotheses}

This study lends itself to several hypotheses:

1. The density of informal trails in Forest Park will be higher in high use areas, close to trailheads, and near desirable features, such as creeks and structures. 
2. Informal trails in Forest Park are caused by: attempts to hide socially unacceptable or illicit activities, access to private property, and shortcutting of formal trails.

3. Understory plant composition adjacent to trails will be affected in several ways:

1. Total species richness and diversity will be higher closer to informal trail edge $(</=2 \mathrm{~m})$ compared with controls;

2. Ruderal and invasive species richness and diversity will decrease with distance from trail edge;

3. Native species richness and diversity will increase with distance from trail edge;

4. Total percent cover will increase with distance from trail edge, while invasive cover will decrease.

4. Understory plants with particular dispersal traits will be affected by informal trails:

1. Plants with hitchhiker, wind, and ballistic dispersal strategies are more likely to occur close to informal trail edges.

2. Plants with "weedy" growth strategies are more likely to occur close to informal trail edges. 


\section{METHODS}

\section{Site Description}

Forest Park is a 2,000 hectare forested park situated within the Portland metropolitan area

(Figure 3). It extends northwest along a ridgeline of the Tualatin Mountains parallel with the Willamette River. The Tualatin Mountains are contiguous with the Coast Range and share vegetation typical of Douglas Fir-Western Hemlock and Douglas Fir-Big Leaf Maple forest communities (Broshot, 2011). Since European settlement, the entire park has experienced some level of logging, through high-grading and woodcutting activities, barring a few isolated patches of intact stands. The park follows an urban to rural gradient with a dense urban area at its southeast end, and rural, small towns along its northern and eastern edges. The park is bounded by Skyline Drive and large private home properties to the west, Highway 30 and industrial areas to the east, dense urban development along its southern edge, and rural home sites and small farms to the north. The park topography is characterized by steep slopes, with soils primarily of Cascade and Goble classes, creating conditions of high slope instability (FPNRMP, 1995). Elevations range from 20m to $335 \mathrm{~m}$ above sea level, with slopes in excess of $40 \%$ throughout much of its extent (NRCS, 2013). The Park has experienced a varied disturbance history. Natural disturbances in Coast Range forests consist primarily of fire and wind (Broshot, 2007; FPNRMP, 1995). The fire regime for these forest types tend to be rare (300-500 year interval) and of high intensity, leading to landscape-level changes. Wind creates small to large gaps that contribute to forest complexity over time. 


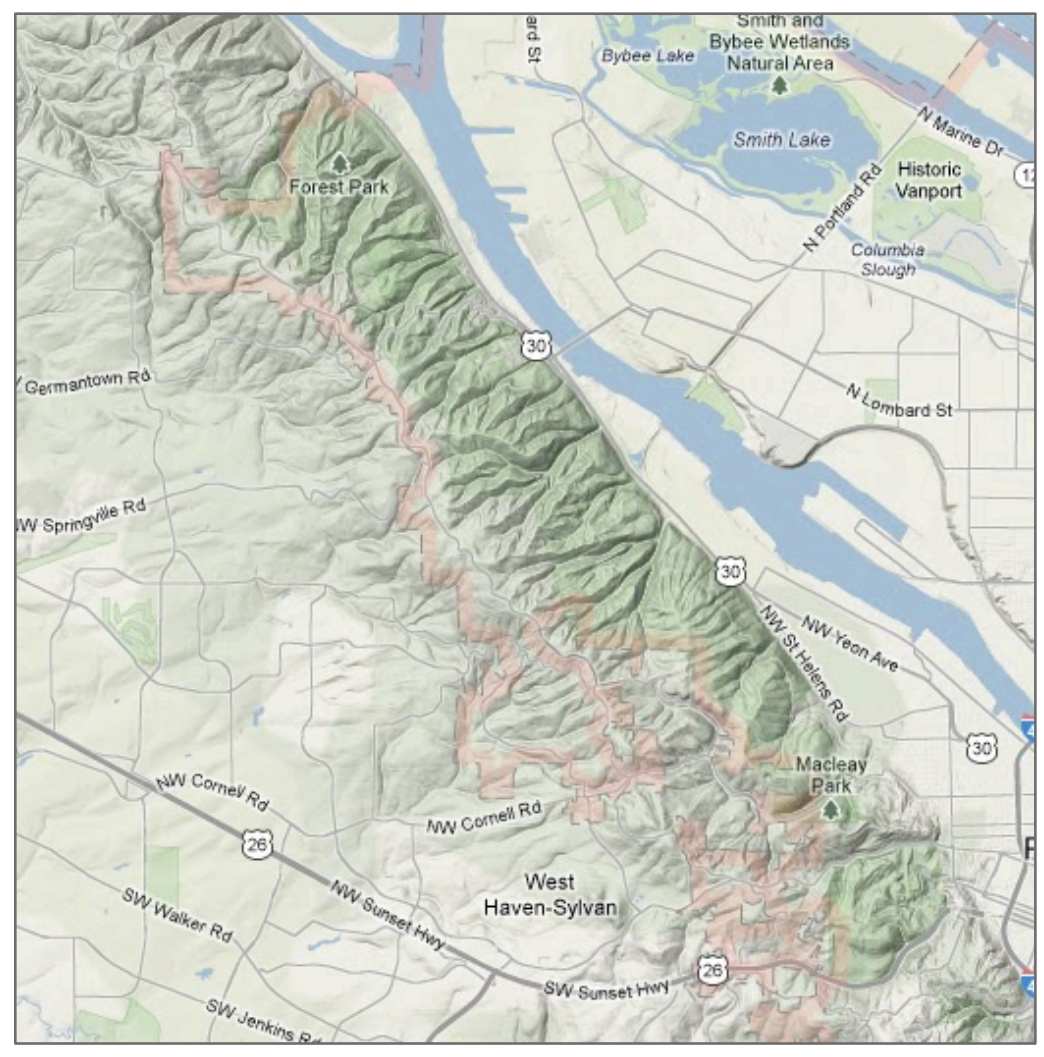

Figure 3. Map of Forest Park.

Anthropogenic factors have dramatically changed the disturbance regime in the past 200 years. Logging replaced fire as the primary landscape-scale disturbance until the area was set aside as a park in the 1950s. Management practices and the proximity to the urban and residential areas have led to fire suppression (FPNRMP, 1995). Early in the last century, utility and fire control access corridors were established, bisecting the forest repeatedly from Skyline Road to Highway 30. Despite fire-suppression, several small fires and one larger fire have occurred in the park, likely started by adjacent development and/or utility access (FPNRMP, 1995). Larger fires have been documented in the 1890s and as recently as 1951, when the largest documented fire in Forest Park occurred, burning over 480 ha in the Central Management Unit. (Broshot, 2007). 
Following establishment as a park, development of recreational facilities, including trails and roads were constructed. Private development along the park's perimeter contributed to edge disturbances, including the introduction of invasive species, notably English ivy. This mosaic of disturbance and urbanization has let to a patchy forest community distribution. In Coast Range forests, the herb layer is suppressed during pioneer and early successional stages by woody debris and dense sub-shrub growth, such as salal (Gautheria shallon) (Broshot, 2007; FPNRMP, 1995).

When logging replaced fire and wind as the primary landscape disturbance in the forest, this pattern was disrupted by anthropogenic factors. High-grading, where only the high quality timber is removed from a stand, and wood-cutting activities, along with fire suppression create different conditions for native plant growth. While logging has not played a role in forest management since the 1940s, the increasing affects of urbanization continue to disrupt native forest processes (Broshot, 2011).

The combined effects of urbanization, fire history, logging, utility corridors, and recreation on plant communities are difficult to characterize. These disturbances can work in combination to create a pre-condition that favors invasibility (Bella, 2011; Hansen \& Clevenger, 2005; McKinney, 2008).

\section{Topography and Soils}

The park topography is characterized by steep slopes, with soils primarily of Cascade and Goble series; along the riparian area of Balch Creek, Wauld gravelly loam (slopes 2060\%) dominates (FPNRMP, 1995; NRCS, 2001). Soil cores from several sites in the Balch Watershed show shallower depth for A1 and A2 horizons than for descriptions for 
these series, but otherwise match described physical characteristics. Historical logging activities may have altered soil structure along skids trails and landings, and numerous old road beds persist throughout the Balch watershed (FPNRMP, 1995). According to the soil survey, due to the combination of soil types and topography, the study area has an erosion rating of "severe" (off-trail/off-road) and low resistance to compaction (NRCS, 2001).

\section{Current Park Use}

The current primary use of the park is for recreation: there are over $110 \mathrm{~km}$ of trails and roads throughout the park. Trail use is extremely popular and unlikely to decline; Portland Parks and Recreation estimates that the park receives 475,000 annual visits. In a 2012 recreation survey of Forest Park, trails ranked as the most important park amenity and "exercise and fitness" as the primary motivation for visits (Forest Park Recreation Survey, 2012). Most common activities are hiking, running, dog-walking, plant or wildlife viewing, and cycling $(38 \%, 25 \%, 14 \%, 10 \%$, and $9 \%$, respectively). While there are numerous small trailheads surrounding the park, a few entrances see the highest use: Thurman Gate (31\%), Macleay Park (25\%), Germantown Road (21\%, Leif and Wildwood trailheads combined), and Lower Saltzman Road (11\%) (Forest Park Recreation Survey, 2012).

Unmanaged recreational use (largely in the form of off-trail activity) in Forest Park is thought to exacerbate environmental stressors, through trampling native plants, compacting and eroding soil, spreading invasive species, and contributing to nutrient loads (human and dog waste, trash, etc.) which was found by researchers in other natural 
areas (Kuss, 1986; Mount \& Pickering, 2009b; Wimpey \& Marion, 2011). The scope and potential ecological effects of informal trails in Forest Park have not been evaluated.

\section{Study Design and Data Collection}

This study is made up of two parts: 1) generation of a population of informal trails through a full-park survey, and 2) measure of understory vegetation for a sample of informal trails surveyed in part 1.

\section{Minimizing Research Impacts}

I recognize that research within the Park can perpetuate existing and/or contribute to the establishment of informal trails and contribute to the spread of invasive species. This understanding is particularly acute given the nature of this study. I sought to time surveys to avoid seed dispersal windows for invasive species of particular concern (e.g. garlic mustard). Care was taken in surveying to minimize contribution to the establishment of informal trails. I minimized the number of visits and number of surveyors to each trail site. Where appropriate, I used dispersed travel for off-trail activities (e.g. for transects). Care was taken in brushing and cleaning of my field gear to minimize the likelihood for transport of plant or fungal propagules. 


\section{Part I: Informal Trail Survey}

All informal trails that persist beyond the formal trail or road corridor were surveyed and mapped along most formal trails, roads, and fire-lanes in the park (Figure 4). The corridor is the area that might reasonably be impacted by regular trail use and maintenance (e.g. user passing, drainage features, tree/limb removal) and extends beyond the active tread on both trails and road corridors (Figure 5). For trails, this "direct impact buffer" has been defined at $3 \mathrm{~m}$ from the active tread edge to both sides of the trail. Active tread for trails varies from $\sim 0.8 \mathrm{~m}$ to $3 \mathrm{~m}$; road/fire lane active tread typically ranges from $2-5 \mathrm{~m}$ on fire lanes and lower use routes, but can be much wider on high use routes such as Leif Erickson or Saltzman Roads. Total trail corridor includes both the active tread and this buffer zone of direct impact. Only informal trails that originate from formal trails, roads, or trailheads were surveyed for this study. All park trails and roads north of Cornell Road and south of Newberry (the park's northern boundary) classified as “open" (Metro GIS trails layer, "status" field) were surveyed, with the exception of: lower Firelane 1 (below Leif Erickson), lower Firelane 9, and the Linnton Trail, due to time constraints.

While I tried to observe every trail in the park, this survey is not exhaustive. The nature of informal trails and off-trail activity is such that delineating them is a moving target, as activity and vegetation change with seasons and over time (C. WaldenSchreiner \& Leung, 2013; Wimpey \& Marion, 2011). It is likely that I missed many informal trails, particularly those that originate from property boundaries, rather than recreational access points or trails. Still, the survey produced a population of trail data 
that informs the study questions and paints a reasonable picture of impacts from recreational off-trail activity at a point in time. 


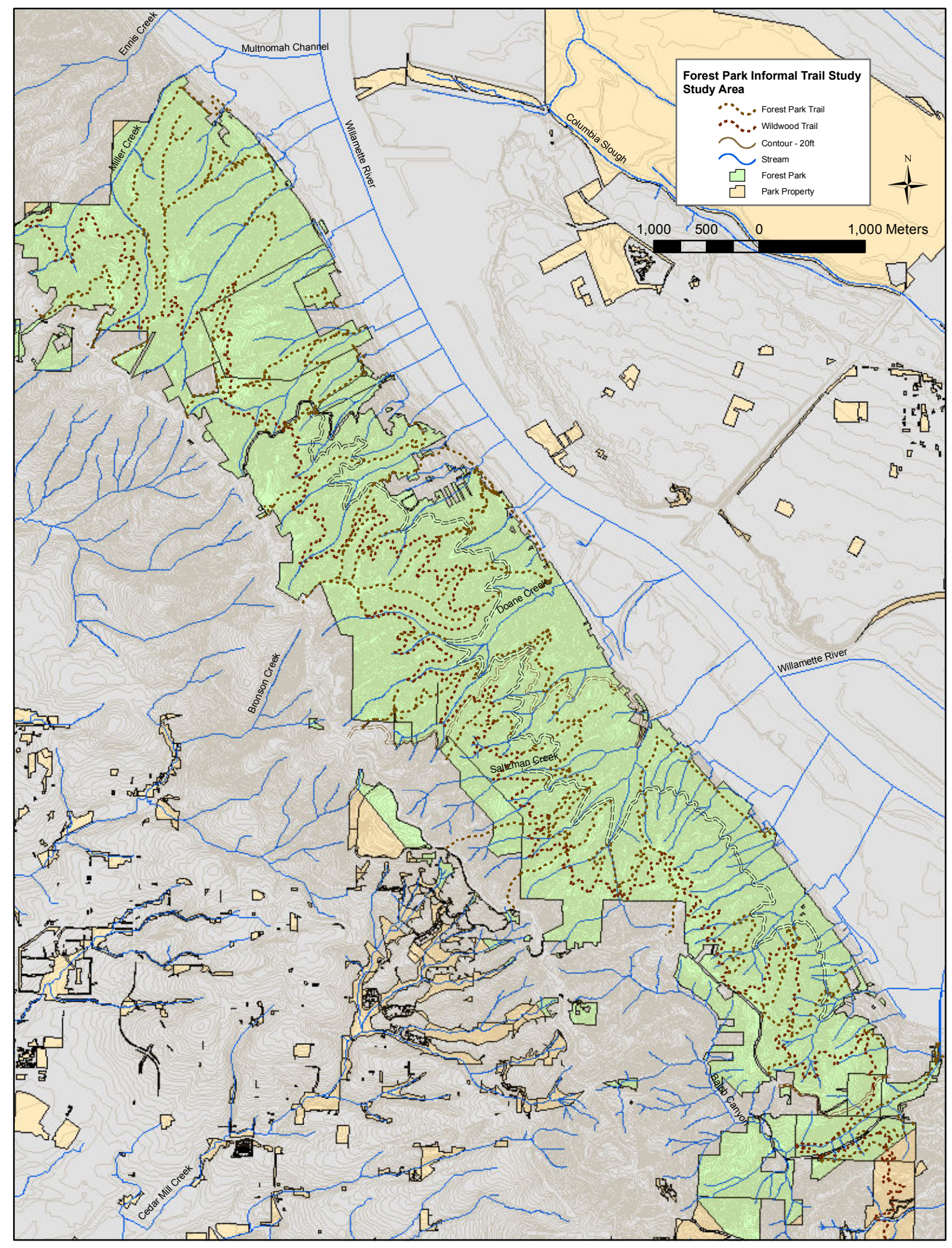

Figure 4. Forest Park, showing all park trails and roads. 
Waypoints and tracks were collected for each informal trail using Garmin GPSMAP 60csx and 62s handheld GPS units; accuracy ranged from 3-6m. Length and width were measured for each informal trail using a transect tape or measuring wheel; for longer trails GPS tracks and waypoints were used to estimate informal trail length. Trail width was defined as the visually observed extent of vegetation trampling.

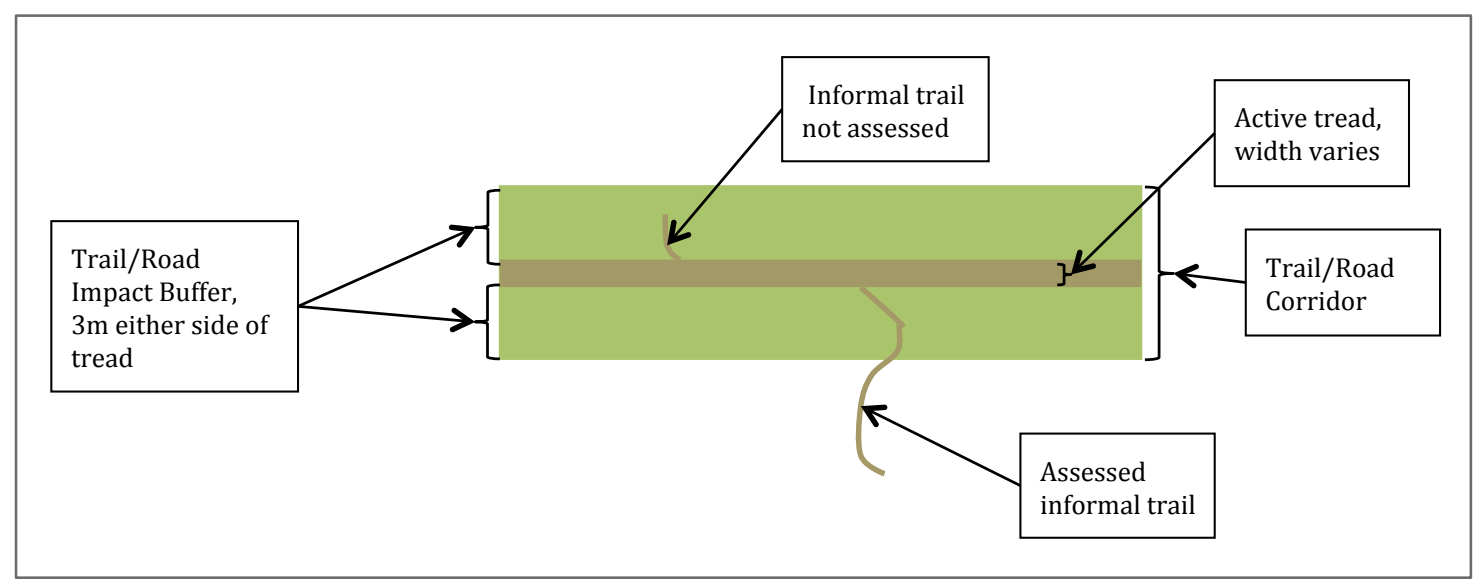

Figure 5. Informal trail survey scheme.

Trail Condition Class was assessed for each informal trail to allow efficient evaluation of relative impact (Table 1). Condition Class ratings are frequently employed in natural area assessments, where large areas and/or numbers of sites must be assessed during a field season (Amacher \& Neill, 2004; Wimpey \& Marion, 2011). Condition Class ratings are used in evaluating effects on soils and vegetation from recreational uses, such as camping and off-trail/road activity, as well as for effects from resource extraction, such as logging skids and landings (Amacher \& Neill, 2004). Trail Condition Class (TCC) is a qualitative measure of relative impact, based upon visible trampling, 
loss of vegetation and organic layer, and soil compaction and erosion (Wimpey \& Marion, 2011).

Condition Class ratings are commonly used to evaluate human impacts to natural areas because of their flexibility for monitoring relative change from an un-impacted state. This method is efficient, allowing for large areas with potentially hundreds of informal trails to be assessed in a reasonable time frame. Condition Class assessments can act as a warning sign for resource degradation and trigger management actions as part of a monitoring plan (J. L. Marion \& Leung, 2006). However, as a qualitative measure, these ratings are subject to observer bias and must be adapted to site-specific conditions. A better understanding of how trails vary within each Condition Class for different soil and landscape characteristics helps in defining meaningful assessments for natural areas and can increase the confidence in the validity of using this approach. Additionally, when combined with GPS tracks for informal trails, spatial analysis can yield a wealth of quantitative data for each informal trail segment to enhance visual assessments.

Table 1: Trail Condition Class Assessment (adapted from Wimpey \& Marion, 2011, with permission)

\begin{tabular}{|c|l|}
\hline $\begin{array}{c}\text { Condition } \\
\text { Class }\end{array}$ & Description \\
\hline 1 & $\begin{array}{l}\text { Trail distinguishable; slight loss of vegetation cover and/or minimal } \\
\text { disturbance of organic litter }\end{array}$ \\
\hline 2 & $\begin{array}{l}\text { Trail obvious; vegetation cover lost and/or organic litter pulverized in } \\
\text { center of tread in most places }\end{array}$ \\
\hline 3 & $\begin{array}{l}\text { Vegetation cover and organic litter lost across the majority of the } \\
\text { tread, considerable soil compaction }\end{array}$ \\
\hline 4 & Soil erosion in the tread beginning in some places \\
\hline 5 & Soil erosion is common along the tread \\
\hline
\end{tabular}


Additional observational data were collected for each informal trail, including: presence of non-native or invasive species at the origin; presence of non-native or invasive species greater than $3 \mathrm{~m}$ from origin; trash, toilet paper, or human waste; when applicable, destination of trail (e.g. creek, structure, another trail, private property); any other unusual or distinct characteristics of the trail (e.g. follows skid road, restoration or closure efforts, steep grades); wildlife evidence (e.g. tracks, scat). Where it could be surmised that an informal trail was a wildlife trail, with unlikely human use (e.g. trails where dense shrubs or other barriers greatly inhibit access, low branches where it was excessively difficult to travel on foot, no opening immediately following barrier to access - particularly in wet areas and/or creek access), it was excluded from the survey. Management unit and formal trail segment from which each informal trail originated was recorded.

\section{Spatial Data Analysis}

Base data layers, in both vector and raster format, were acquired from public databases (RLIS, PP\&R, and USGS). Maps were prepared using the datum NAD83 and the coordinate system NAD_1983_HARN_StatePlane_Oregon_North_FIPS_3601. Base data layers (acquired from RLIS, the City, and USGS) include: aerial photos, DEM, ownership/ parcels, vegetation cover, hydrology, utilities, roads, trails, and ecological health. LiDAR data were used to assist in determining historical use corridors. DEM and LiDAR layers were downloaded from seamless.usgs.gov. Trail layers were downloaded from the RLIS website and/or acquired from the public data files available through PSU. 
State and County boundaries were acquired from the Oregon Geospatial Enterprise Office. These layers were used to generate base maps for field use and spatial analysis.

GPS waypoints and tracks were converted to ESRI ArcMAP v10 shapefiles for editing and analysis. Due to the variability GPS signals in the park (due to vegetation cover and topography, as well as continuous changes in satellite alignment), considerable editing of GPS tracks was needed to create an accurate representation of the informal trail network. Trail measurements (length and width), field map notes, GPS waypoints, and aerial images were used to assist in editing. GPS data were converted to the datum used for the GIS basemap (WGS84 to NAD83). I added attributes for each mapped informal trail added to the spatial data layer, so that trail features could be illustrated.

To identify informal trail "hotspots", I used Line and Point Density tools in Spatial Analyst to create a raster dataset representing the density of informal trails within each cell (C. Walden-Schreiner \& Leung, 2013; Wimpey \& Marion, 2011). Line density provides lineal density of informal trails within each cell, such that longer trails, spanning multiple cells, increases trail density. Point density, using waypoints from each informal trail origin, shows density by trail number, rather than lineal extent. Additionally, to better illustrate relative impact of informal trails to the landscape, I generated a map displaying trail density (as line data) combined with Condition Class rating for each informal trail in the Population field. 


\section{Part II: Analysis of Understory Vegetation}

In order to better characterize understory vegetation response to informal trails, an assessment of species cover adjacent to informal trails, and at control sites, was conducted for a sample of trails identified in Part 1. Criteria were applied in producing the sample from the total informal trail population $(n=382)$ : only trails greater than $10 \mathrm{~m}$ in length and of Condition Class 2 or 3 were used. Trails less than $10 \mathrm{~m}$ were not of sufficient length for transect placement (as transects were only placed at $10 \mathrm{~m}$ and greater from trail origin). Trails scored with Condition Class 1 were determined have had too little distinguishable impact for consistent trail edge measure, and that transect activities themselves could produce sufficient site disturbance to elevate the trail to a Condition Class 2. From this reduced trail population $(n=185)$, a systematic sample was generated $(n=30)$ : trails were ordered by numerical trail ID, then every fifth trail in the list was selected for evaluation. The series for sampling (every $5^{\text {th }}$ trail) was selected to allow for efficient data collection within the limited field season while producing a sufficiently large sample size (i.e. 30) for meaningful analysis. There were a few trails that upon field reconnaissance had conditions unsuitable for vegetation transects within the study scheme: informal trail followed active creek drainage and/or where the informal trail ran parallel to formal trail within $10 \mathrm{~m}$ ). In these situations, the next trail on the list (by numerical order) was used for evaluation. Moran's I test (via ape package in R) was used to assure that sampled informal trails did not exhibit spatial autocorrelation for selected variables (total species richness and diversity) using latitude and longitude point data at informal trail origin. 
Transects were placed perpendicular to informal trails at intervals from their origin (Figure 6). Transect placement (to the left or right of the informal trail) was randomized for each transect. A measuring tape was used to measure $10 \mathrm{~m}$ from the informal trail origin for placement of transects. Each transect was placed perpendicular to the informal trail, beginning at the trail edge (extent of trampled vegetation). Percent cover by species was measured for quadrats at 0,1 , and $2 \mathrm{~m}$ from the trail edge, with a quadrat at $10 \mathrm{~m}$ as an "un-impacted control". Controls at $10 \mathrm{~m}$ provide sufficient distance from informal and formal trail corridors that influence was expected to be minimal (Dickens et al., 2005; Potito \& Beatty, 2005; Roovers et al., 2005). Control locations were adjusted as needed to be at least $10 \mathrm{~m}$ from any other trail, road, or other park feature.

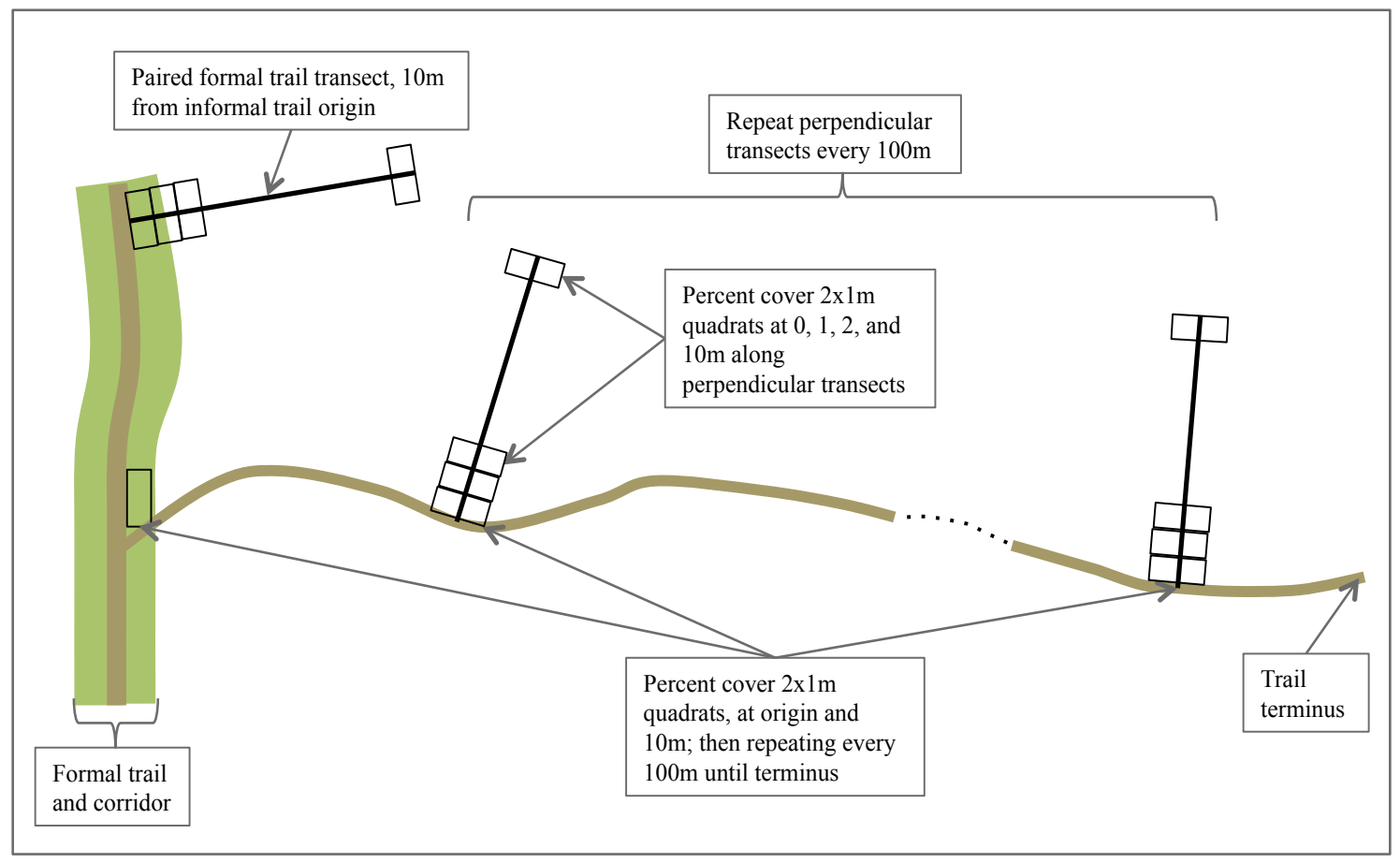

Figure 6. Transect and quadrat placement scheme. 
Percent cover was estimated using two 1-meter-square sampling plots. Each quadrat measures $2 \mathrm{~m}$ by $1 \mathrm{~m}$, with the long side placed parallel to the informal trail. Previous studies of effects to vegetation from formal trails has shown the most pronounced effects to occur within $1.5 \mathrm{~m}$ distance from the tread edge ((Bhuju \& Ohsawa, 1998; Potito \& Beatty, 2005). Thus with quadrats spanning 0-1m, 1-2m, and 2-3m distances from the tread edge, it was expected that any influence from the informal trails would be detected. Each 1-meter square plot was estimated separately and recorded, then the average of the two plots was calculated to determine the total percent cover by species for each quadrat for analysis.

For comparison, paired transects along the formal trail from which each informal trail originated were also placed, at $10 \mathrm{~m}$ along the formal trail from the origin of the informal trail (proximity to minimize topographic and vegetation differences). Transects and quadrats for informal and formal trails were placed in the same manner. For informal trails greater than $100 \mathrm{~m}$ in length, additional transects were placed at $100 \mathrm{~m}$ intervals until termination. Understory plants, except for grasses, were identified to species and recorded as percent cover. Total shrub, bare ground, grasses, lycopodia, and large woody debris (LWD) percent cover were also captured for each quadrat. Percent canopy, and ratio of conifer to deciduous canopy, was estimated visually and bracketed into percent cover ranges: 0-20, 21-40, 41-60, 61-80, 81-90, 91-95, and 96-100.

Plant identification was determined primarily using Plants of the Pacific Northwest Coast (Pojar, 2004), with additional plant identification from USDA PLANTS database, Institute for Applied Ecology, and King County Noxious Weed Control Program websites. Species were grouped by dispersal type and functional groups for 
analysis (Amrein, Rusterholz, \& Baur, 2005; Roovers et al., 2005; Scheller \& Mladenoff, 2002). Primary dispersal type was determined from plant identification sources into the following categories: endozoochory (seed consumed by animals, e.g. berries and nuts), epizoochory (hitch-hiker seeds: transported by humans, pets, or wildlife on clothing, hair, or fur), amenochory (wind), hydrochory (water), autochory (gravity/or ballistic), and rhizomatous species. Plants were also grouped by growth habit and ecology in the following categories: fern, shrub, sub-shrub (evergreen shrubs occurring in the understory layer, $<1 \mathrm{~m}$ in height), graminoid, lycopodia, total canopy, deciduous canopy, vine, weedy or ruderal species, ephemeral, or forb (excluding ephemeral and weedy species). Weedy species include non-native forbs as well as ruderal native forbs. Ephemeral species are those that reach maximum size in the spring, before June 1, and die back following canopy closure. Species list with dispersal and growth habit/ecology groupings is in Appendix $B$.

\section{Species Data Analysis}

Data were compiled by informal trail and for each quadrat by species or taxa as percent cover. Richness and Shannon-Weaver diversity were calculated for each quadrat (Figure 7). Shannon-Weaver diversity index accounts for abundance and evenness of species, commonly used for plant data. Additionally, species were grouped by dispersal strategy, ecology, and native status.

$$
H=-\sum_{i=1}^{s} p_{i} \ln p_{i}
$$

Figure 7. Shannon-Weaver diversity index $(H): s=$ total number of species (richness), p $i$ is the proportion of species $(s)$ made up of the $i$ th species. 
Data were analyzed using $\mathrm{R}$ statistical software ( $\mathrm{R}$ Development Core Team). Where sample data could not be transformed to meet test assumptions (such as normal distribution and equal variances) rank-based analyses were used. Sample sites were compared in pairs by distance as close to trail (trail-affected) versus $10 \mathrm{~m}$ from trail (non trail-affected control) using rank-based two-tailed Wilcoxon t-tests $(\alpha=0.05)$ (Memmott, Martinez, \& Cohen, 2000; Menéndez et al., 2006). Quadrats were compared from both formal and informal trails (at 0, 1, and 2m) with control sites (10m).

Multivariate analysis was conducted using the MetaMDS and ANOSIM functions in vegan and MASS packages in R. Non-metric multidimensional scaling (NMDS) was used for exploratory analysis of the herbaceous data only, to elucidate the relationships among taxa based on trail type, distance from trail edge, and canopy characteristics. MDS is a non-Eigenanalysis ordination where a dissimilarity matrix is generated using a selected distance measure, and predefined dimensions. It attempts to represent the ordination of objects in a low-dimensional space while preserving the distance relationships among objects. For Non-metric MDS, a dissimilarity matrix is generated using the predefined distance measure and dimensions, where a rank-based measure is used to generate distance vectors along each MDS axis. This type of analysis is particularly useful for species data (Barros et al., 2013; Roovers et al., 2005; Scheller \& Mladenoff, 2002). 
NMDS was run to calculate the distance matrix; Bray-Curtis distance measure was used, as it is more commonly used for ecological data, particularly community data by taxon. Stress value was calculated to determine goodness-of-fit of the ordination with the observed data (from the dissimilarity matrix). In order to increase the likelihood of finding the global minimum, several runs were conducted, all originating from random positions within the MDS space. Twenty iterations were completed for each run to assure the stress had reached a minimum. The ordination that produced the lowest stress was selected as the solution. In order to dampen the effects of dominant species, data were log-transformed. NMDS plots were generated by category (dispersal type or growth habit/ecology) to see how the relationships among vegetation communities in the ordination space were reflected by distance from trail and trail type. Environmental Fit function (envfit) was then used to plot vectors for dominant dispersal groups and growth habit within the NMDS ordination space. Vectors for total canopy cover, and percent deciduous and conifer cover were also added as environmental vectors to see whether canopy plays a role in plant groups by dispersal and growth form. Each plot was created to see how particular species or groups define the ordination space. These were then compared with plots by distance from trail edge to explore relationships between understory community assemblages and trails.

In order to test the differences in vegetation composition at distances from trails, an Analysis of Similarity (ANOSIM) was conducted. Pairwise analysis was conducted between close to trail edge $(0,1$, and $2 \mathrm{~m})$ and control $(10 \mathrm{~m})$ categories, as well as between formal and informal trails, to determine which, if any, were significantly 
different. For each test, the Bray-Curtis dissimilarity measure was used, with 999 permutations to generate the R-distribution for each pair.

\section{RESULTS}

\section{Informal Trail Survey - Spatial Analysis}

It was hypothesized that informal trails were widespread in Forest Park and that their location would be related to several factors: use level, proximity to trailheads, intersections, and creeks, and access for both privacy and private property. This was supported by my results. Three hundred eighty-two informal trails were identified, mapped, and assessed for Condition Class. Mean informal trail length is $25 \mathrm{~m}$, and ranges from $4 \mathrm{~m}$ (minimum length surveyed) to $720 \mathrm{~m}$. Although, a few very long trails skew the mean (median is $12 \mathrm{~m}$ ): $80 \%$ of all trails are less than $20 \mathrm{~m}$ in length. Park trails and roads and informal trails mapped as part of this study are shown in Figure 8. Within the Balch Creek watershed, where the greatest number of informal trails was found, there is a range of informal trails, from numerous short spurs along the creek to long routes to private property, as illustrated in Figure 9. (Full site maps for each management unit are located in Appendix A.) 


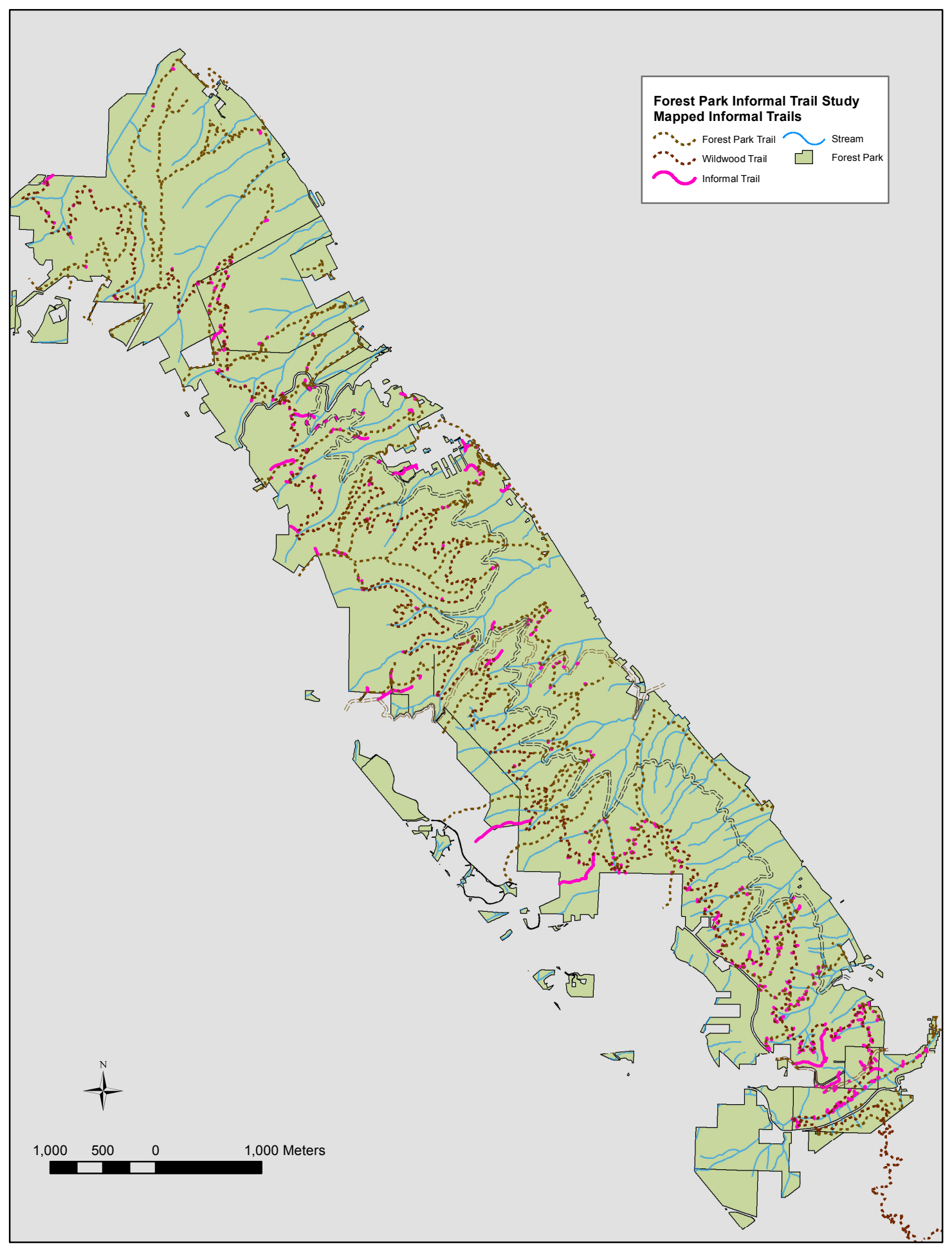

Figure 8. Park trails and roads and informal trails mapped as part of this study. 


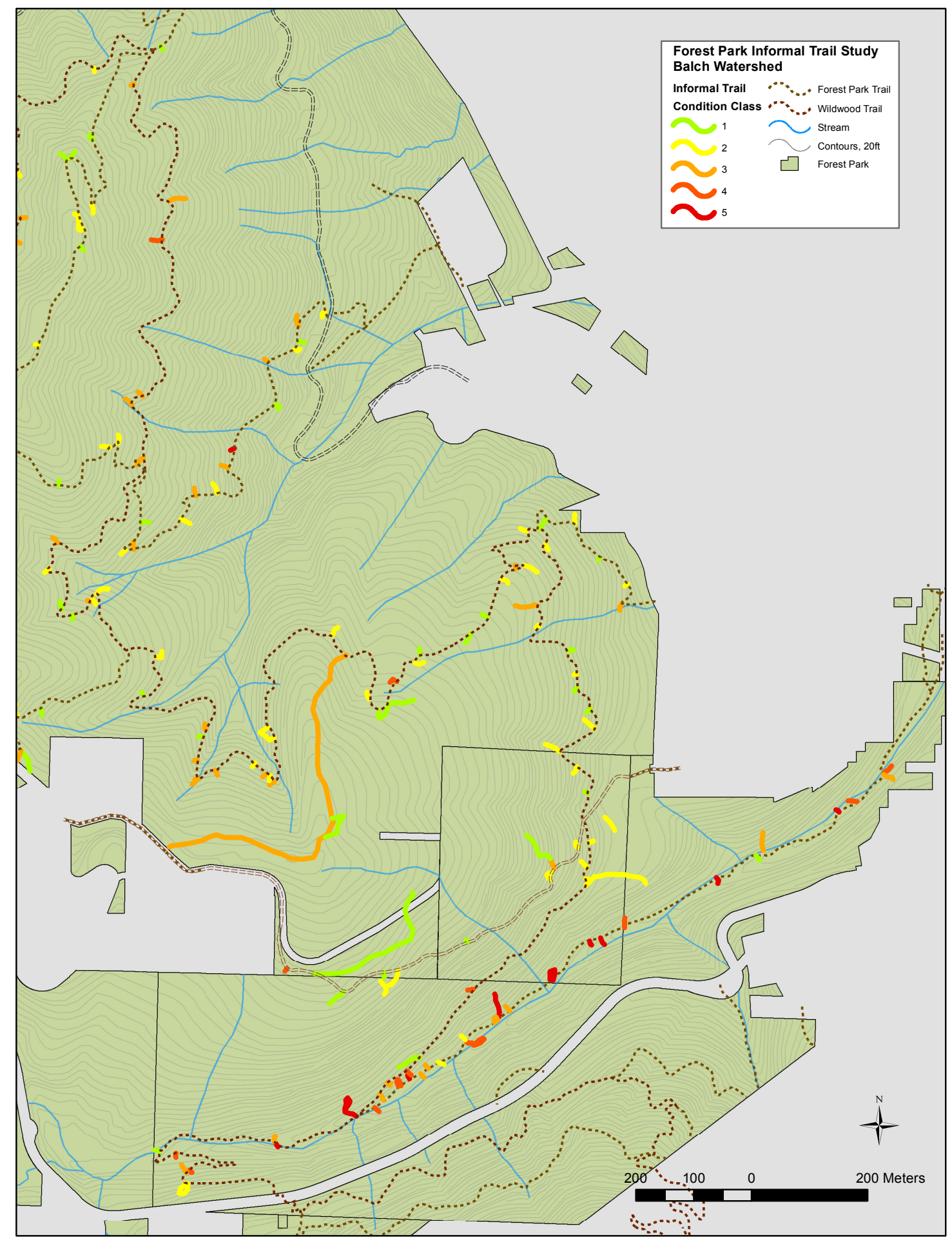

Figure 9. Informal trails by Condition Class for the Balch Watershed area. 
Informal trails were grouped by Condition Class to illustrate how frequency, and lineal and areal extent vary by class. Observational data for informal trails (Table 2) shows Condition Classes 2 and 3 are most common, but Condition Class 5 trails have a greater area of impact per linear distance (they are consistently wider than informal trails of lower Condition Class). In addition to scoring of Condition Class, observations related to informal trail presence were recorded and grouped, to show how trail presence might be related to various topographical and park features (e.g. trailheads, turns, creeks). Alignments uphill of formal trails accounted for $54 \%$ of all informal trails, with turns accounting for $13 \%$, as shown in Figure 10. Flat areas (on slopes $<10 \%$ ) accounted for only $3 \%$ of informal trails, but the topography of Forest Park itself is such that few areas would fall into this slope class.

Table 2. Informal trails grouped by Condition Class showing frequency, total length, and total area of impact. $n=382$.

\begin{tabular}{|l|r|r|r|r|r|r|r|}
\hline $\begin{array}{l}\text { Condition } \\
\text { Class }\end{array}$ & Frequency & $\begin{array}{c}\text { Total } \\
\text { Length } \\
(\mathrm{m})\end{array}$ & $\begin{array}{c}\text { Total } \\
\text { Area }\left(\mathrm{m}^{2}\right)\end{array}$ & $\begin{array}{c}\text { Mean } \\
\text { Length } \\
(\mathrm{m})\end{array}$ & $\begin{array}{c}\text { Median } \\
\text { Length } \\
(\mathrm{m})\end{array}$ & $\begin{array}{c}\text { Mean } \\
\text { Area } \\
(\mathrm{m} 2)\end{array}$ & $\begin{array}{c}\text { Median } \\
\text { Area }\left(\mathrm{m}^{2}\right)\end{array}$ \\
\hline CC1 & 98 & 1848 & 648 & 19 & 12 & 7 & 4 \\
\hline CC2 & 148 & 4463 & 1776 & 30 & 12 & 12 & 5 \\
\hline CC3 & 94 & 2354 & 1175 & 25 & 12 & 12 & 5 \\
\hline CC4 & 29 & 486 & 306 & 17 & 10 & 11 & 6 \\
\hline CC5 & 17 & 238 & 463 & 14 & 8 & 27 & 10 \\
\hline
\end{tabular}




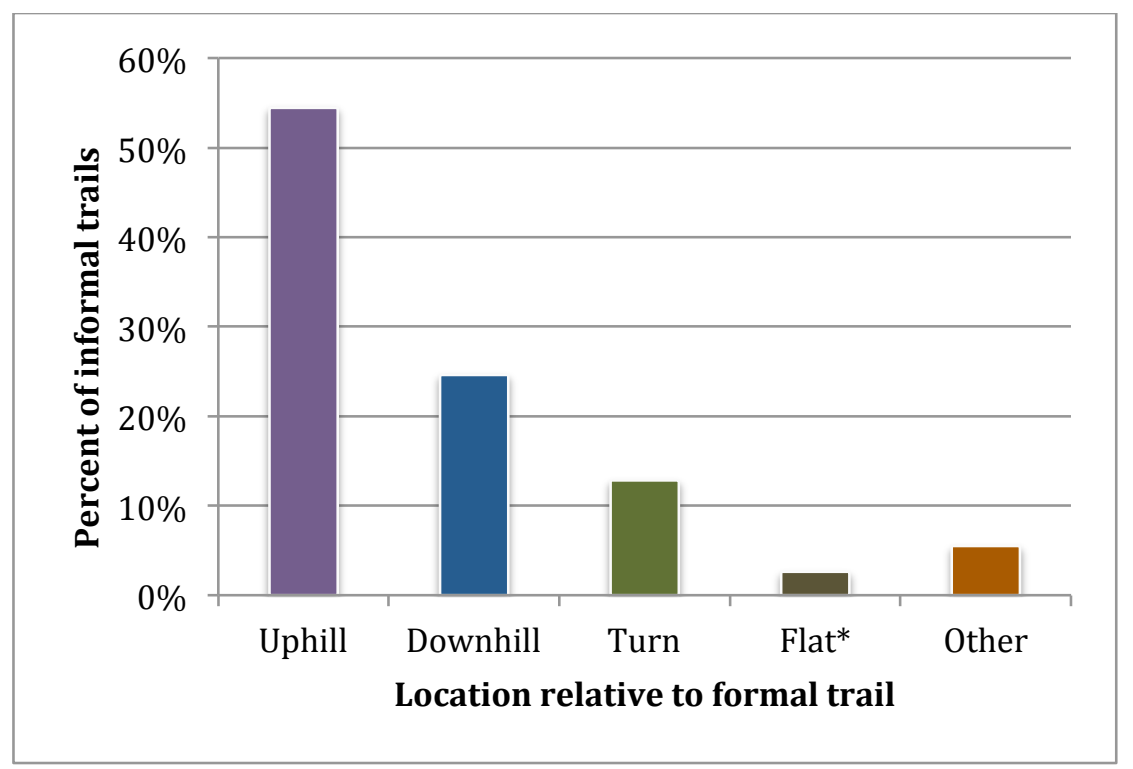

Figure 10. Informal trail origin relative to formal trail or road. Slopes of $<10 \%$ were classified as "Flat". n=382.

\section{Hidden Behaviors}

When grouped by observed trail type (Figure 11), trails terminating at private property represent only $4 \%$ of the total number of trails but make up $29 \%$ of the trail length. The most common observed associations with informal trails are water-related (e.g. creek access) comprising $19 \%$ of and human waste comprising $29 \%$ of all informal trails. It should be noted that these designations are based upon direct observations of activity, feature, or other identifying character (for the "human waste" category, this was commonly toilet paper, but could also include: trash, clothing, animal waste bags, or other waste products). Trails with evidence of "human waste" were short ( $80 \%$ are less than $20 \mathrm{~m}, 50 \%$ are less than $10 \mathrm{~m}$ ) and with some form of vegetation or topographic screening from the formal trail (e.g. 57\% uphill, 17\% terminate behind a tree or berm). 
Disturbance corridors originating from non-recreational sources were identified via maps (GIS trail data and visual inspection of LiDAR) and on-the-ground assessment (e.g. road bed evident, or Enlish holly stumps). Logging skids and old roadbeds constitute pre-park-establishment disturbances, but many other non-recreational disturbance corridors are from more recent or continued uses, such as holly removal areas and utility access. I identified 23 informal trails ( $7 \%$ of total) within these non-recreation disturbance corridors, comprising $16 \%$ of total trail length (Figure 11).

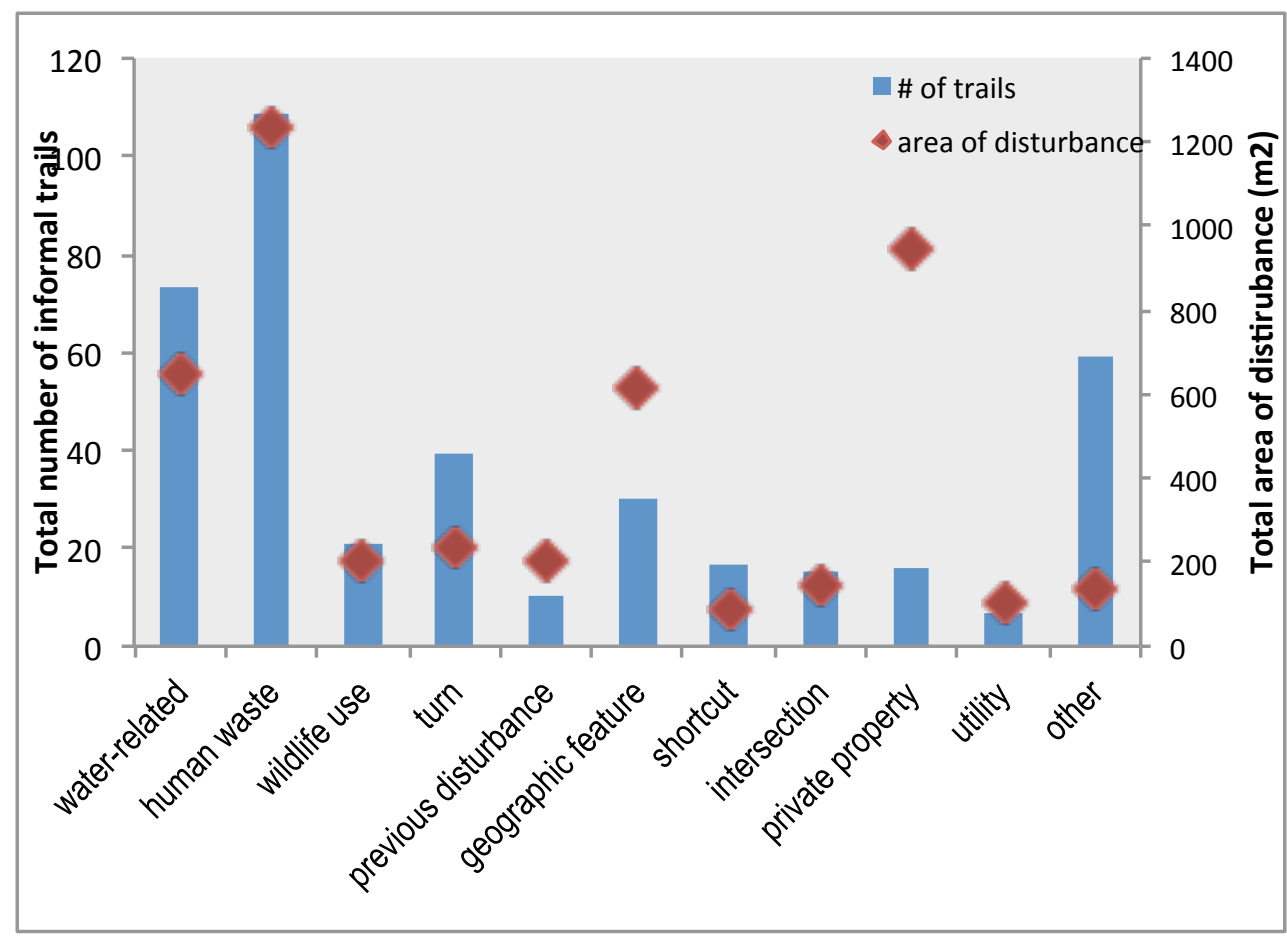

Figure 11. Informal trail frequency (blue bar) and area of impact (red diamond) by association with park feature or observed use. $n=382$.

\section{Wildlife Use}

While trails that appeared to have exclusively wildlife use were not included in the survey, evidence of wildlife use on trails assessed as having use by humans and/or pets were noted. Twenty-one trails (6\%) were scored as having direct evidence of wildlife 
use (tracks, fur, or scat), and another $40(10 \%)$ were suspected of having wildlife use based upon their location, e.g. for water access. However, it is likely that many formal and informal trails see regular wildlife use, particularly by elk and deer. As well, some informal trails with evidence of human use likely originally formed through wildlife passage.

\section{Informal Trail Density}

I analyzed informal trails for trail density and correlation with park features, including trailheads, private property, and use level, using line and point density functions in ArcGIS. Density analyses reveal informal trail hotspots within the park based upon lineal extent, frequency of trail formation, and relative trail impact (Condition Class) per unit area. Density of informal trails in length (m) per hectare park-wide and by management unit is shown in Figure 12. Both total trail length within an area (even a single trail that is very long will produce a relatively high density within that corridor area) and with many short trails (high trail frequency) result in increased trail density. Density concentrations were found along corridors to private property (particularly along the western perimeter in the Central Management Unit, Figure 12), and near most major trailheads and areas of high use, such as Germantown and Lower Macleay, and throughout the Balch Creek watershed area.

I used a second method, point density function, to look for hotspots as a function of the frequency of informal trail occurrence (Figure 13). Rather than accounting for trail length, this analysis shows relative density by number of informal trails, using point data from the trail origin. While most highlighted areas in this map overlap with those on the line density map (Figure 12), there are some notable differences. This method did not 
highlight isolated long private property trails. Instead, hotspots along Balch Creek and near Germantown and Lower Macleay trailheads were emphasized. An additional low intensity hotspot was highlighted near the Newton trailhead in the Northern Management Unit. Trails along the entire South Management Unit show concentration of informal trails, following trail use activity levels. However, despite a high level of use, there is an absence of informal trails along Leif Erickson in the South Management Unit and from the Thurman Gate trailhead.

Hotspot density combined with Condition Class to better visualize relative impact intensity areas. As shown in Figure 13, areas with low relative use but high trail density are less emphasized. The Balch Creek area, which shows up as a hotspot in all three analyses, is particularly noticeable in this view. A combination of high use and high offtrail activity along the creek is reflected. In contrast, the numerous but lower use $(\mathrm{CC} 1)$ informal trails common near the Newton Trailhead in the Northern Management Unit results in no hotspot identified in this area. This is probably a more meaningful representation of overall impact from informal trail corridors, but even low-use trail proliferation may still highlight areas where management actions can be most effective before disturbance leads to changes in plant assemblages.

From these spatial analyses, I determined that creeks, trailheads, and intersections are associated with informal trail presence (Figures 9, 13, 14). Highest trail density occurs along Balch Creek, originating from Lower Macleay and Wildwood Trails (Figures 12, 13). Creeks and popular trailheads are primary locations of hotspots of informal trail density. As noted previously, the most common trail entrance, the Thurman Gate at Leif Erickson Drive, does not have any concentration of informal trails, 
regardless of the type of density analysis used. However, trails immediately adjacent to Leif Erickson do show high informal trail density. 


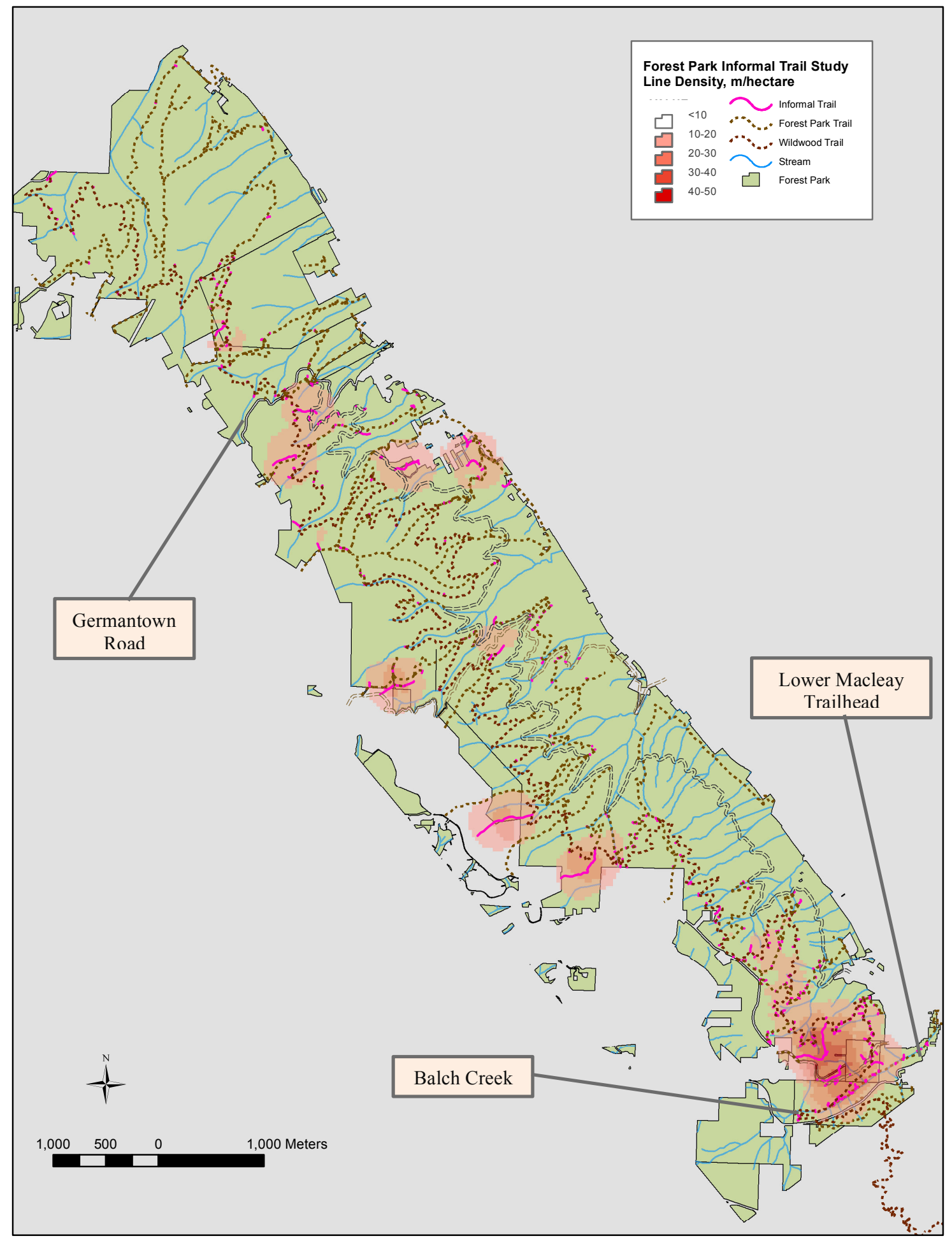

Figure 12. Trail density in meters per hectare. Trail length per hectare creates higher intensity where greater number of trails, but also where long trails form. 


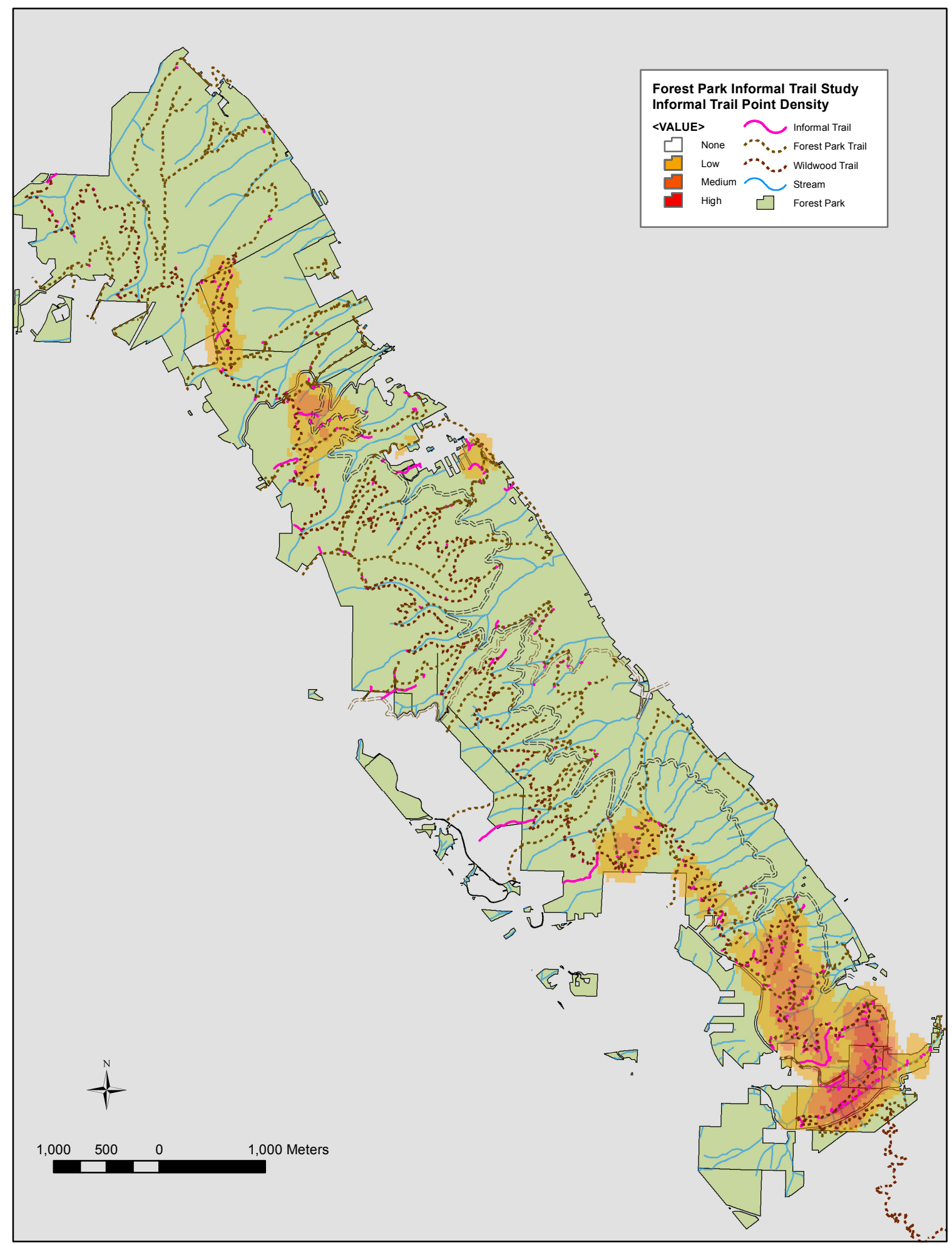

Figure 13. Trail density hotspots. Trail density by number of trails per unit area, based upon trail origin. Colored areas show relative intensity of informal trail formation. 


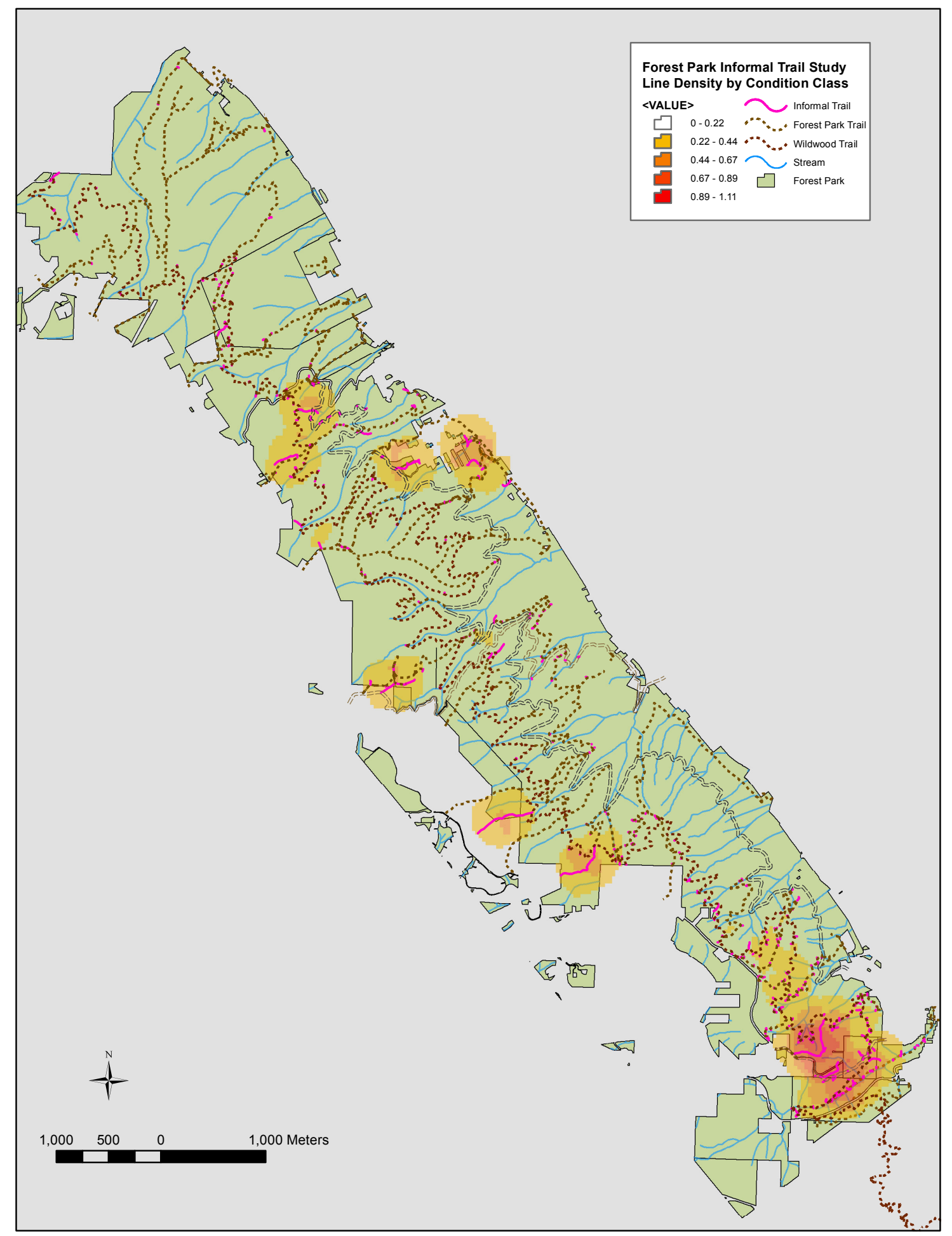

Figure 13. Trail density hotspots by lineal extent and Condition Class. Values represent a combination of trail density $(100 \mathrm{~m} / \mathrm{ha})$ and trail Condition Class, so they can be interpreted as relative impact - with higher off-trail activity areas shown increasing impact from yellow to red. 


\section{Understory Species Richness, Diversity, and Percent Cover}

\section{Summary Data}

Understory cover analysis was conducted using data collected from thirty perpendicular transects along informal trials. Transects were systematically sampled from informal trails scored as Condition Class 2 or 3 and greater than $10 \mathrm{~m}$ in length $(\mathrm{n}=185)$, to allow sufficient sample size for analysis and transect placement at $10 \mathrm{~m}$ from the trail origin. For each informal trail, comparison data were also collected from formal trails $10 \mathrm{~m}$ from the origin of each informal trail. For fifteen informal trails, with lengths greater than $100 \mathrm{~m}$, additional transects were placed at $100 \mathrm{~m}$ intervals until trail termination. Fourteen informal trails were scored as Condition Class 2; sixteen were Condition Class 3.

Seventy-three species were identified from over 330 quadrats at varying distances from informal and formal trails. Twenty-two species occurred in fewer than three quadrats. Of the fifty-one remaining, a few species dominate in both frequency of occurrence and percent cover: Polystichum minutum (sword fern), Hydrophyllum tenuipes (Pacific waterleaf), Rubus ursinus (trailing blackberry), Hedera helix (English ivy), Mahonia nervosa (Oregon grape), and Viola glabella (yellow wood violet) (see Table 3). Sword fern and Oregon grape were also highly variable, with percent cover sometimes varying from 0 to $100 \%$ within a single transect. 
Table 3. Summary of percent cover in all quadrats for the six most common species.

\begin{tabular}{|l|r|r|r|}
\hline & \multicolumn{3}{|c|}{ Percent Cover } \\
\hline Species & $\begin{array}{c}\text { \% } \\
\text { Occurrence }\end{array}$ & Mean & $\begin{array}{c}\text { Standard } \\
\text { Deviation }\end{array}$ \\
\hline Polystichum minutum & 71 & 27 & 29 \\
\hline Rubus ursinus & 44 & 3 & 6 \\
\hline Hedera helix & 39 & 13 & 27 \\
\hline Mahonia nervosa & 37 & 11 & 21 \\
\hline Hydrophyllum tenuipes & 34 & 2 & 5 \\
\hline Viola glabella & 30 & 1 & 2 \\
\hline
\end{tabular}

\section{Species Richness}

I hypothesized that total, invasive, and ruderal species richness and diversity would be higher close to informal trail edges (within $2 \mathrm{~m}$ ) than at control sites (at $10 \mathrm{~m}$ ), but that native diversity would be reduced. Summary data for species richness, diversity, and total percent cover show trends related to distance from trail edge for both formal and informal trails. Species richness and diversity are both higher closer to the trail edge. This pattern is strongest for formal trails, but is evident for informal trails as well, even for those transects at $>100 \mathrm{~m}$ from the origin, as shown in Figures 15b, 15a, and 16, respectively. Difference in richness across distances and by both formal and informal trails is primarily a function of change in ruderal native species. For formal trails, richness is significantly different at all trail distances $(0,1$, and $2 \mathrm{~m})$ for total and ruderal richness and at $0 \mathrm{~m}$ for invasive richness (Table 4). For informal trails, total species richness is significantly higher than controls at $0 \mathrm{~m}$, and ruderal native species richness is significantly higher at both $0 \mathrm{~m}$ and $1 \mathrm{~m}$, as shown in Table 4 . For quadrats at all distances close-to-trail, 0,1 , or $2 \mathrm{~m}$, neither formal nor informal trail were significantly different from controls $(10 \mathrm{~m})$ in terms of native richness. 
Table 4. Wilcoxon t-test for total, native, ruderal, and invasive species richness for distance from trail edge and control quadrats (at $10 \mathrm{~m})$. Significant values $(\alpha=0.05)$ shown highlighted in gray.

\begin{tabular}{|c|c|c|c|c|c|c|c|c|c|}
\hline \multirow{2}{*}{$\begin{array}{l}\text { Trail Type } \\
\text { Formal }\end{array}$} & \multirow{2}{*}{\begin{tabular}{|l|} 
Distance Pair \\
\end{tabular}} & \multicolumn{2}{|c|}{ Total Richness } & \multicolumn{2}{|c|}{ Native Richness } & \multicolumn{2}{|c|}{ Ruderal Richness } & \multicolumn{2}{|c|}{ Invasive Richness } \\
\hline & & W & $p$-value & W & $p$-value & W & $p$-value & W & $p$-value \\
\hline & $0 \mathrm{~m} v 10 \mathrm{~m}$ & 777 & $<0.001$ & 1072.5 & 0.075 & 1503 & $<0.001$ & 1312 & $<0.001$ \\
\hline & $1 \mathrm{~m} v 10 \mathrm{~m}$ & 652.5 & 0.003 & 548 & 0.084 & 640.5 & $<0.001$ & 521.5 & 0.164 \\
\hline & $2 m$ v $10 m$ & 631.5 & 0.007 & 532.5 & 0.137 & 552.5 & 0.007 & 518.5 & 0.179 \\
\hline \multicolumn{10}{|l|}{ Informal } \\
\hline & $0 \mathrm{~m} v 10 \mathrm{~m}$ & 607.5 & 0.02 & 494 & 0.368 & 624.5 & $<0.001$ & 534.5 & 0.113 \\
\hline & $1 \mathrm{~m} v 10 \mathrm{~m}$ & 572 & 0.07 & 485.5 & 0.439 & 565.5 & 0.006 & 535 & 0.108 \\
\hline & $2 m$ v $10 m$ & 473 & 0.74 & 445.5 & 0.877 & 494 & 0.136 & 496.5 & 0.324 \\
\hline \multicolumn{10}{|c|}{ Informal >100m } \\
\hline & $0 \mathrm{~m} v 10 \mathrm{~m}$ & 199.5 & 0.0002 & 190 & 0.001 & 180 & 0.001 & 127.5 & 0.433 \\
\hline & $1 \mathrm{~m} v 10 \mathrm{~m}$ & 145 & 0.1767 & 140 & 0.254 & 127.5 & 0.164 & 112.5 & 1.000 \\
\hline & $2 m \vee 10 m$ & 131 & 0.4387 & 123 & 0.666 & 120 & 0.351 & 114 & 0.953 \\
\hline
\end{tabular}



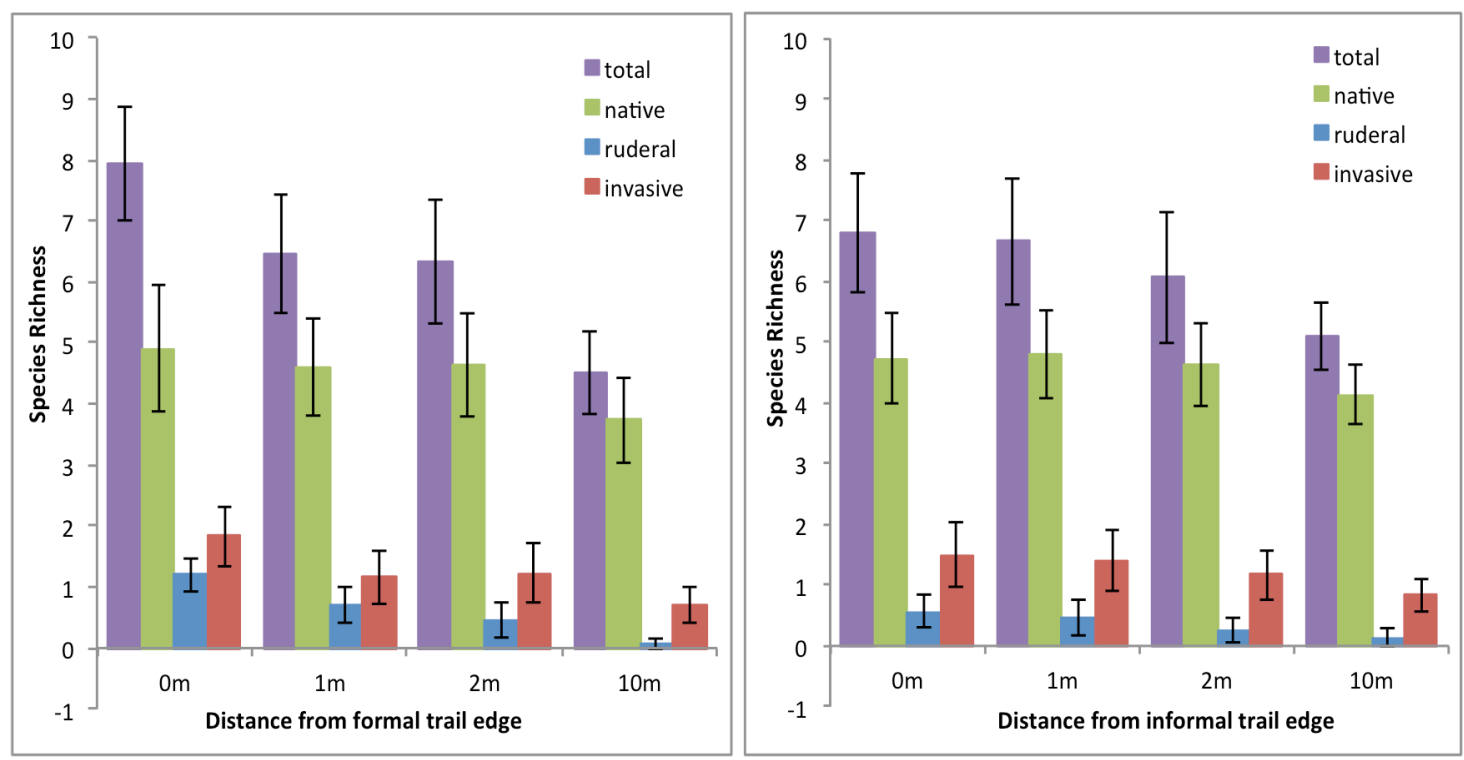

Figures $15 \mathrm{a} \& \mathrm{~b}$. Mean species richness by distance from trail edge for formal (left) and informal (right) trails. Each column represents mean total species richness, which is shown divided into native species (green), ruderal natives (blue), and invasive species (red); total richness is also shown (purple). Error bars represent 95\% confidence interval.

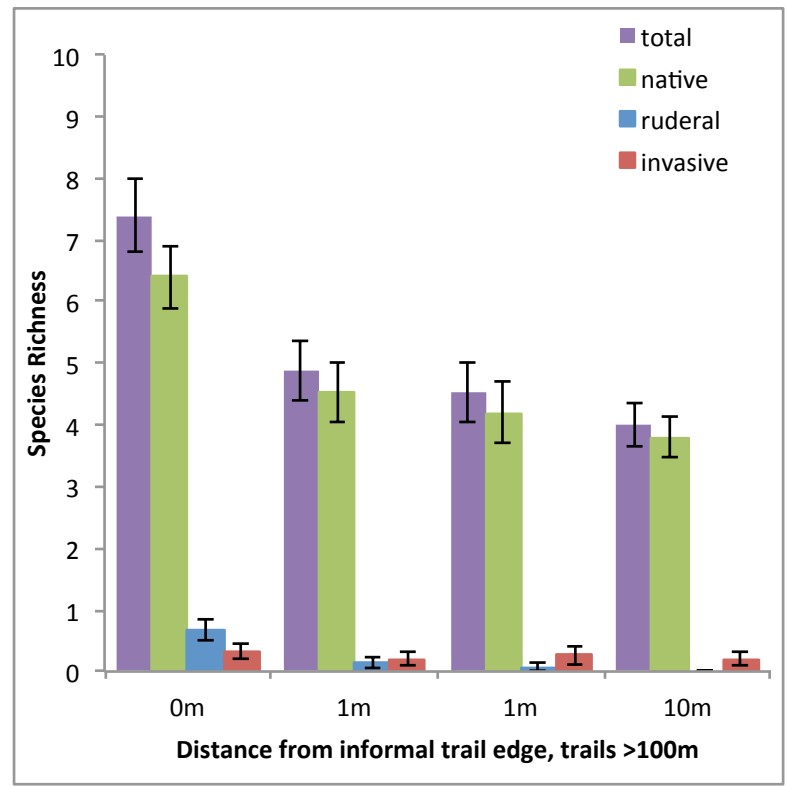

Figure 16. Mean species richness by distance from trail edge for informal trails at distances greater than $100 \mathrm{~m}$ $(n=15)$. Each column represents mean total species richness, which is shown divided into native species (green), ruderal natives (blue) and invasive species (red); total richness is shown purple. Error bars represent 95\% CI. 
For longer informal trails sampled at $100 \mathrm{~m}$ intervals $(n=15)$, the patterns for richness look different (Figure 16). While they still show a general trend of increasing total species richness closer to trail edge, invasive species are few and consistent across distances $(0,1$, and $2 \mathrm{~m})$, and ruderal species only differ at the $0 \mathrm{~m}$. While no significant increases were seen for native species as a group for formal or informal trails, a significant increase is seen for informal trails at greater than $100 \mathrm{~m}$ for native species at 0m when compared with controls at 10m (Table 4).

\section{Shannon-Weaver Diversity}

As shown in Figure 17, total diversity decreases the further one is away from a trail edge. This pattern holds for both formal and informal trails, and is even evident for informal trails at distances greater than $100 \mathrm{~m}$ from trail origin. When species are grouped into native (excluding ruderal species), ruderal native, and non-native invasive species differences follow the same patterns as for species richness (Table 5, Figure 18). For formal trails, diversity is significantly higher for invasive and ruderal species at 0,1 , and $2 \mathrm{~m}$ (near trail edge) compared with controls $(10 \mathrm{~m})$. For informal trails differences are significant at 0 and $1 \mathrm{~m}$, but not at $2 \mathrm{~m}$ (Table 5). These results indicate that invasive species and ruderal native species account for changes in total diversity near both formal and informal trails. 


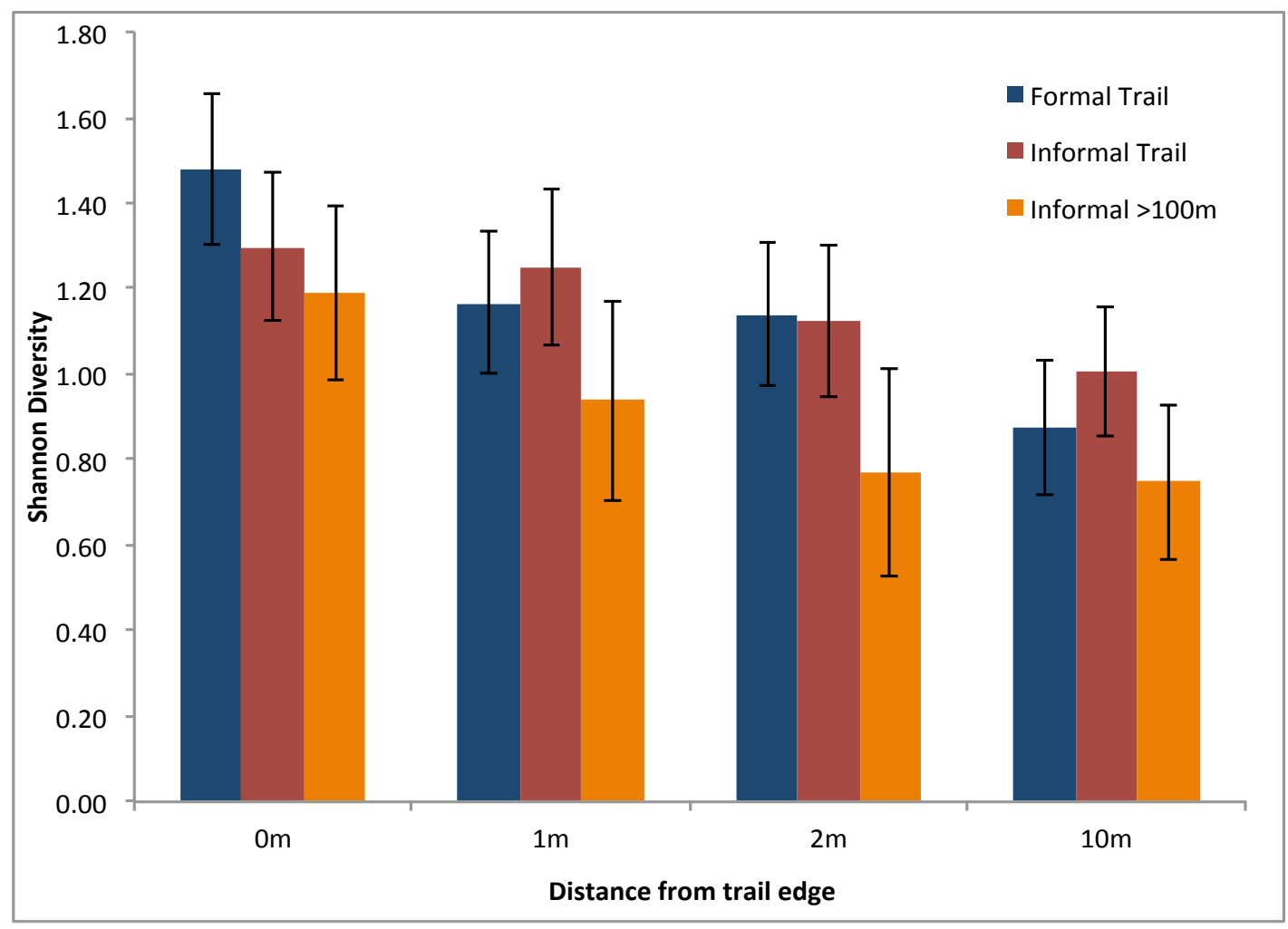

Figure 17. Shannon-Weaver diversity as a function of distance from informal (red) and formal (blue) trails $(\mathrm{n}=30)$. Diversity for informal trails at $>100 \mathrm{~m}$ from origin are also shown (orange, $\mathrm{n}=15$ ). Diversity is increased closer to the trail for both formal and informal trails. Error bars represent $95 \%$ CI.

Table 5. T-test for Shannon-Weaver diversity for distance from trail edge to controls (at 10m); significant $p$-values are highlighted in gray $(\alpha=0.05)$.

\begin{tabular}{|c|c|c|c|c|c|c|c|c|c|c|c|c|c|}
\hline \multirow{2}{*}{\begin{tabular}{|l|} 
Trail Type \\
Formal \\
\end{tabular}} & \multirow[t]{2}{*}{ Distance Pair } & \multicolumn{3}{|c|}{ Total Diversity } & \multicolumn{3}{|c|}{ Native Diversity } & \multicolumn{3}{|c|}{ Ruderal Diversity } & \multicolumn{3}{|c|}{ Invasive Diversity } \\
\hline & & t-value & $\mathrm{df}$ & p-value & t-value & $d f$ & p-value & t-value & $\mathrm{df}$ & $p$-value & t-value & $\mathrm{df}$ & $p$-value \\
\hline & $0 \mathrm{~m} v 10 \mathrm{~m}$ & 3.784 & 58 & 0.001 & 1.053 & 58 & 0.301 & 3.550 & 58 & 0.001 & 1.882 & 58 & 0.070 \\
\hline & $1 \mathrm{~m} \vee 10 \mathrm{~m}$ & 2.594 & 58 & 0.015 & 0.972 & 58 & 0.339 & 3.571 & 58 & 0.001 & 0.943 & 58 & 0.353 \\
\hline & $2 m$ v $10 m$ & 2.319 & 58 & 0.028 & 1.043 & 58 & 0.306 & 2.197 & 58 & 0.036 & 1.356 & 58 & 0.186 \\
\hline \multicolumn{14}{|l|}{\begin{tabular}{|l|} 
Informal \\
\end{tabular}} \\
\hline & $0 \mathrm{~m}$ v $10 \mathrm{~m}$ & 2.570 & 58 & 0.0156 & 1.469 & 58 & 0.152 & 3.331 & 58 & 0.002 & 0.933 & 58 & 0.358 \\
\hline & $1 \mathrm{~m} v 10 \mathrm{~m}$ & 2.061 & 58 & 0.0484 & 1.122 & 58 & 0.271 & 3.064 & 58 & 0.005 & 1.122 & 58 & 0.271 \\
\hline & $2 m$ v $10 m$ & 0.990 & 58 & 0.3305 & 0.623 & 58 & 0.538 & 1.859 & 58 & 0.073 & 0.436 & 58 & 0.666 \\
\hline \multicolumn{14}{|c|}{ Informal >100m } \\
\hline & $0 \mathrm{~m} \vee 10 \mathrm{~m}$ & 3.136 & 58 & 0.0039 & 2.556 & 58 & 0.016 & 3.505 & 58 & 0.002 & 0.521 & 58 & 0.606 \\
\hline & $1 \mathrm{~m} v 10 \mathrm{~m}$ & 1.247 & 58 & 0.2224 & 1.074 & 58 & 0.292 & 1.264 & 58 & 0.216 & 0.384 & 58 & 0.704 \\
\hline & $2 m$ v $10 m$ & 0.134 & 58 & 0.8944 & 0.018 & 58 & 0.986 & 0.982 & 58 & 0.334 & 0.409 & 58 & 0.685 \\
\hline
\end{tabular}



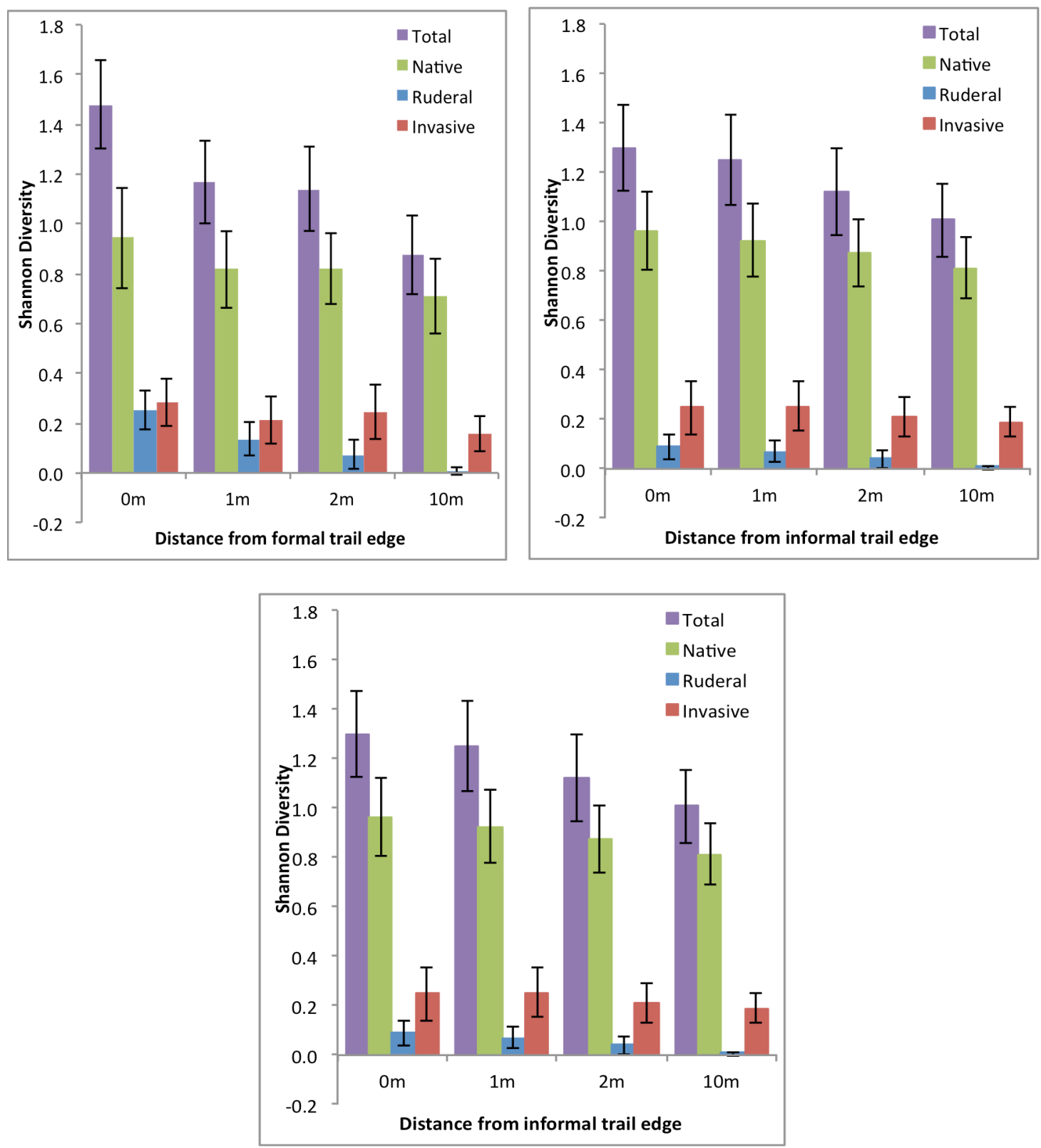

Figure 18. Native, invasive, and ruderal Shannon-Weaver diversity by distance from trail edge for formal (upper left), informal (upper right), and informal trails $>100 \mathrm{~m}$ (lower). Error bars represent $95 \% \mathrm{CI}$. 


\section{Percent Cover}

Total herbaceous percent cover increases further from the trail edge for both formal and informal trails (Figure 19). While differences were not significant (Table 6), the patterns for both formal and informal trails show an increase in total cover with increasing distance from the trail edge. Further, this change in cover is a product of increase in native cover, not a change in introduced species cover. This is in contrast with total richness and total diversity, which both decrease with increasing distance from the trail edge.
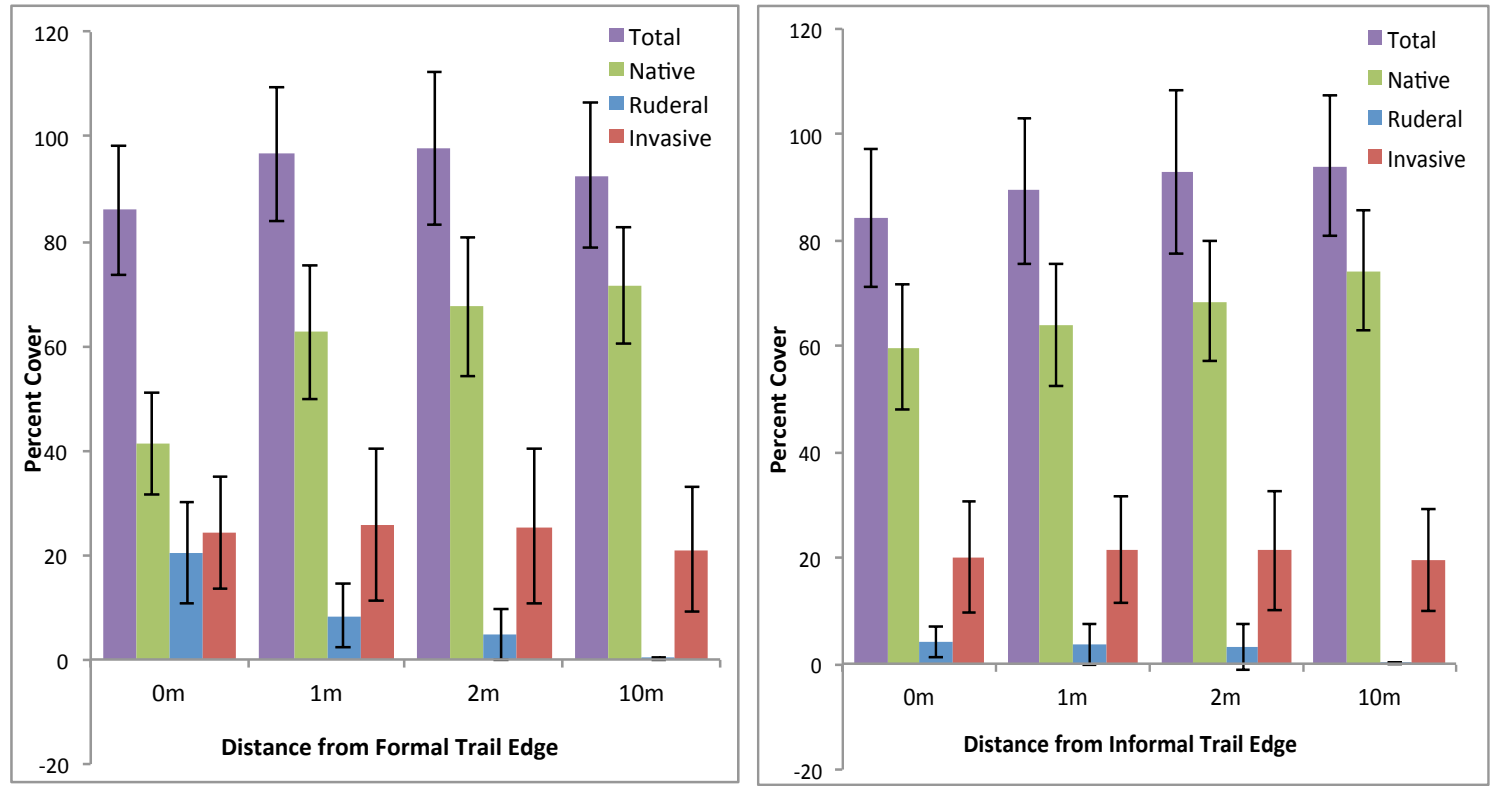

Figure 19 Mean total percent cover as a function of distance from trail edge for formal (left) and informal (right) trails. Bars represent 95\% CI. 
Table 6. Wilcoxon tests of percent total, native, and invasive herbaceous cover by distance from trail edge $(0,1,2 \mathrm{~m})$ and control $(10 \mathrm{~m})$ pairs. Significant $\mathrm{p}$-values are highlighted in gray $(\alpha=0.05)$.

\begin{tabular}{|c|c|r|r|r|r|r|r|}
\hline Trail Type & Distance Pair & \multicolumn{2}{c|}{ Total \% Cover } & \multicolumn{2}{c|}{ Native \% Cover } & \multicolumn{2}{c|}{ Invasive \% Cover } \\
\hline Formal & & \multicolumn{1}{c}{ W } & p-value & \multicolumn{1}{c|}{ W } & p-value & W & p-value \\
\hline & $0 \mathrm{~m}$ v 10m & 662.5 & 0.070 & 540 & 0.004 & 1121.5 & 0.027 \\
\hline & $1 \mathrm{~m}$ v 10m & 411.5 & 0.727 & 377 & 0.383 & 496.5 & 0.340 \\
\hline & $2 \mathrm{~m}$ v 10m & 456 & 0.756 & 421 & 0.838 & 472.5 & 0.559 \\
\hline Informal & & & & & & & \\
\hline & $0 \mathrm{~m}$ v 10m & 362.5 & 0.275 & 337.5 & 0.141 & 447 & 0.860 \\
\hline & $1 \mathrm{~m}$ v 10m & 387.5 & 0.476 & 358.5 & 0.249 & 472.5 & 0.571 \\
\hline & $2 \mathrm{~m}$ v 10m & 423.5 & 0.087 & 400 & 0.601 & 429.5 & 0.939 \\
\hline
\end{tabular}

Trends for total herbaceous richness, diversity, and percent cover show patterns that are consistent across formal and informal trails, but with informal trails showing patterns less strongly and significant differences extending shorter distances from the trail edge. When sub-grouped by native, ruderal, and invasive species ruderal species play a key role in differences between areas close to trail edge and control sites. With these groupings, transects for informal trails at greater than $100 \mathrm{~m}$ look considerably different, with the greatest change related to native species, rather than invasive or ruderals.

Analysis of informal trails greater than $100 \mathrm{~m}$ was not carried forward for other methods due to limited data (fifteen transects sampled at $100 \mathrm{~m}$ intervals along six informal trails). Fifteen samples did not seem sufficient to analyze using multivariate tools. However, initial results for richness and diversity suggest that transects placed at more frequent intervals along informal trails could help to explain the changes along trail corridors related to distance from origin and the spread of invasive and ruderal propagules. 


\section{Dispersal and Growth Strategies}

I conducted Non-metric Multidimensional Scaling (NMDS) analyses for understory, shrub, and canopy data summarized by two different groupings to elucidate patterns that might be correlated with distance from formal and informal trails: by primary dispersal mechanisms and by growth habit and ecology. NMDS analysis can help to better understand factors influencing the herbaceous community assemblages.

Vectors representing the variation in each dispersal type were overlaid in the NMDS ordination to identify which species are driving alignment within the ordination space (Figure 20a). Results of this analysis revealed differences in distance from informal trail edge based upon plant dispersal type. From this plot, endozoochory (foodbased, "endozoo") and rhizome dispersal mechanisms are in opposite directions, and influence dissimilarity along both the horizontal and vertical axis. Wind, hitch-hiker, and gravity/ballistic vectors influence dissimilarity positively along the NMDS 2 axis (arrows point up), while plants employing endozoochory and water dispersal mechanisms influence negatively along this axis. Additionally, these "weedy" dispersal mechanisms (or R-strategy: hitch-hiker, wind, and gravity/ballistic) vectors point in the opposite direction of canopy cover, and generally towards to topside of the NMDS space. This suggests that plants with "weedy" dispersal mechanisms are strongly correlated with decreased total canopy cover. In contrast, based upon the variables in this ordination, for plants that disperse via water and rhizomes, canopy cover type is more important (deciduous versus conifer) than total canopy cover. 

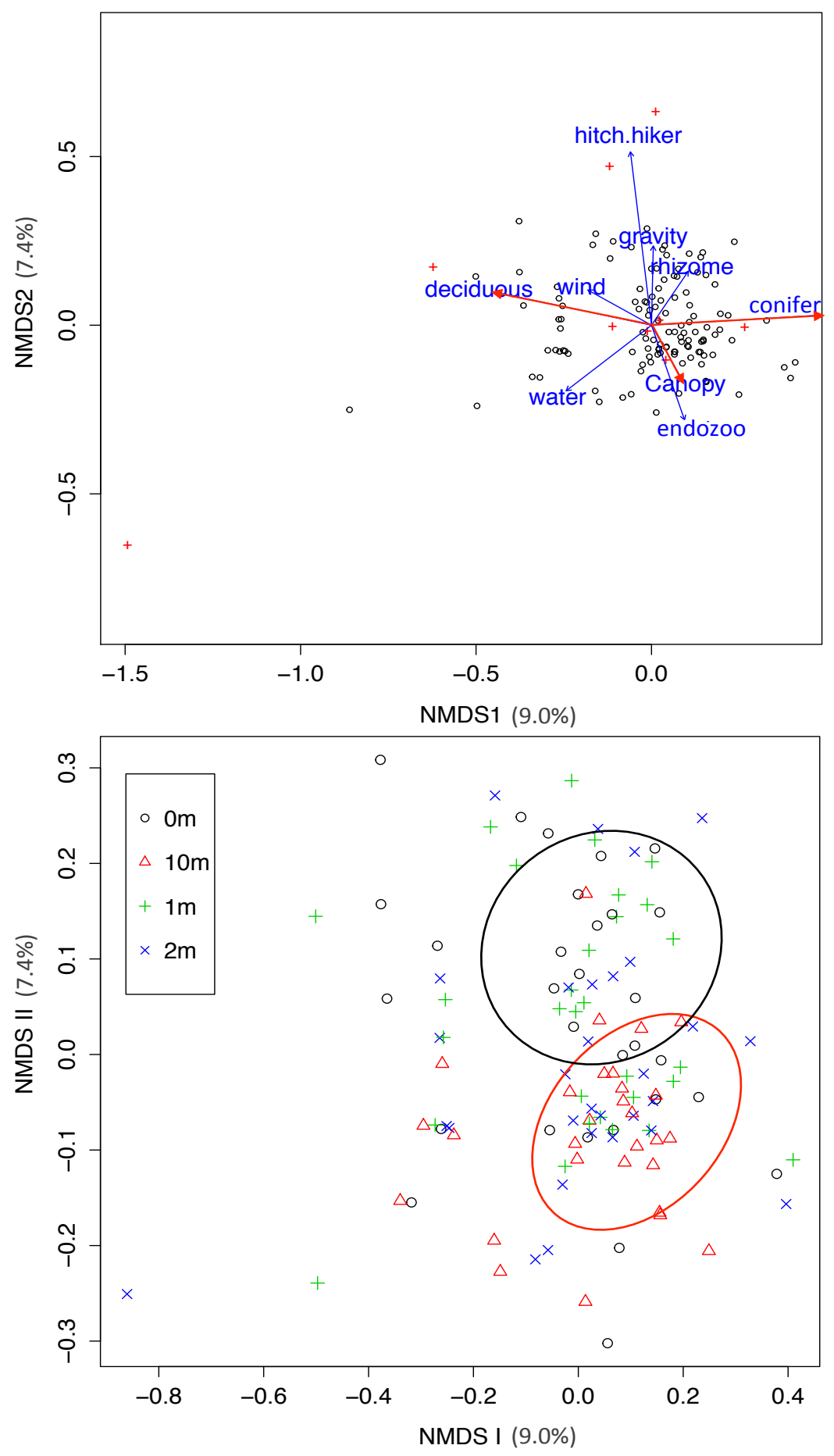

Figures 20a\&b. Figure a: NMDS informal trail and control quadrats with vectors for selected dispersal mechanisms and canopy cover. Figure b: NMDS informal trail and control quadrats by distance from trail edge for selected dispersal mechanisms (blue vectors) and canopy cover type variables (red vectors). Percent variance explained by each axis shown in parentheses next to axis label. Clusters for $0 \mathrm{~m}$ (black) and $10 \mathrm{~m}$ (red) distances are highlighted with ovals. Logtransformed, $\mathrm{K}=2$, stress $=0.18$. 
NMDS for dispersal groups by distance from trail edge show strong clustering of sites at by distance from formal trails (Figure 20b). For informal trails, the pattern was less pronounced, but a separation within the ordination space for quadrats at $10 \mathrm{~m}$ versus those at $0 \mathrm{~m}$ was evident, as shown by clusters highlighted in Figure $20 \mathrm{~b}$. Controls at $10 \mathrm{~m}$ (red triangles) were clustered at the right end of the plot, varying primarily along NMDS II. Plants at the trail edge $(0 \mathrm{~m})$ were separated by both axes. However, while informal trails do not appear to have a strong influence on community make-up at this scale, the same patterns hold for relationships among dispersal mechanisms and canopy cover.

For formal trails, NMDS plots showed stronger separation by dispersal mechanism within the ordination space by distance from trail edge (Figures 21a and $b$ ). Plants with weedy dispersal mechanisms and canopy cover were strongly aligned, and defined almost exclusively along NMDS axis 1 (Figure 20a). Plants dispersed via endozoochory and rhizomes, as well as deciduous canopy cover, were separated primarily along NMDS axis 2 , the vertical axis. This showed a stronger association with "weedy" dispersal mechanisms as defining separation in the ordination from along NMDS axis 1 (though the plots are roughly reversed for informal trails, the relative relationships among vectors and distance from trail edge are the same). Clusters by distance from trail edge are defined along the horizontal axis, for $0 \mathrm{~m}$ and $10 \mathrm{~m}$ distances (Figure 20b), suggesting that distance from trail edge may explain some of the dissimilarity in plant communities by dispersal mechanisms. 

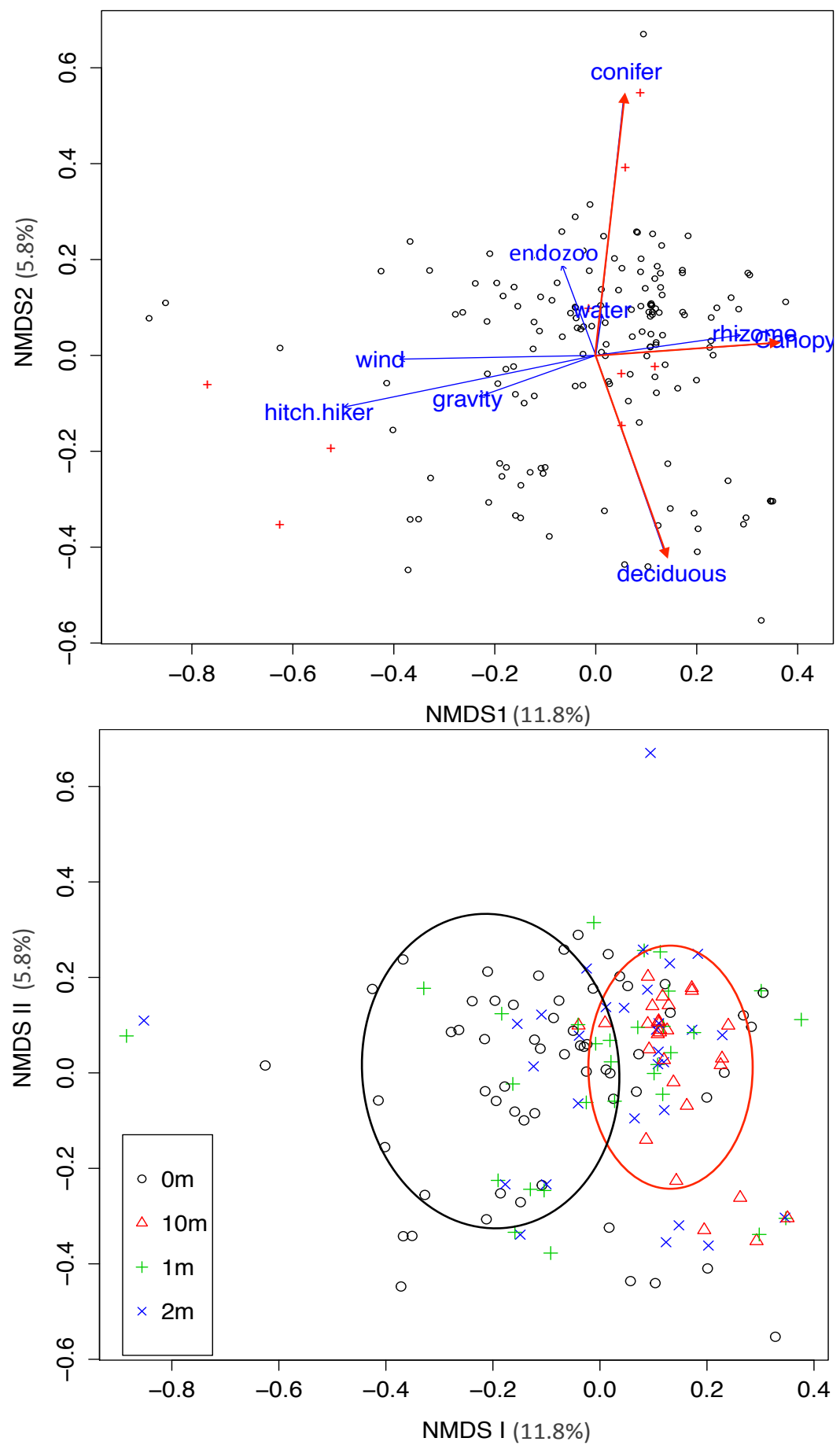

Figure $21 \mathrm{a} \& \mathrm{~b}$. Figure a: NMDS for formal trail and control quadrats with vectors for selected dispersal mechanisms and canopy cover. Figure b: NMDS for formal trail and control quadrats by distance from trail edge for selected dispersal mechanisms (blue vectors) and canopy cover type variables (red vectors). Percent variance explained by each axis shown in parentheses next to axis label Clusters for $0 \mathrm{~m}$ (black) and $10 \mathrm{~m}$ (red) distances are highlighted with ovals. Logtransformed, $\mathrm{K}=2$, stress $=0.16$. 
The Analysis of Similarity (ANOSIM) conducted between distances from trail edge and controls $(10 \mathrm{~m})$ showed significant differences in dispersal mechanisms for understory communities (log-transformed data) for $0 \mathrm{~m}$ and $10 \mathrm{~m}$-control pairs (Figures 22 and $23, \mathrm{r}=0.047, \mathrm{p}=0.038 ; \mathrm{r}=0.035, \mathrm{p}=0.006$, respectively). The analyses also revealed that there is high within and between group dissimilarity among the categories (except for formal trails at $10 \mathrm{~m}$ ) for both formal and informal trails, as shown by the height and overlap of the boxes in Figures 22 and 23. This follows patterns seen in NMDS ordinations - clustering is noticeable at $0 \mathrm{~m}$ and $10 \mathrm{~m}$ distances for both formal and informal trail dispersal groups, but no pattern at $1 \mathrm{~m}$ and $2 \mathrm{~m}$ distances.

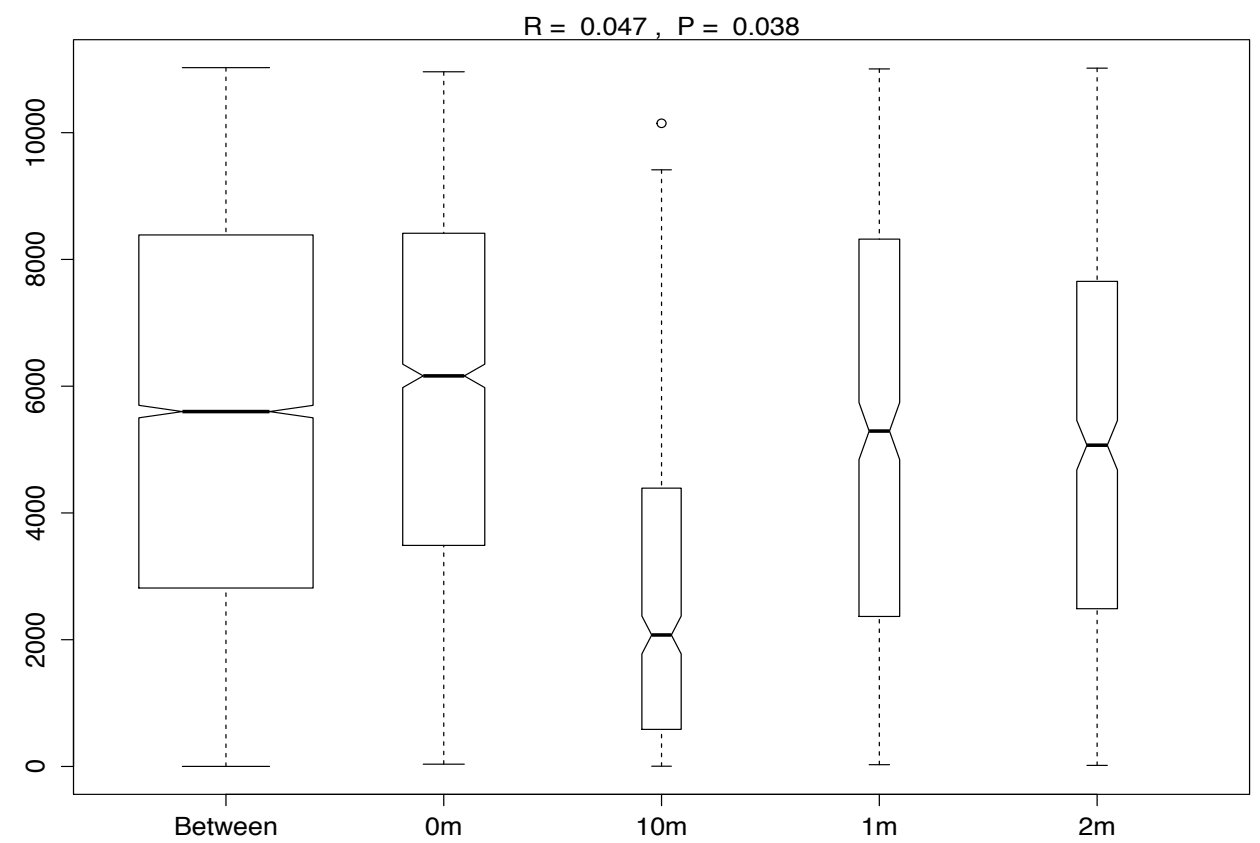

Figure 22. ANOSIM plot for formal trails by distance from trail edge for log-transformed dispersal group data. 


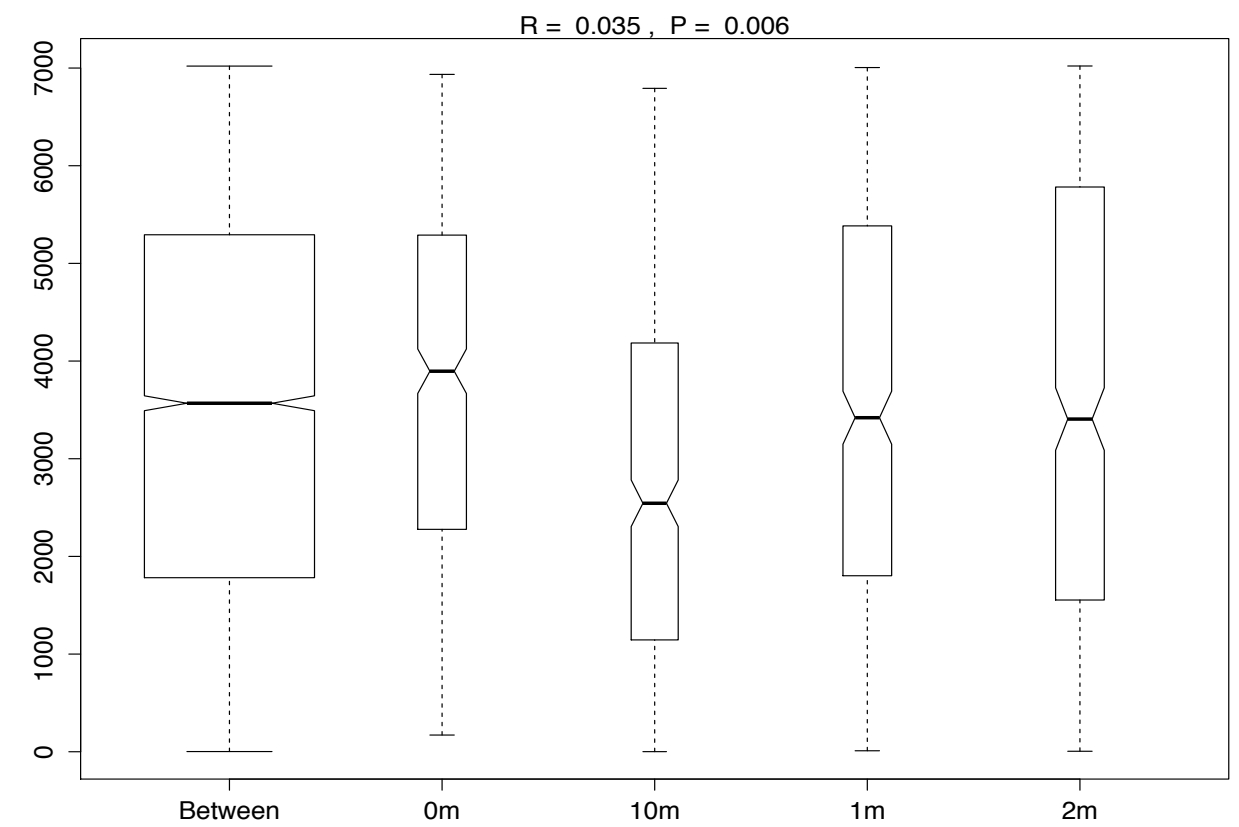

Figure 23. ANOSIM plot for informal trails by distance from trail edge for log-transformed dispersal group data.

When understory species were grouped by growth habit and life form, patterns associated with distance from trail edge were difficult to discern. As with NMDS by dispersal mechansim, vectors were fit to the ordination to see which functional groups contributed most to the alignment in the NMDS space (Figures 24 and 45). For informal trail quadrats and controls, "weedy" species and grasses strongly follow the vector for deciduous canopy cover and opposite sub-shrub and fern cover (Figure 24a). Shrub and vine cover, by contrast is orthogonal to weedy species. Canopy cover, fern, and sub-shrub are defined primarily by the primary axis (NMDS 1), with vectors negatively associated with NMDS 2, while weedy species and grasses are more positively associated. When the ordination is plotted by distance from informal trail edge, patterns based upon distance are not strong, but some clustering defined by NMDS 1 can be seen for $0 \mathrm{~m}$ and $10 \mathrm{~m}$. 
This exploratory analysis suggests that informal trails influence the presence of weedy species and grasses, at the expense of fern and sub-shrub species. When the same ordinations are generated for formal trails, the separation by groups within the NMDS space are similar, e.g. weedy and grass vectors point in the similar directions, as do subshrub and ferns (Figure 25a). However for formal trails the clustering by distance from trail edge is much stronger, suggesting that this factor plays a more defined role in dissimilarity between sites (Figure 25b). While informal trails did not show significant results for these species groupings by distance $(0,1,2$, and $10 \mathrm{~m})$ when tested in ANOSIM, formal trails did for $\log$-transformed data for $0 \mathrm{~m}$ and $10 \mathrm{~m}$ pairing $(\mathrm{r}=0.0897$, $\mathrm{p}=0.001)$.

Like ordinations by dispersal, some clustering by distance from trail edge is evident along the horizontal axis for both formal and informal trails. Further weedy and grass species tend to employ dispersal mechanisms more associated with clustering nearest to the trail edge $(0 \mathrm{~m})$, hitch-hiker, wind, and gravity/ballistic mechanisms. In all ordinations, canopy cover also varies strongly along the horizontal axis, demonstrating an association with species assemblages as well as distance from trail edge. 

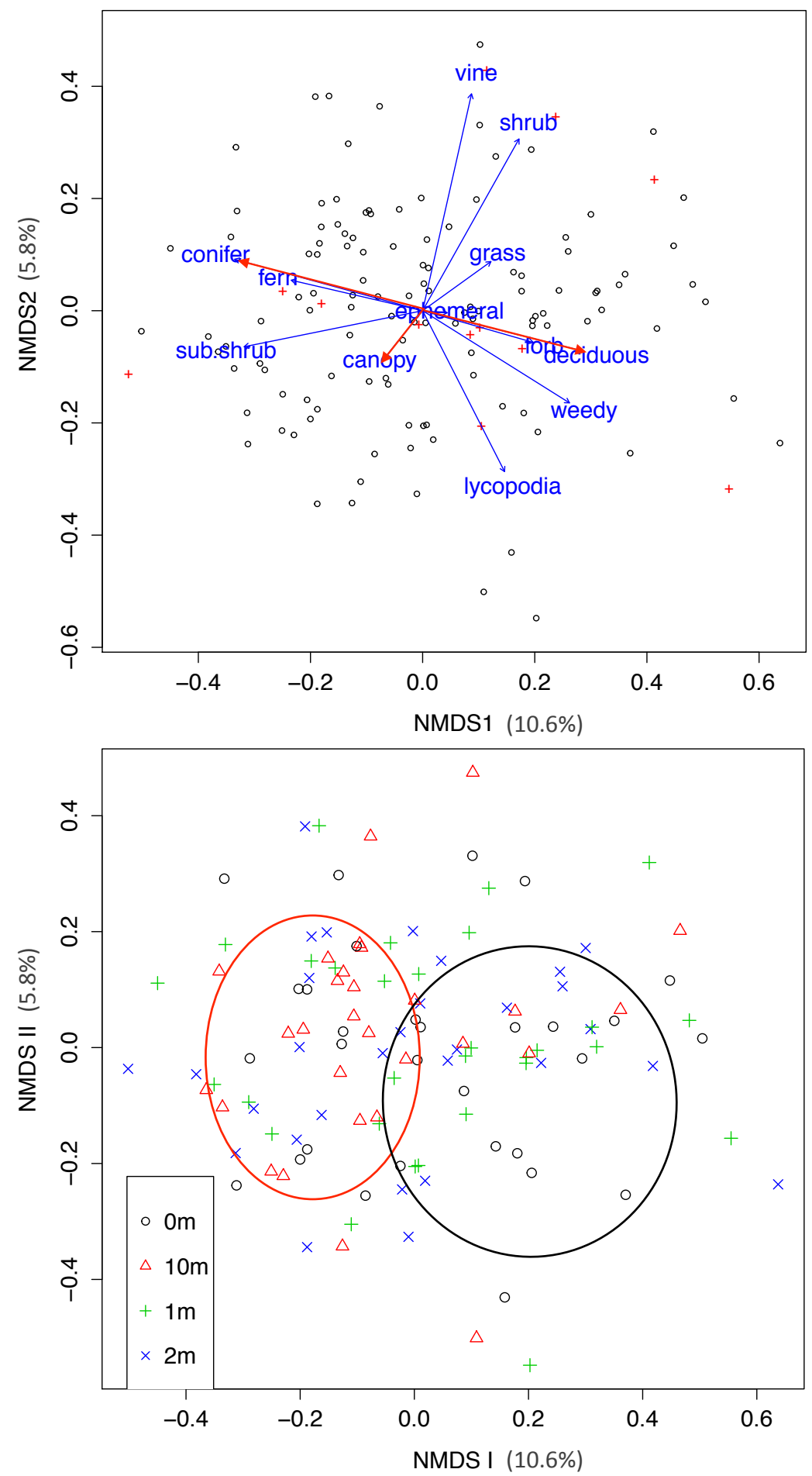

Figures 24a and b. NMDS plots for informal trail quadrats by growth habit and ecological groups, log-transformed data. Upper plot shows NMDS with vectors for each grouping (blue vectors) and for canopy cover variables (red vectors). Percent variance explained by each axis shown in parentheses next to axis label Lower plot shows quadrats by distance from trail edge. Log-transformed, $\mathrm{K}=3$, stress $=0.14$. 

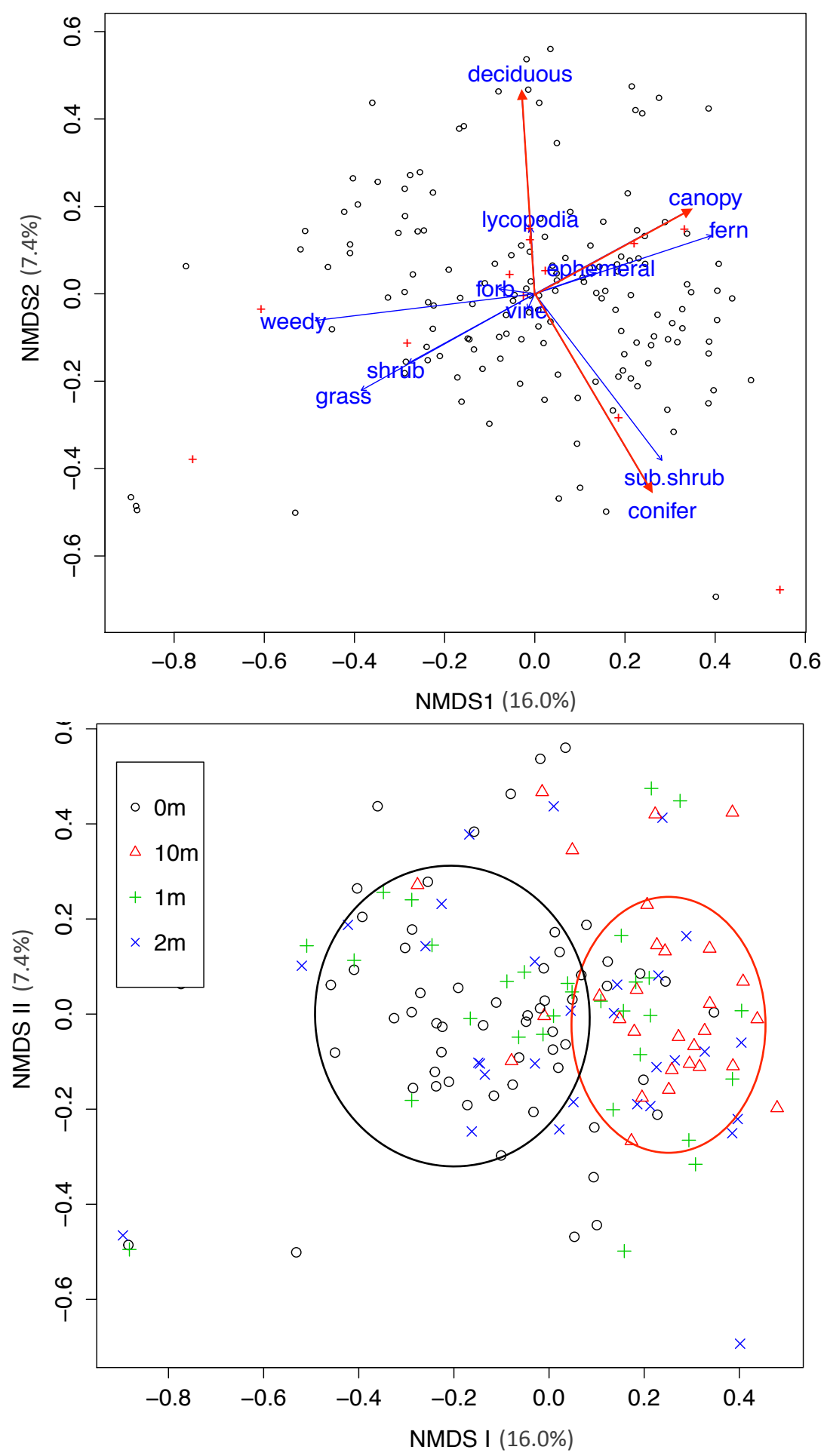

Figures 25a and $\mathrm{b}$. NMDS plots for formal trail quadrats by growth habit and ecological groups, log-transformed data. Upper plot shows NMDS with vectors for each grouping (blue vectors) and for canopy cover variables (red vectors). Percent variance explained by each axis shown in parentheses next to axis label Lower plot shows quadrats by distance from trail edge. Log-transformed, $\mathrm{K}=3$, stress $=0.15$. 


\section{DISCUSSION}

Informal trails are widespread throughout the park, but concentrated in high use areas particularly along Balch Creek. Observations from system mapping suggest that "hidden" behaviors drive many informal trails. Quadrats located within one meter of informal trails showed higher richness and diversity due to increased number of introduced and ruderal species. Formal trails exhibit these same patterns to a stronger degree and over a greater distance (two meters) from the trail edge. Distance from trail edge explained variation in plant communities when grouped by dispersal type, but not by growth form. The presence of informal trails leads to significant changes in Forest Park plant communities that favor invasive and ruderal species, but these effects appear limited to two meters from the trail edge.

\section{Hypothesis 1: Location and Density of Informal Trails}

I found that informal trails are widespread in Forest Park, particularly near trailheads, trail intersections, and along creeks, and that they are more common in high use areas. Lower Macleay Park is the second most popular trailhead and, despite having restroom facilities, has the highest density of informal trails (even without inclusion of the many trails that are less than four meters that were not captured by this study). This supports my first hypothesis and is in agreement with results from other studies of informal trails (Barros et al., 2013; Dickens et al., 2005; C. Walden-Schreiner \& Leung, 2013; Wimpey \& Marion, 2011). 
Lower Macleay and Wildwood trails parallel Balch Creek for about two kilometers, along this length includes an intersection and a popular park feature: the Stone House (Figure 26). Both of these features are huge draws for park users. For most of its length, Lower Macleay Trail is within 10m of the stream and always within sight. It's a compelling feature, providing a valuable educational resource for school groups. Runners, hikers, and dog walkers are a near constant presence. The Stone House is a popular picnic area, and it is also not uncommon to see beer bottles and trash. Dogs, children, and hikers access the creek to explore and view wildlife. But this access has a cost in significant stream bank damage. The few places without access trails to stream are where a fence has been placed or the bank is too steep. Loss of riparian vegetation and compaction of bank soil contributes to erosion and stream sedimentation, affecting water quality and aquatic organisms (Y. Leung \& Marion, 2000).

Balch Creek is home to resident cutthroat trout and managed under the Balch Creek Watershed Protection Plan, with special erosion control standards (FPNRMP, 1995). Trail grade is positively correlated with Condition Class and informal trails are more likely to originate perpendicular to the formal trail and along a "fall line" (Wimpey \& Marion, 2011). With the creek in clear view and close proximity to the trail, the temptation seems too great for park users (both human and canine). Fences have been erected along several sections for user safety and bank protection, while signs alert users to avoid trampling vegetation. Small landslides and trail failure are common along the creek canyon, with steep slopes and heavy winter and spring rainfall (Figure 26). The proliferation of informal trails to access the creek had led to loss of riparian vegetation 
and considerable compaction and erosion of stream banks, which could contribute to slope instability and degradation of water quality along the creek.
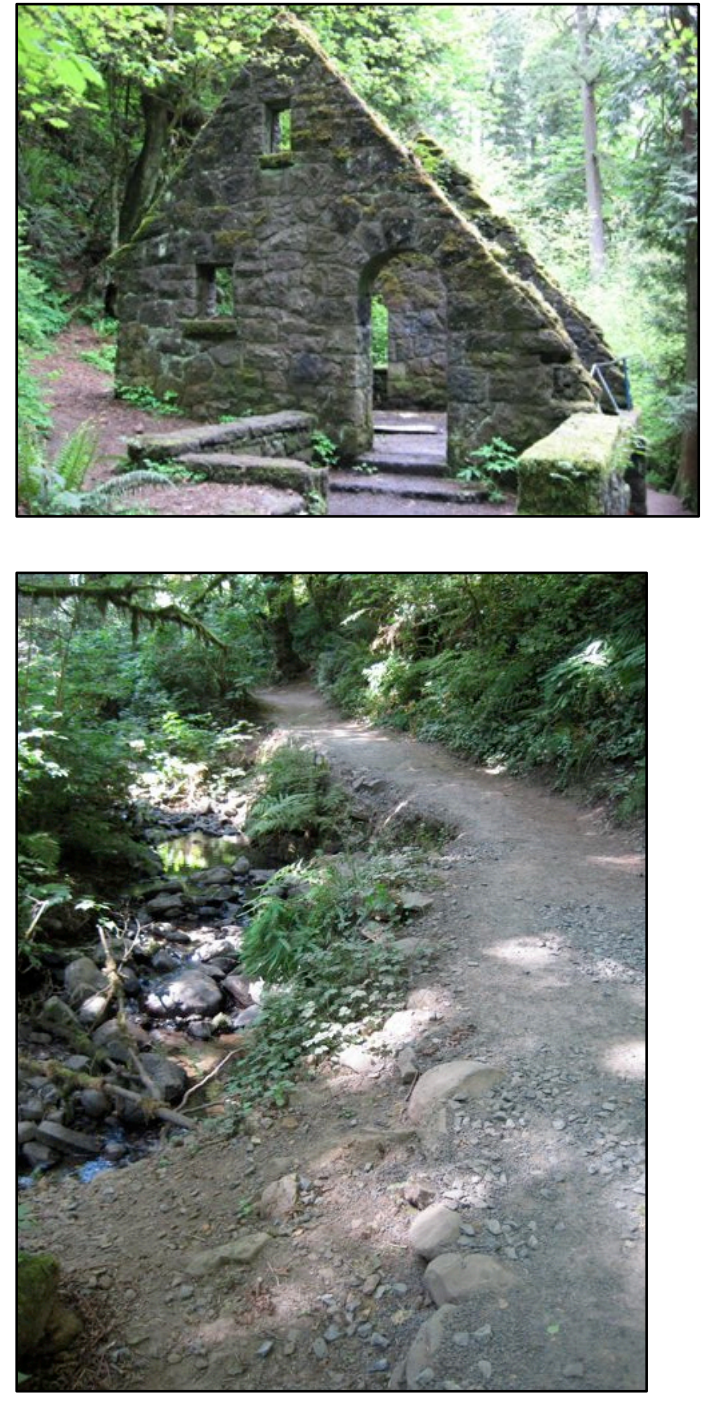

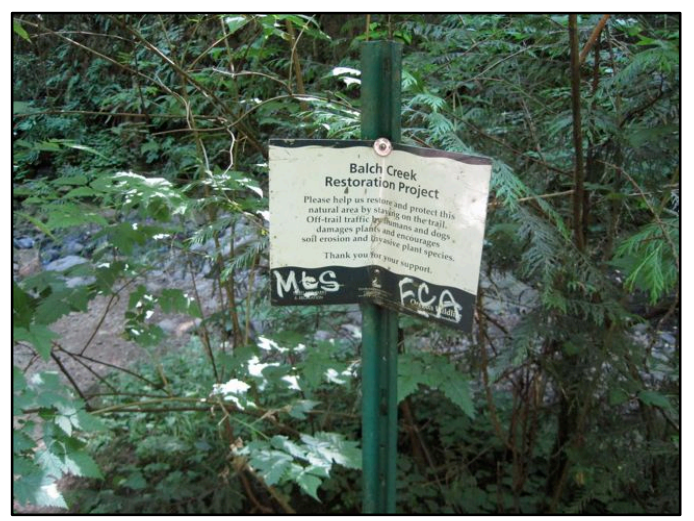

Figure 26. Impacts from off-trail activity along Balch Creek. The Stone House has numerous informal trails surrounding and extending from it (upper left); signs and fences have been added in some locations along the creek to reduce off-trail activity (upper right); Erosion and loss of riparian vegetation along where the trail follows too closely to the stream (lower left).

By contrast, there are few trails originating near the most popular trailhead at Thurman Gate. This illustrates how topography rather than just user number can greatly affect off-trail activity. Leif Erickson Drive, the very popular trail that originates from the Thurman Gate trailhead is a wide road. Its construction on the steep forest slopes led to nearly vertical cut and fill slopes for several meters on either side of the road, limiting 
access. While an effective tool in preventing off-trail activity, trails on roadbeds have many other environmental impacts, including disruption of surface and subsurface water flow, daylighting of the canopy facilitating dispersal and spread of invasive species, and fragmentation of habitat (Tague \& Band, 2001). From a social standpoint they can also affect user experience, as the wide and often less sinuous corridor provides a less intimate forest experience.

By management unit, the presence of informal trails follows formal trail use patterns, with highest number (per formal trail mile) in the South Management Unit and very few informal trails in the North Management Unit, where park use is constrained by distance from the urban area and trailhead facilities. However, even in the North Management Unit, proliferation of informal trails is evident especially near trailheads on Germantown Road and Newton. Near the Newton Trailhead, topography is likely one factor driving the presence of informal trails. There are relatively few users - this trailhead sees $3.7 \%$ of visitors - but the area near the trailhead is one of the few areas in the park that is relatively flat (less than $20 \%$ slope), facilitating off-trail access (Forest Park Recreation Survey, 2012).

\section{Hypothesis 2: Hidden Behaviors}

Formation of informal trails in Forest Park appears to have several primary drivers. I hypothesized that informal trails would be caused by user attempts to hide behaviors, but I was surprised at how many trails seemed to be associated with these behaviors, particularly for bathroom needs, as opposed to formal trail shortcuts and access to desirable features (Hypothesis 1). Based upon my measurements and observations of 
informal trails in this study, short (less than $20 \mathrm{~m}$ ) trails perpendicular to and uphill from the formal trail, which terminate behind a tree or other "screening" material, were the most common trail type. The dense forest and relative seclusion and potential distance (in space or time) from known facilities seems to create a setting where users feel comfortable traveling off-trail to relieve themselves.

Trails accessing private property differ greatly from most other trails observed. While few in number (4\%), they tend to be an order of magnitude longer than other informal trails, such that they make up $29 \%$ of total trail length mapped. Some of these trails may have been used for decades to access the park from home sites (according to adjacent property owner testimony). Some, at least in part, follow legacy corridors from logging or utility activities. These trails also exhibit evidence of active maintenance, often terminating at a property boundary with a sign or gate (Figure 27). While it is understandable that adjacent property owners want direct access to park facilities from their homes, it presents a disproportionate impact by a small number of privileged users. It seems unlikely that private property owners intend harm to the park or see their access as privileged over other park users, but this is the effect. And while many of these trails may have been created from historic use, it is clear that many of these trails are maintained by current users. Education of private property owners and other park users could be helpful in addressing these issues. Even if closing these trails is unrealistic, making property owners aware of the existing and potential impacts, particularly regarding spread and establishment of invasive species, could help to reduce these impacts. 

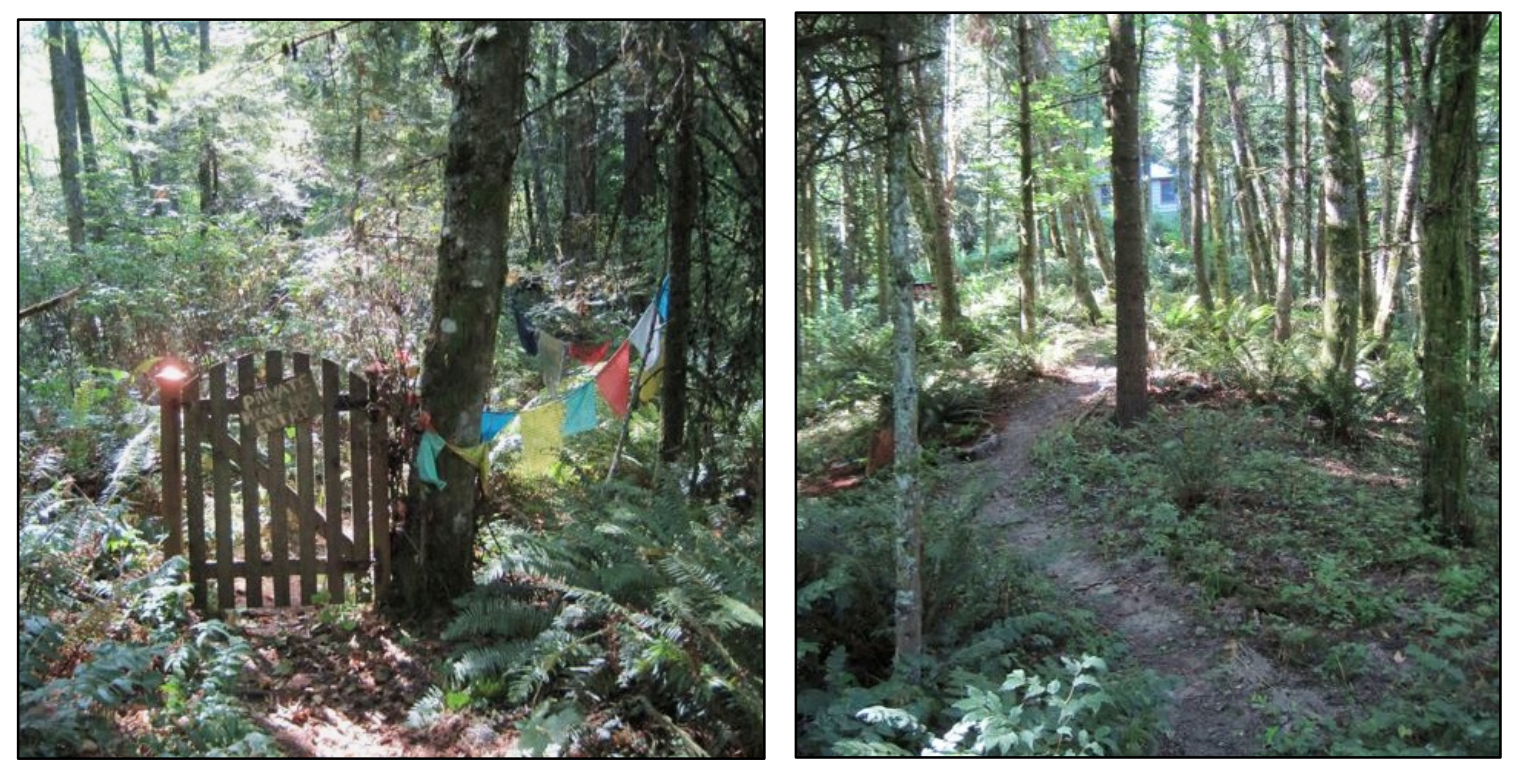

Figure 27. Trails to private property are longer than most informal trails and some show evidence of active maintenance.

\section{Hypothesis 3: Richness, Diversity, and Percent Cover}

I found significant increases in total richness and diversity close to informal trails as compared with controls, supporting my hypothesis. I also predicted that non-ruderal native richness and diversity would decrease close to trails, while invasive and ruderal richness and diversity would increase as compared with controls. There were changes in invasive and native species as predicted, but the only significant differences by group were from increased ruderal native species. While there is a pattern of decreasing total percent cover closer to trail edges, total percent plant cover was not significantly lower adjacent to trail edges than for controls, even when grouped by native and invasive cover. The only significant difference for percent cover was for formal trails at $0 \mathrm{~m}$ compared with controls when grouped by native and invasive, but total cover was not changed. 
Increased total richness and diversity was significant for both informal and formal trails at distances of 1 meter and 3 meters, respectively. Increased richness and diversity along trail edges has been observed in other trail studies (Barros et al., 2013; Potito \& Beatty, 2005; Roovers et al., 2005). Disturbances associated with informal trail formation remove native vegetation and expose soil, creating openings for ruderal and more stress-tolerant species to occupy. Additionally, trampling and compaction along the informal trail corridor can reduce vertical vegetation layers, affecting not just the herbaceous layer, but also shrubs and tree branches, increasing light availability at the forest floor (Kuss \& Hall, 1991; Kuss, 1986). Over the long term, compaction of soil may suppress tree and shrub seedlings, further exacerbating these affects.

\section{Hypothesis 4a: Dispersal}

I hypothesized that plant community differences adjacent to informal trails would be affected by dispersal mechanism. Seeds dispersed via hitch-hiker (epizoochory), wind (amenochory), and ballistic strategies (or combination) are more likely to be dispersed by users traveling along informal trails. Additionally, these dispersal mechanisms are associated with r-strategy species, often "ruderal", "pioneer", invasive, or opportunistic species, whether of native or non-native provenance, these species are more likely to be transported along a user corridor and to colonize following disturbance (C. Pickering \& Mount, 2010; Potito \& Beatty, 2005; Scheller \& Mladenoff, 2002). I found significant differences in plant community assemblages by distance from trail edge ( $0 \mathrm{~m}$ compared with $10 \mathrm{~m}$ control) when species were grouped by dispersal type. This effect was true for both informal and formal trails, suggesting that trails may facilitate dispersal and spread 
of hitch-hiker and wind dispersed and other small seeds. As informal trails create hundreds of kilometers of additional corridors to the park interior, this can lead to considerable changes in understory plant communities throughout the park.

\section{Hypothesis 4b: Growth Form and Ecology}

I hypothesized that plants with certain growth form and life history attributes would be correlated with distance from informal trail edge. While I did not find significant differences in plant growth form related to formal or informal trails, NMDS did reveal some clustering as a function of distance. In addition to dispersal type, growth habit affects plant success with disturbance. While ferns and sub-shrubs are tolerant to disturbance, they are slow growing and primarily spread through rhizomes. This growth habit may be impeded by informal trails over the longer term, as soil compaction interferes with rhizome, root, and mycorrhizal growth, as well as available soil moisture and air. Additionally, they may have trouble competing with non-native and ruderal species once they are established within the corridor. "Weedy" species, non-native invasive and ruderal natives, are primarily hemicryptophyte (low growing, rosette perennials and grasses) and theophyte (annuals) in growth form (see Appendix B for growth form by species). In addition to growth forms that may be more successful with frequent disturbance, these types of plants also typically produce large numbers of small seed, easily transported along informal trail corridors by humans, dogs, and wildlife. 


\section{Study Limitations and Considerations for Future Research}

While I tried to observe as many informal trails as I could in the park, this survey is not exhaustive. It is likely that I missed many informal trails, particularly those that originate from property boundaries, rather than recreational access points or trails. The nature of informal trails and off-trail activity is such that delineating them is a moving target, as activity and vegetation change with seasons and over time (C. Walden-Schreiner \& Leung, 2013; Wimpey \& Marion, 2011). Still, the survey produced a population of trail data that informed the study questions and painted a reasonable picture of impacts from recreational off-trail activity at a point in time.

The characterization of informal trails and their effects to natural areas is a relatively new area of study. Most studies to date have focused on spatial analysis and motivations for user behavior (Marion, 2006; C. Walden-Schreiner \& Leung, 2013; Wimpey \& Marion, 2011). These previous studies support my observations on informal trail density as related to use level, access points, and desirable features. However, the urban setting of my study highlights two particular sources of trail formation that have not been well described: bathroom trails and private property access. These are likely more common in urban settings and necessitate very different management strategies and outreach efforts. How do sources of human and domesticated animal waste contribute to nutrient load and pathogen sources in natural areas? Does access from private property influence the species transported along trail corridors?

Two studies have looked at the effects of informal trails on plant communities and found that they act in similar ways to other trail or road corridors in disturbance to vegetation, soils, and spread of invasive and ruderal species, supporting the results 
presented here (Barros et al., 2013; Dickens et al., 2005). However, I have not found other studies that looked at effects to plant communities in high-use and/or urban natural areas, as presented here.

\section{Condition Class}

Condition Class was not a subject of any particular hypothesis, but provided a useful tool in evaluating informal trails and in selecting trails of similar relative impact for sampling. Sampled trails all fell within Trail Condition Classes 2 or 3. As defining them within classes is somewhat subjective, and since trails may change in condition class along their length, depending upon vegetation, slope, litter depth, and other factors, ratings are assigned based upon predominant trail character (for their length, or for a defined trail segment) (Jeff Marion, 2006; Wimpey \& Marion, 2011). This is particularly true for informal trails in Condition Class 1, where they may visually recover within a growth season without sustained use.

Greatest change to soils and trampling of vegetation from informal trails occurs from Condition Class 1 to 2, with a stabilization of impacts from trampling and compaction as trails progress from Condition Class 2 to 3, while at Condition Classes 4 and 5, the additional effects are primarily due to soil loss (Wimpey \& Marion, 2011). Presumably, continued travel increases likelihood of invasion (as trails progress from CC1 to 3), but initial disturbance is perhaps more important (Potito \& Beatty, 2005; Roovers et al., 2005). At what level of use - number of user passes within a set period of time or by Condition Class - is dispersal and spread of invasive species likely to occur? Is there some threshold impact from informal trail activity where changes in plant 
communities occur? This study showed at Condition Classes 2 and 3, significant differences in richness and diversity occur, that these differences extend $0-2 \mathrm{~m}$ from either side of each informal trail edge, and that plants with "weedy" dispersal characteristics are associated with informal trails. As numerous studies and experiments have shown, the trampling and compaction from off-trail activity has significant impacts to vegetation, and that these effects vary by tolerance and resilience associated with a plants' particular growth habits (Cole, 1995; Kuss, 1986; Liddle, 1975; Littlemore \& Barker, 2003).

\section{Historic Corridors}

It is difficult to sort out which trails formed through more recent recreational use and those that may have been sustained or reopened following historical use. While only 23 informal trails $(7 \%)$ were attributed as following non-recreational disturbance corridors (though they make up $16 \%$ of total trail length and disturbance area), the history of disturbance within the park makes it likely that many more follow previous disturbance.

\section{Wildlife}

Direct wildlife evidence and suspected wildlife activity was recorded for 61 informal trails, but it is likely that many trails are used by wildlife, both formal and informal, and some informal trails may have been first created by wildlife (Y.-F. Leung, Newburger, Jones, Kuhn, \& Woiderski, 2011). Most of the trails with evidence or suspected wildlife activity were near creeks, popular places for humans and dogs, as well. Wildlife may use trails for some of the same reasons that humans do - ease of travel through the forest and access to desirable features (notably water and openings) (Dickens et al., 2005; Y.-F. 
Leung et al., 2011). Natural landscapes developed with pressures from native wildlife, with effects to stream banks, soil, and vegetation part of the ecological processes. Human activities off-trail creates paths that may facilitate wildlife use, but can also displace wildlife and contribute to habitat fragmentation (Y.-F. Leung et al., 2011; Wimpey \& Marion, 2011). Informal trail creation and use by humans have a much greater impact to natural areas and compound disturbances to wildlife (Dickens et al., 2005; Y.-F. Leung et al., 2011; Wimpey \& Marion, 2011).

\section{Topography}

Topography certainly plays a role in formation of informal trails and may also influence vegetation patterns. Similar cues that "invite" off-trail activity can similarly act as openings for invasive and ruderal species. Though not measured in this study, observation revealed that ridges were a common location for informal trails, particularly long, private property and utility access routes. Ridges may also allow greater canopy opening, thus allowing more light and air flow that could facilitate dispersal and growth of ruderal species. Ridgelines also may have acted as historical use corridors for similar reasons - they are often easier to ascend due to lower average slope grade (as compared with adjacent hillsides and drainages) and less dense vegetation impeding access.

Wimpey \& Marion found that flat areas were twice as likely to have informal trail formation than other slope classes (2011). While there are few flat areas in Forest Park, these areas, such as trail access points from Skyline, along ridge tops, and near the Newton trailhead, do show increased informal trail formation compared with areas of similar use but with topographical constraints. The lack of trails along Leif Erickson, 
except near trail intersections is due in part to the very steep cut and fill slopes resulting from the road construction.

There are several reasons why trails were observed to occur primarily to the uphill side of formal trails $(54 \%)$ or at turns $(13 \%)$. It is easier to hide from view upslope or off the outside of a turn. It is also physically easier to ascend slopes than descend them, and to see what obstacles might inhibit travel (e.g. logs, dense vegetation, etc.). Turns are frequently placed in areas where slope is less than the prevailing slope, in order to ease switchback construction. Finally, existing informal trails are easier to see when they originate upslope, creating increased releaser cues than for downslope informal trails.

\section{Canopy Cover}

Decreased canopy cover and greater proportion of that cover from deciduous trees is correlated with non-native and ruderal species. This study showed that canopy cover is one of the strongest predictors of non-native and ruderal species presence along trail corridors. Canopy cover relationship with growth habit and ecological groups suggest that these patterns are consistent outside of trail influence. While this relationship wasn't explored as part of this study, my results suggest that decreased canopy cover correlates with increased shrub and vine presence, while increased canopy correlates with subshrubs and ferns. Further, increased deciduous cover (as a proportion of total cover) correlated with weedy species and graminoids. When grouped by primary dispersal mechanism, similar patterns emerge: canopy cover is inversely correlated with wind and hitch-hiker dispersal mechanisms, and positively correlated with rhizomatous species. Do these species establish along informal trails because of the disturbance or because of the 
increased light, or some interactive effect? Have informal trails suppressed canopy closure over time? Are informal trails more likely to form where there is a canopy opening? It is difficult to separate the influence of canopy on species assemblages versus those of informal trails.

While the effect of informal trails on the vegetation appears limited to within one to two meters of the trail edge, are there other ways that informal trails might affect vegetation in the longer term? Even narrow disturbance corridors created by informal trails contribute to fragmentation and increase edge effects (Barros et al., 2013; Kuss, 1986). Changes to soil characteristics could inhibit the spread of rhizomatous species and mycorrhizae across an area bisected by trails (Kuss, 1986; Littlemore \& Barker, 2003).

\section{Implications for Park Management}

Forest Park is the one of the largest urban parks in the country. Its trails and forested open space provide an outstanding recreational experience for the region's residents. As importantly, it provides critical urban refuge for native wildlife and plants (Broshot, 2007). Off-trail activity resulting in the formation of informal trails is common in natural areas, particularly in high-use and/or urban natural areas, such as Forest Park. Trails and roads are well known vectors in the spread and establishment of invasive species. Maintenance of native plant communities and minimizing disturbance from non-native and invasive species are among the primary ecological goals for Forest Park managers (PP\&R, 2011). Unlike other Portland parks and open spaces, the particular resource and recreation goals for Forest Park led to the creation of the Forest Park Natural Resources Management Plan (1995) to guide its management. 
Forest Park represents an unparalleled resource where citizens can enjoy the peace, solitude, ruggedness, variety, beauty, unpredictability and unspoiled naturalness of an urban wilderness environment; a place that maintains this wilderness quality while allowing appropriate passive recreational and educational use without degrading natural resources; an urban laboratory for environmental research and resource enhancement and restoration; America's premier urban ancient forest.

- A Vision for Forest Park, FPNRMP

Optimizing the park experience for the metro area's growing active outdoor population can be at odds with conservation goals. Recent reports highlight these concerns: Forest Park Desired Future Condition Report (PP\&R, July 2010), Forest Park Singletrack Advisory Committee Report (August 2010), and Forest Park: A Call to Action (City Club, May 2010) stressing the need for further study particularly regarding wildlife and user impacts. Additionally, a formal recreational user survey report was released in 2012, evaluating user preferences and experience goals for the Park (Forest Park Recreation Survey, 2012). Understanding the extent and impacts of informal trails helps Forest Park managers target resources for education and restoration, to protect natural areas for wildlife and park users alike.

\section{Trail Reclamation}

Trails of Condition Class 1 will likely recover on their own within a relatively short period of time without continued use. For informal trails greater than Condition Class 2, relief disturbance may not be sufficient to allow recovery in the short term. Scarification of compacted soil, addition of organic material, and native plantings can help to facilitate recovery (Jeff Marion, 2006). Roovers, et al (2005) found that vegetation recovered after 
six years and composition tended to reflect that away from trailside, rather than perpetuating ruderal species, suggesting that exclusion of use might be sufficient to allow recovery. However, plantings and closure activities help to disguise the trail corridor, which may be more effective at deterring continued use, while also speeding up the recovery process.

\section{Restrooms}

Observations of informal trail location (e.g. near trailheads, upslope from formal trails), length (less than 20m), and vegetation screening (e.g. behind trees or shrubs), along with direct evidence (e.g. toilet paper) suggest that a primary reason for off-trail activity is order to go to the bathroom. While several trailheads have restroom facilities, given the park's size, these facilities seem insufficient. A survey of park users indicated that the second most requested improvement to the park would be additional or improved restroom facilities (PP\&R, 2012). Some restroom facilities are not located at parking areas, but several hundred meters from the trailhead. This reduces vandalism but likely reduces their use, instead sending some users into the forest. Short of adding more restrooms, providing restroom location information at trailhead kiosks and intersection maps could reduce some off-trail activity.

\section{Fences}

It's not a popular solution, but observations suggest that fences can be highly effective, particularly when used in conjunction with educational signs (Bradford \& Mcintyre, 
2007; Marion, 2006). While fences can work, users will go around them if they don't span area of concern (Figure 28), or incorporate other barriers, signs, etc. Vegetation and large woody debris can make effective barriers. Users often look for opening in corridor, rather than trail on the ground - this is one of the reasons historical corridors continue to see use.
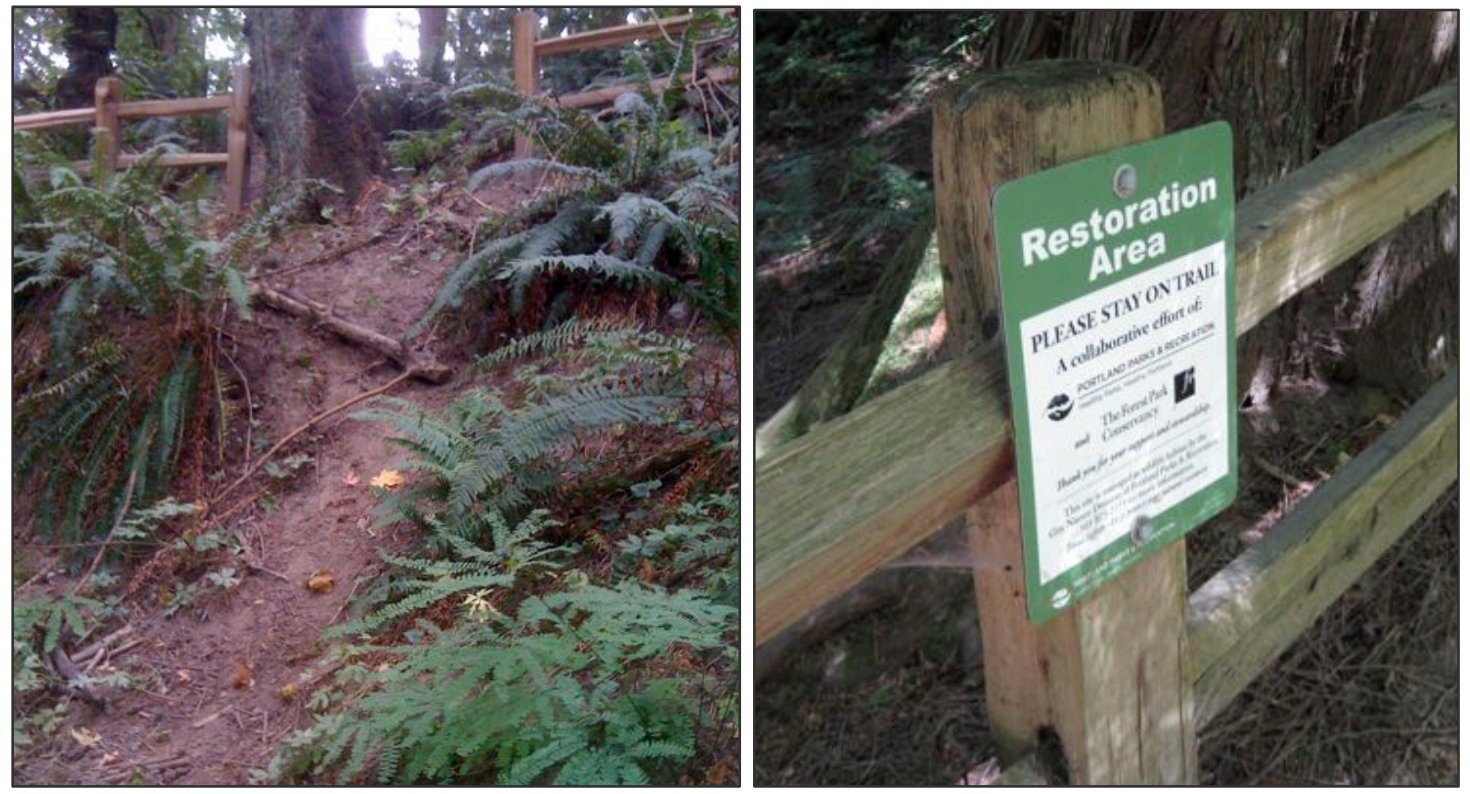

Figure 28. Fencing along Wildwood Trail within the Balch Watershed. Users shortcut trail at fence gap (left); Sign added to fence to inform users about restoration efforts (right).

\section{Education}

Letting park users know impacts of going off trail - impacts to wildlife, water quality, and native plants, spread of non-natives - can be an effective strategy in addressing the behaviors of some park users (Marion, 2006). Studies and surveys show that many park users are conscientious about resource protection, but may simply be unaware of their impacts (Forest Park Recreation Survey, 2012; Bradford \& Mcintyre, 2007; personal communication with park users). Signs at restoration sites, and particularly along streams 
and at bridge crossings (especially for users with dogs), can be effective in providing information to users when messages incorporate awareness and internal locus of control (e.g. "your feet trample plants and spread invasives, please stay on the trail") (Bradford \& Mcintyre, 2007). However, it is recognized that certain user behaviors are unlikely to be influenced by educational efforts, such as those engaging in illegal activities. 


\section{CONCLUSION}

For many reasons, users do not stay upon established, formal trails, for pursuits as wide-ranging as desire for efficiency (to points of interest), privacy (restroom needs), to illicit activities. This study helped to characterize the extent and nature of informal trails in Forest Park and shed light on their effects to understory plant communities. I found that off-trail activity is widespread, but concentrated in high-use areas, in the park leading to the formation of hundreds of discernible trails. Impacts from informal trails in Forest Park extend beyond the footprint of the trail on the ground, affecting understory plant communities two to three meters from the trail edge. However, the role of invasive species in these changes is less clear. Ruderal native species appear to make up much of the differences in richness and diversity, while total plant cover was unaffected. Ruderal natives and non-native invasive species share many ecological characteristics (dispersal strategies, disturbance tolerance and resilience, growth forms) and disturbance conditions associated with informal trails appears to favor both. Species patterns associated with informal trails in this study suggests that they act in much the same way as formal trails in facilitating the spread of invasive species. Understanding the extent and impacts of informal trails helps managers target resources for education and restoration, to protect natural areas for wildlife and park users alike. 


\section{LITERATURE CITED}

Amacher, M. C., \& Neill, K. P. O. (2004). Assessing Soil Compaction on Forest Inventory \& Analysis Phase 3 Field Plots Using a Pocket Penetrometer (No. RMRS-RP-46WWW) (p. 7). Fort COllins, CO.

Amrein, D., Rusterholz, H. P., \& Baur, B. (2005). Disturbance of suburban Fagus forests by recreational activities: Effects on soil characteristics, above-ground vegetation and seed bank. Applied Vegetation Science, 8, 175-182.

Barros, A., Gonnet, J., \& Pickering, C. (2013). Impacts of informal trails on vegetation and soils in the highest protected area in the Southern Hemisphere. Journal of Environmental Management, 127, 5060. doi:10.1016/j.jenvman.2013.04.030

Bella, E. M. (2011). Invasion Prediction on Alaska Trails: Distribution, Habitat, and Trail Use. Invasive Plant Science and Management, 4(3), 296-305. doi:10.1614/IPSM-D-10-00083.1

Bhuju, D. R., \& Ohsawa, M. (1998). Effects of nature trails on ground vegetation and understory colonization of a patchy remnant forest in an urban domain. Biological Conservation, 85, 123-135.

Broshot, N. E. (2007). The influence of urbanization on forest stand dynamics in Northwestern Oregon. Urban Ecosystems, 10(3), 285-298. doi:10.1007/s11252-007-0023-x

Broshot, N. E. (2011). Mortality and recruitment in an urban forest (Forest Park in Portland, Oregon) between 1993 and 2003. Urban Ecosystems, 14(4), 553-567. doi:10.1007/s11252-011-0170-y

Chatterjea, K. (2007). Assessment and demarcation of trail degradation in a nature reserve using GIS: case of Bukit Timah Nature Reserve. Land Degradation and Development, 18(March), 500-518. doi:10.1002/ldr

City of Portland. (2008). City of Portland Invasive Plant Strategy Report 2008. October.

Cole, D. N. (1995). Experimental trampling of vegetation. II. Predictors of resistance and resilience*. Journal of Applied Ecology, 32(1), 215-224.

Cole, D. N. (2004). Monitoring and Management of Recreation in Protected Areas : the Contributions and Limitations of Science (No. 2) (p. 17). Missoula, MT.

Cole, D. N., Foti, P., \& Brown, M. (2008). Twenty years of change on campsites in the backcountry of Grand Canyon National Park. Environmental Management, 41(6), 959-70. doi:10.1007/s00267-0089087-5

Dennehy, C., Alverson, E. R., Anderson, H. E., Clements, D. R., Gilbert, R., \& Kaye, T. N. (2011). Management Strategies for Invasive Plants in Pacific Northwest Prairies, Savannas, and Oak Woodlands. Northwest Science, 85(2), 329-351. doi:10.3955/046.085.0219

Dickens, S. J. M., Gerhardt, F., \& Collinge, S. K. (2005). Recreational Portage Trails as Corridors Facilitating Non-Native Plant Invasions of the Boundary Waters Canoe Area Wilderness (USA). Conservation Biology, 19(1), 1653-1657. doi:10.1111/j.1523-1739.2005.00232.x

Forest Park Recreation Survey. (2012) (pp. 1-43). Portland, OR. 
FPNRMP. (1995). Forest Park Natural Resources Management Plan (p. 240). Portland, OR.

Guntenspergen, G. R., \& Levenson, J. B. (1997). Understory plant species composition in remnant stands along an urban-to-rural land-use gradient. Urban Ecosystems, 1, 155-169.

Hall, C. N., \& Kuss, F. R. (1989). Vegetation Alteration along Trails in Shenandoah National Park, Virginia. Biological Conservation, 48, 211-227.

Hansen, M. J., \& Clevenger, A. P. (2005). The influence of disturbance and habitat on the presence of nonnative plant species along transport corridors. Biological Conservation, 125(2), 249-259. doi:10.1016/j.biocon.2005.03.024

Holmes, S. E., Roy, B., Reed, J. P., \& Johnson, B. R. (2010). Context-dependent pattern and process: the distribution and competitive dynamics of an invasive grass, Brachypodium sylvaticum. Biological Invasions, 12(7), 2303-2318. doi:10.1007/s10530-009-9645-7

Kuss, F. R. (1986). A review of major factors influencing plant responses to recreation impacts. Environmental Management, 10(5), 637-650. doi:10.1007/BF01866768

Kuss, F. R., \& Hall, C. N. (1991). Ground flora trampling studies: Five years after closure. Environmental Management, 15(5), 715-727. doi:10.1007/BF02589629

Lei, S. A. (2004). Soil Compaction from Human Trampling, Biking, and Off-road Motor Vehicle Activity in a Blackbrush (Coleogyne ramosissima) Shrubland. Western North American Naturalist, 64(1), $125-130$.

Leung, Y., \& Marion, J. L. (2000). Recreation Impacts and Management in Wilderness : A State-ofKnowledge Review The Field of Recreation Ecology (pp. RMRS-P-15-VOL-5, 23-48).

Leung, Y.-F., Newburger, T., Jones, M., Kuhn, B., \& Woiderski, B. (2011). Developing a monitoring protocol for visitor-created informal trails in Yosemite National Park, USA. Environmental Management, 47(1), 93-106. doi:10.1007/s00267-010-9581-4

Liddle, M. J. (Monks W. E. S. G. B. (1975). A selective review of the ecological effects of human trampling on natural ecosystems. Biological Conservation, (7), 17-36.

Littlemore, J., \& Barker, S. (2003). The ecological response of forest ground flora and soils to experimental trampling in British urban woodlands. Urban Ecosystems, 5, 257-276.

Lori Bradford, \& Mcintyre, N. (2007). Off The Beaten Track : Messages As A Means Of Reducing Social Trail Use At St . Lawrence Islands National Park. Journal of Park and Recreation Administration, 25(1), 1-21.

Manning, R., Jacobi, C., \& Marion, J. L. (2006). Recreation Monitoring at Acadia National Park. The George Wright Forum, 23(2), 59-72.

Marion, J. (2006). Guidance for Managing Informal Trails (p. 12).

Marion, J. L., \& Leung, Y. (2001). Trail Resource Impacts and An Examination of Alternative Assessment Techniques. Journal of Park and Recreation Administration, 19(3), 17-37. 
Marion, J. L., \& Leung, Y. (2006). Monitoring Trail Conditions : New Methodological Considerations. The George Wright Forum, 23(2), 36-49.

Marion, J., \& Reid, S. (2007). Minimising Visitor Impacts to Protected Areas: The Efficacy of Low Impact Education Programmes. Journal of Sustainable Tourism, 15(1), 5-27. doi:10.2167/jost593.0

McKinney, M. L. (2008). Effects of urbanization on species richness: A review of plants and animals. Urban Ecosystems, 11(2), 161-176. doi:10.1007/s11252-007-0045-4

Memmott, J., Martinez, N. D., \& Cohen, J. E. (2000). Predators, parasitoids and pathogens: species richness, trophic generality and body sizes in a natural food web. Journal of Animal Ecology, 69(1), 1-15. doi:10.1046/j.1365-2656.2000.00367.x

Menéndez, R., Megías, A. G., Hill, J. K., Braschler, B., Willis, S. G., Collingham, Y., ... Thomas, C. D. (2006). Species richness changes lag behind climate change. Proceedings. Biological Sciences / The Royal Society, 273(1593), 1465-70. doi:10.1098/rspb.2006.3484

Millward, A. a., Paudel, K., \& Briggs, S. E. (2011). Naturalization as a strategy for improving soil physical characteristics in a forested urban park. Urban Ecosystems, 14(2), 261-278. doi:10.1007/s11252-0100153-4

Monz, C. a, Cole, D. N., Leung, Y.-F., \& Marion, J. L. (2010). Sustaining visitor use in protected areas: future opportunities in recreation ecology research based on the USA experience. Environmental Management, 45(3), 551-62. doi:10.1007/s00267-009-9406-5

Mount, A., \& Pickering, C. M. (2009a). Testing the capacity of clothing to act as a vector for non-native seed in protected areas. Journal of Environmental Management, 91(1), 168-79. doi:10.1016/j.jenvman.2009.08.002

Mount, A., \& Pickering, C. M. (2009b). Testing the capacity of clothing to act as a vector for non-native seed in protected areas. Journal of Environmental Management, 91(1), 168-79. doi:10.1016/j.jenvman.2009.08.002

NRCS. (2001). Web Soil Survey. Retrieved May 12, 2013, from http://websoilsurvey.nrcs.usda.gov

Pickering, C. M. (2010). Ten Factors that Affect the Severity of Environmental Impacts of Visitors in Protected Areas. Ambio, 39(1), 70-77. doi:10.1007/s13280-009-0007-6

Pickering, C., \& Mount, A. (2010). Do tourists disperse weed seed? A global review of unintentional human-mediated terrestrial seed dispersal on clothing, vehicles and horses. Journal of Sustainable Tourism, 18(2), 239-256. doi:10.1080/09669580903406613

Potito, A. P., \& Beatty, S. W. (2005). Impacts of recreation trails on exotic and ruderal species distribution in grassland areas along the Colorado Front Range. Environmental Management, 36(2), 230-6. doi: $10.1007 / \mathrm{s} 00267-003-0177-0$

Rew, L. J., Maxwell, B. D., Dougher, F. L., \& Aspinall, R. (2006). Searching for a Needle in a Haystack: Evaluating Survey Methods for Non-indigenous Plant Species. Biological Invasions, 8(3), 523-539. doi:10.1007/s10530-005-6420-2 
Roovers, P., Bossuyt, B., Gulinck, H., \& Hermy, M. (2005). Vegetation recovery on closed paths in temperate deciduous forests. Journal of Environmental Management, 74(3), 273-81. doi:10.1016/j.jenvman.2004.10.003

Scheller, R. M., \& Mladenoff, D. J. (2002). Understory Species Patterns and Diversity in Old-Growth and Managed Hardwood Forests. Ecological Applications, 12(5), 1329-1343.

Tague, C., \& Band, L. (2001). Simulating the impact of road construction and forest harvesting on hydrologic response. Earth Surface Processes and Landforms, 26(2), 135-151 . doi:10.1002/10969837(200102)26:2<135::AID-ESP167>3.3.CO;2-A

Thurston, E., \& Reader, R. J. (2001). Impacts of Experimentally Applied Mountain Biking and Hiking on Vegetation and Soil of a Deciduous Forest. Environmental Management, 27(3), 397-409. doi: $10.1007 / \mathrm{s} 002670010157$

Underwood, E. C., Klinger, R., \& Moore, P. E. (2004). Predicting patterns of non-native plant invasions in Yosemite National Park, California, USA. Diversity and Distributions, 10(5-6), 447-459. doi:10.1111/j.1366-9516.2004.00093.x

Vitosek, P., D’Antonio, C., Loope, L., \& Westbrooks, R. (1996). Biological Invasions as Global Environmental Change. American Scientist, 84(5), 468-478.

Walden-Schreiner, C. A. (2012). Developing a Method to Characterize Visitor Use and its Spatial Association with Informal Trails in Yosemite Valley Meadows. North Carolina State University.

Walden-Schreiner, C., \& Leung, Y.-F. (2013). Spatially characterizing visitor use and its association with informal trails in Yosemite Valley meadows. Environmental Management, 52(1), 163-78. doi:10.1007/s00267-013-0066-0

Westman, W.E. (1990). Park Management of Exotic Plant Species: Problems and Issues. Conservation Biology, 4(3), 251-260.

Wimpey, J., \& Marion, J. L. (2011). A spatial exploration of informal trail networks within Great Falls Park, VA. Journal of Environmental Management, 92(3), 1012-22. doi:10.1016/j.jenvman.2010.11.015 


\section{APPENDIX A}

Informal Trails by Condition Class by Management Unit

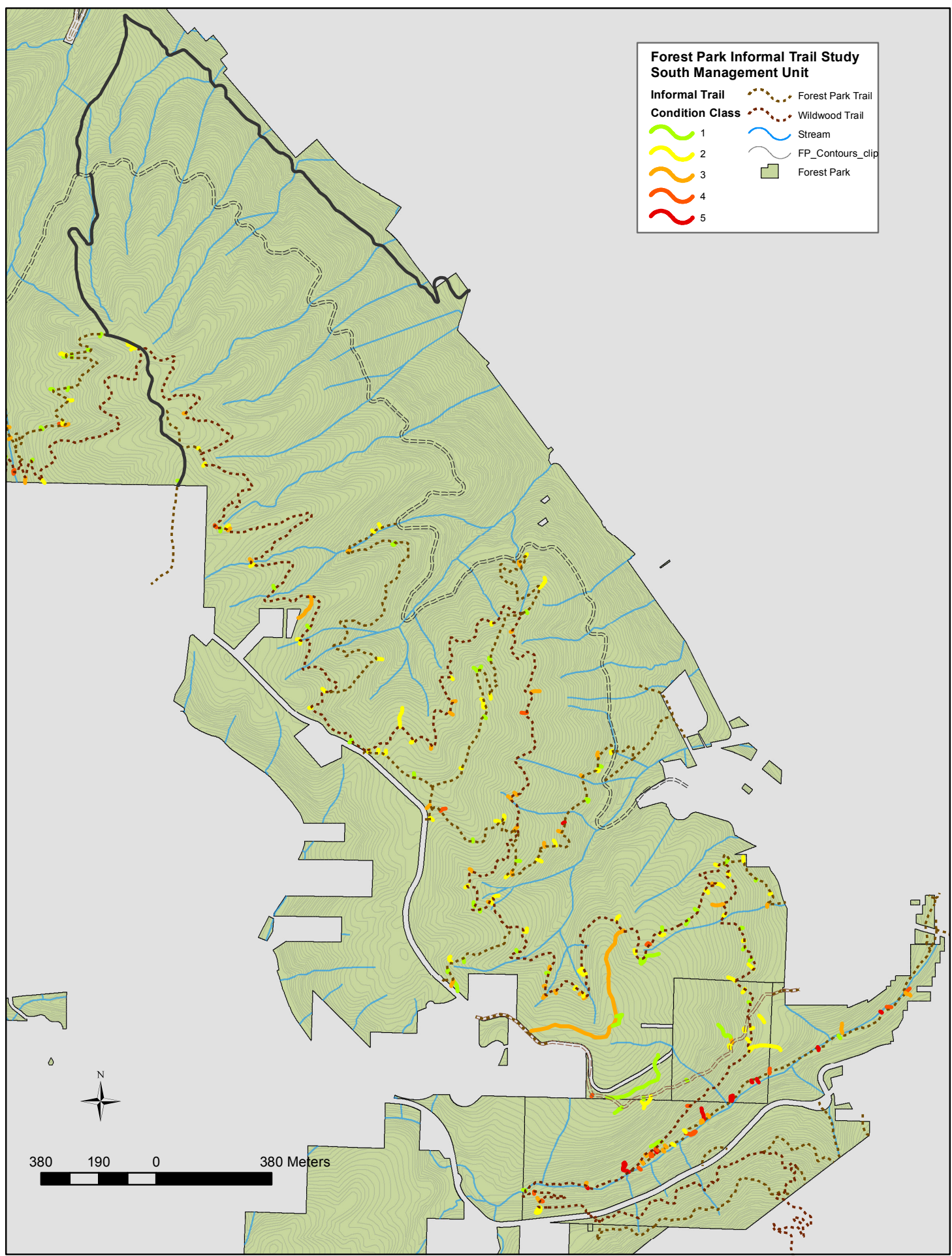




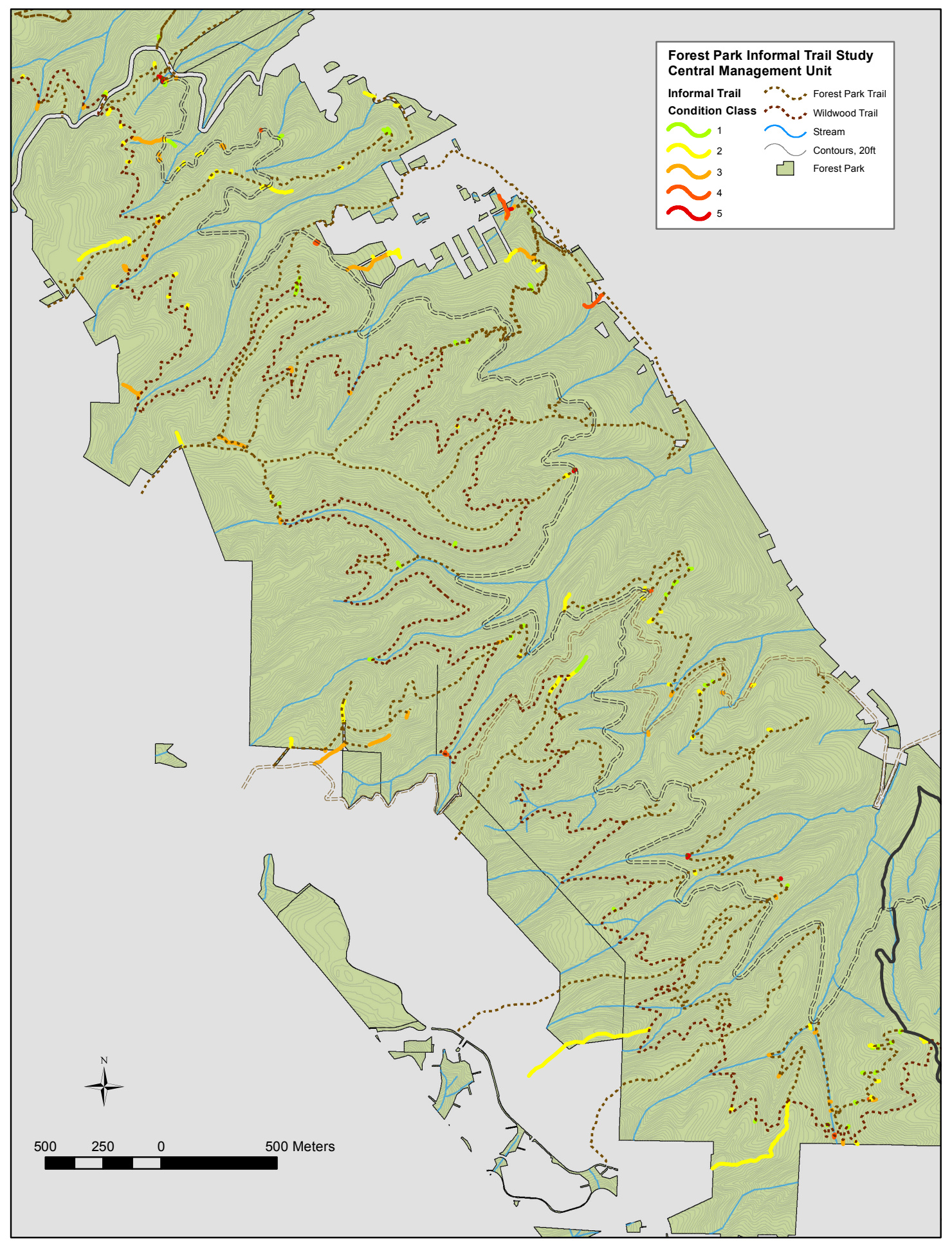




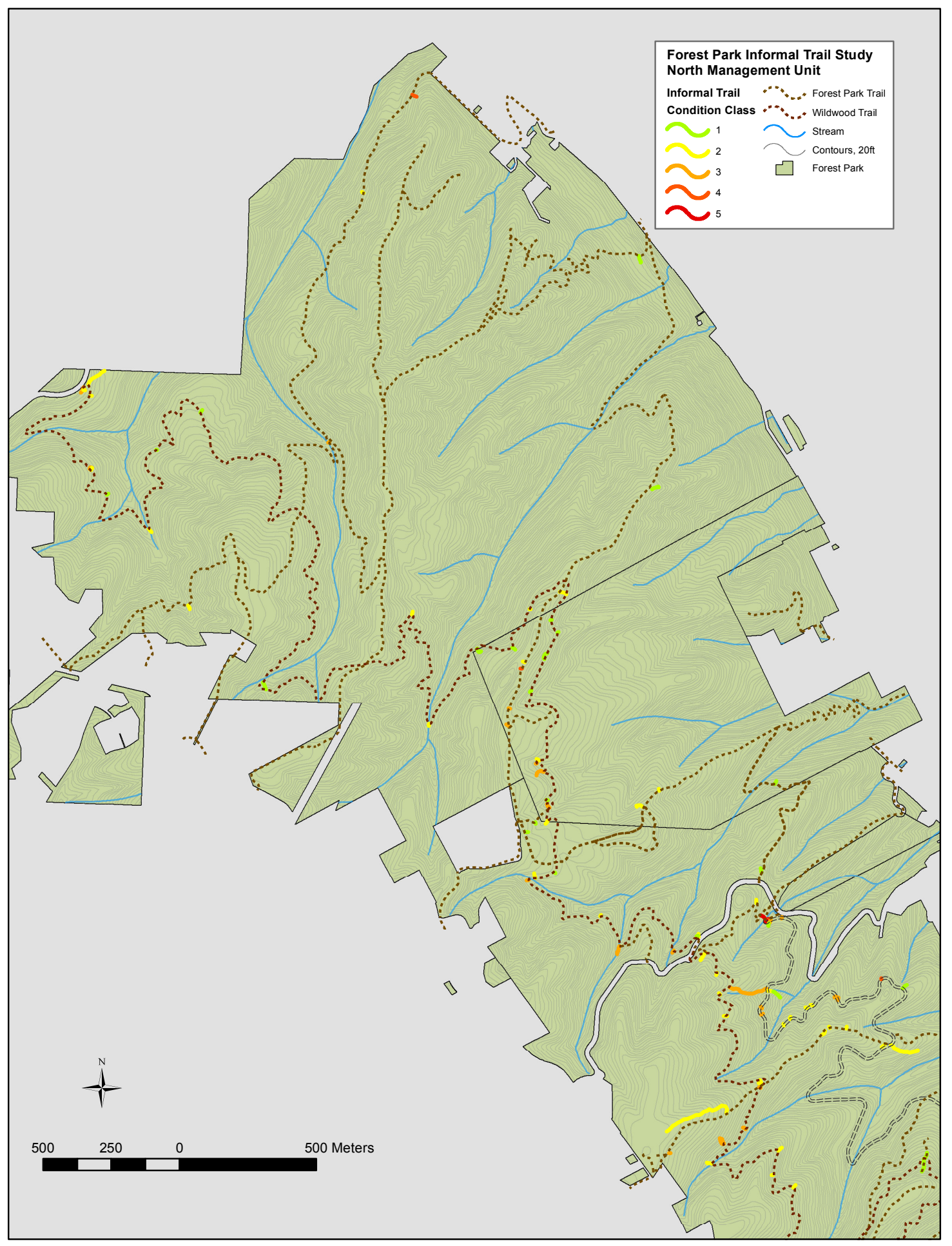




\section{APPENDIX B}

\section{Species Observed in Quadrats}

\begin{tabular}{|c|c|c|c|c|c|c|c|}
\hline Species & $\begin{array}{l}\text { Species } \\
\text { code }\end{array}$ & Life Form & $\begin{array}{l}\text { Functional } \\
\text { Group }\end{array}$ & $\begin{array}{l}\text { Native } \\
\text { Status }\end{array}$ & Seed Type & \begin{tabular}{|c|} 
Dispersal Type \\
(primary, secondary)
\end{tabular} & Ecology \\
\hline Acer circinatum (vine maple) & $\mathrm{ACCl}$ & mesoPH-D & shrub & Native & samara & wind & tolerant \\
\hline Actaea rubra (red baneberry) & ACRU & $\mathrm{CR}$ & ephemeral & Native & berry & rhizome & $\mathrm{MF}$ \\
\hline Achlys triphylla (vanillaleaf) & ACTR & $\mathrm{CR}$ & forb & Native & achene & rhizome & $\mathrm{MF}$ \\
\hline Adiantum pedatum (maidenhair fern) & ADPE & $\mathrm{CR}$ & fern & Native & spore & rhizome & $\mathrm{MF}$ \\
\hline Alliaria petiolata (garlic mustard) & ALPE & $\mathrm{HC}$ & weedy & NIS & capsule & ballistic & invasive \\
\hline Alnus rubra (red alder) & ALRU & PH-D & tree & Native & nutlet & wind & pioneer \\
\hline Anemone deltoidea (three-leaf anemone) & ANDE & $\mathrm{CR}$ & ephemeral & Native & achene & rhizome & SS \\
\hline Asarum caudatum (wild ginger) & ASCA & $\mathrm{CR}$ & forb & Native & capsule & rhizome & MF \\
\hline Athyrium filix-femina (ladyfern) & ATFI & $\mathrm{CR}$ & fern & Native & spore & rhizome & $\mathrm{MF}$ \\
\hline Circaea alpina (enchanters nightshade) & $\mathrm{ClAL}$ & $\mathrm{CR}$ & forb & Native & capsule & rhizome & MF \\
\hline Cirsium vulgare (bull thistle) & CIVU & $\mathrm{HC}$ & weedy & $\mathrm{NIS}$ & achene & wind, hitch-hiker & ruderal \\
\hline Clatonia sibircia (siberian candy flower) & CLSI & $\mathrm{CR}$ & forb & Native & capsule & rhizome & tolerant \\
\hline Clematis vitalba (clematis) & CLVI & $\mathrm{CH}$ & vine & NIS & achene & wind & invasive \\
\hline Convolvulus arvensis (field bindweed) & COAR & $\mathrm{HC}$ & vine & NIS & capsule & animal & invasive \\
\hline Daucus carota (queen anne's lace) & DACA & $\mathrm{CH}$ & weedy & NIS & achene & hitch-hiker & ruderal \\
\hline Dicentra formosa (Pacific bleeding heart) & DIFO & $\mathrm{CR}$ & forb & Native & capsule & rhizome & MF \\
\hline Prosartes hookeri (Hooker's fairybells) & $\mathrm{DIHO}$ & $\mathrm{CR}$ & ephemeral & Native & berry & rhizome & MF \\
\hline Epilobium ciliatum (fringed willowherb) & $\mathrm{EPCl}$ & $\mathrm{HC}$ & weedy & Native & capsule & wind, hitch-hiker & ruderal \\
\hline Equisetum fluviatile (water horsetail) & EQFL & $\mathrm{CR}$ & weedy & Native & spore & water, wind & ruderal \\
\hline Galium aparine (cleavers) & GAAP & $\mathrm{TH}$ & weedy & Native & nutlet & hitch-hiker & ruderal \\
\hline Gautheria shallon (salal) & GASH & nanoPH-E & sub-shrub & Native & berry & animal & tolerant \\
\hline Galium triflorum (sweet-scented Bedstraw) & GATR & $\mathrm{TH}$ & ephemeral & Native & nutlet & rhizome & tolerant \\
\hline Geum macrophyllum (large-leaf avens) & GEMA & $\mathrm{HC}$ & weedy & Native & achene & itch-hiker, rhizome & ruderal \\
\hline Geranium robertianum (herb-Robert) & GERO & $\mathrm{HC}$ & weedy & NIS & capsule & hitch-hiker & invasive \\
\hline Glechoma hederacea (ground ivy) & GLHE & $\mathrm{HC}$ & weedy & NIS & nutlet & gravity, stolon & invasive \\
\hline Graminoids & Grass & $\mathrm{HC}$ & graminoid & weedy & spikelet & hitch-hiker & ruderal \\
\hline Hedera sp, helix \& hiberica (English ivy) & $\mathrm{HEHE}$ & $\mathrm{CH}$ & vine & NIS & berry & animal & invasive \\
\hline Holodiscus discolor (ocean spray) & HODI & mesoPH-D & shrub & Native & achene & wind & pioneer \\
\hline Hypericum scouleri (Scouler's St Johnswort) & HYSCS & $\mathrm{HC}$ & weedy & NIS & capsule & wind & ruderal \\
\hline Hydrophyllum (Pacific waterleaf) & HYTE & $\mathrm{CR}$ & forb & Native & capsule & rhizome & tolerant \\
\hline Ilex aquifolium (English holly) & ILAQ & mesoPH-E & shrub & NIS & berry & animal & invasive \\
\hline Lapsana communis (nipplewort) & LACO & $\mathrm{TH}$ & weedy & NIS & achene & gravity, hitch-hiker & invasive \\
\hline Mycelis muralis (wall lettuce) & MYMU & $\mathrm{TH}$ & weedy & NIS & achene & wind & invasive \\
\hline Lilium columbianum (Columbia lily) & LICO & $\mathrm{CR}$ & forb & Native & capsule & bulb, gravity & OF \\
\hline Lycopodia & Moss & $\mathrm{HC}$ & lycopodia & Native & spore & water, wind & tolerant \\
\hline Maianthemum dilatum (false lily of the valley) & MADI & $\mathrm{CR}$ & forb & Native & berry & rhizome & SS \\
\hline Mahonia nervosa (Oregon grape) & MANE & nanoPH-E & sub-shrub & Native & berry & animal & tolerant \\
\hline Moehringia macrophylla (largeleaf sandwort) & MOMA & $\mathrm{CH}$ & forb & Native & capsule & rhizome & tolerant \\
\hline Monotropa uniflora (indianpipe) & MOUN & $\mathrm{CR}$ & forb & Native & capsule & rhizome & $\mathrm{MF}$ \\
\hline Oemleria cerasiformis (Indian plum) & OECE & mesoPH-D & shrub & Native & berry & animal & OF \\
\hline Osmorhiza berteroi (mountain sweet-cicely) & OSBE & $\mathrm{HC}$ & forb & Native & achene & hitch-hiker & $\mathrm{OF}$ \\
\hline Oxalis corniculata (creeping woodsorrel) & OXCO & $\mathrm{HC}$ & weedy & NIS & capsule & water & ruderal \\
\hline Petasites palmatus (coltsfoot) & PEPA & $\mathrm{HC}$ & forb & Native & achene & rhizome & wet \\
\hline Plantago major (common plantain) & PLMA & $\mathrm{HC}$ & weedy & NIS & capsule & wind & ruderal \\
\hline Polystichum munitum (sword fern) & POMU & $\mathrm{CR}$ & fern & Native & spore & rhizome & tolerant \\
\hline Prunus laurocerasus (cherry laurel) & PRLA & mesoPH-E & weedy & NIS & berry & rhizome & tolerant \\
\hline Prunella vulgaris (selfheal) & PRVU & $\mathrm{HC}$ & weedy & NIS & nutlet & hitch-hiker, gravity & ruderal \\
\hline Pteridium aquillinum (Braken fern) & PTAQ & $\mathrm{CR}$ & fern & Native & spore & rhizome & ruderal \\
\hline Rhamnus purshiana (cascara) & RHPU & mesoPH-D & shrub & Native & berry & animal & $\mathrm{MF}$ \\
\hline Rosa nutkana (Nootka rose) & RONU & mesoPH-D & shrub & Native & hip & animal & OF \\
\hline Rumex crispus (curly dock) & RUCR & $\mathrm{HC}$ & weedy & NIS & achene & wind, hitch-hiker & ruderal \\
\hline Rubus discolor (himilayan blackberry) & RUDI & $\mathrm{CH}$ & vine & NIS & berry & animal & ruderal \\
\hline Rubus parviflorus (thimbleberry) & RUPA & mesoPH-D & shrub & Native & berry & animal & OF \\
\hline Rubus spectabilis (Salmonberry) & RUSP & mesoPH-D & shrub & Native & berry & animal & wet \\
\hline Rubus ursinus (trailing blackberry) & RUUR & $\mathrm{HC}$ & shrub & Native & berry & animal & ruderal \\
\hline Sambucus racemosa (red elderberry) & SARA & mesoPH-D & shrub & Native & berry & animal & wet, OF \\
\hline Maianthemum racemosa (false Soloman's seal) & SMRA & $\mathrm{CR}$ & forb & Native & berry & rhizome & OF \\
\hline Maianthemum Stellata (starry Soloman's seal) & SMST & $\mathrm{CR}$ & forb & Native & berry & rhizome & OF \\
\hline Solidago canadensis (Canada goldenrod) & SOCA & $\mathrm{CR}$ & weedy & Native & achene & rhizome, wind & ruderal \\
\hline Sorbus sitchensis (western mountain ash) & SOSI & mesoPH-D & shrub & Native & berry & animal & OF \\
\hline Streptopus amplexifolius (twisted stalk) & STAM & $\mathrm{CR}$ & forb & Native & berry & rhizome & $\mathrm{MF}$ \\
\hline
\end{tabular}




\begin{tabular}{|c|c|c|c|c|c|c|c|}
\hline Species & $\begin{array}{l}\text { Species } \\
\text { code }\end{array}$ & Life Form & $\begin{array}{c}\text { Functional } \\
\text { Group }\end{array}$ & $\begin{array}{l}\text { Native } \\
\text { Status }\end{array}$ & Seed Type & \begin{tabular}{|c|} 
Dispersal Type \\
(primary, secondary)
\end{tabular} & Ecology \\
\hline Stachys cooleyae (Cooley's hedgenettle) & STCO & $\mathrm{CR}$ & forb & Native & nutlet & water & OF \\
\hline Stellaria crispa (starwort) & STCR & $\mathrm{CH}$ & forb & Native & capsule & rhizome & tolerant \\
\hline Symphiocarpus albus (snowberry) & SYAL & mesoPH-D & shrub & Native & berry & animal & OF \\
\hline Taraxicum officinale (common dandelion) & TAOF & $\mathrm{HC}$ & weedy & NIS & achene & wind & ruderal \\
\hline Tellima grandiflora (fringe cup) & TEGR & $\mathrm{CR}$ & forb & Native & capsule & rhizome & $\mathrm{F}$ \\
\hline Thuja plicata (western red cedar & THPL & PH-E & tree & Native & cone & wind, animal & $\mathrm{MF}$ \\
\hline Tiarella trifoliata (foamflower) & TITR & $\mathrm{CR}$ & forb & Native & capsule & rhizome & MF \\
\hline Tolmiea menziesii (piggy-back plant) & TOME & $\mathrm{CR}$ & forb & Native & capsule & rhizome & tolerant \\
\hline Trientalis latifolia (broad-leaf starflower) & TRLA & CR & forb & Native & capsule & rhizome & $\mathrm{F}$ \\
\hline Trillium ovatum (trillium) & TROV & $\mathrm{CR}$ & forb & Native & capsule & rhizome & $\mathrm{MF}$ \\
\hline Urtica dioecia & URDI & $\mathrm{CR}$ & weedy & Native & achene & rhizome & ruderal \\
\hline Vancouveria hexandra ( inside-out-flower) & VAHE & $\mathrm{CR}$ & forb & Native & follicle & rhizome & $\mathrm{MF}$ \\
\hline Vaccinium parviflorum (red huckleberry) & VAPA & mesoPH-D & shrub & Native & berry & animal & SS \\
\hline Veronica spp. & Veronica & $\mathrm{CR}$ & weedy & NIS & capsule & hizome, hitch-hiker & ruderal \\
\hline Viola glabella (stream violet) & VIGL & $\mathrm{CR}$ & forb & Native & capsule & rhizome & tolerant \\
\hline Vicia sativa (garden vetch) & VISA & $\mathrm{TH}$ & weedy & NIS & pod & animal & ruderal \\
\hline
\end{tabular}

CR - Cryptophyte

HC - Hemicryptophyte

$\mathrm{CH}$ - Chaemophyte

TH - Theophyte

$\mathrm{PH}$ - Phanerophyte

E - conifer

D - Decidious

meso - $>2 \mathrm{~m},<5 \mathrm{~m}$ height (shrubs)

nano $-<2 m$ height (sub-shrubs) 